MEDIATED TEMPORAL CONSCIOUSNESS: MEMORY AND CONCEPTS OF TIME THROUGH ENGAGEMENT WITH ONLINE NEWS ARCHIVES

A Dissertation
presented to
the Faculty of the Missouri School of Journalism
at the University of Missouri-Columbia
In Partial Fulfillment
of the Requirements for the Degree
Doctor of Philosophy
TERRY L. BRITT
Dr. Tim Vos, Dissertation Supervisor
DECEMBER 2018


The undersigned, appointed by the dean of the Missouri School of Journalism, have examined the dissertation entitled

MEDIATED TEMPORAL CONSCIOUSNESS: MEMORY AND CONCEPTS OF TIME THROUGH ENGAGEMENT WITH ONLINE NEWS ARCHIVES

presented by Terry L. Britt,

a candidate for the degree of doctor of philosophy,

and hereby certify that, in their opinion,

it is worthy of acceptance.

Dr. Tim P. Vos

Dr. Earnest Perry

Dr. Yong Volz

Dr. Lissa Behm-Morawitz

Dr. Nelson Cowan 


\section{Dedications}

It was early in my journey toward a Ph.D. at the University of Missouri that I met the one person I thought I would never meet here. She is now my wonderful wife, Amy Britt, and I will always cherish and appreciate the love and support she has provided as I completed my doctoral program. Likewise, I give a special thanks to my two sons, Ryan Britt and Jesse Crews, and the wonderful family of which I became a part through Amy, particularly our parents Charles and Lillie Downing, and brother-in-law and sister-in-law Bill and Lori Walker. I also give thanks to a set of fantastic doctoral colleagues I got to know and befriend here at the Missouri School of Journalism over a three-and-one-half year period. Special thanks goes to Dorothy Carner, head of the Journalism Library at the University of Missouri and a great friend as well.

Finally, I offer a special dedication of this work to my own parents, John and Faye Britt, who did not live to see their oldest son achieve the highest academic degree possible. As human memory goes, my own is daily filled with their images, the good times, the hard times, and the meaning of all of it. 


\section{ACKNOWLEDGEMENTS}

I would like to thank each of my dissertation committee members for their time, patience, and guidance throughout the comprehensive examination and dissertation process over the past 18 months, as well as for their contributions as instructors in various courses during my doctoral program at the University of Missouri: Dr. Tim Vos (committee chair and dissertation supervisor), Dr. Earnest Perry (advisor) and Dr. Yong Volz, Missouri School of Journalism; Dr. Lissa Behm-Morawitz, Department of Communication; and Dr. Nelson Cowan, Department of Psychology. Additional thanks for guidance and assistance with research work and training go to the following: From the Missouri School of Journalism, Dr. Margaret Duffy, Dr. Sungkyoung Lee, Dr. Shelly Rodgers, Dr. Cynthia Frisby, Dr. Ryan Thomas, Dr. Glen Cameron, Dr. Keith Greenwood, and Dr. Amanda Hinnant; from the University of Missouri Department of Communication, Dr. Ben Warner; from the University of Missouri Department of Psychology, Dr. Jamie Arndt, Dr. Bruce Bartholow, and Dr. Laura Scherer; and from Texas Tech University, Dr. Paul Bolls. 


\section{TABLE OF CONTENTS}

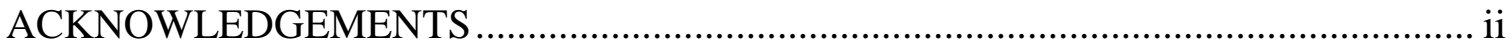

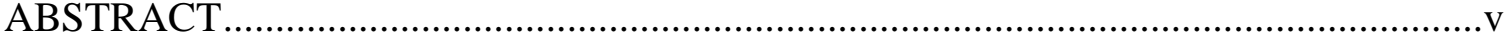

\section{Chapter}

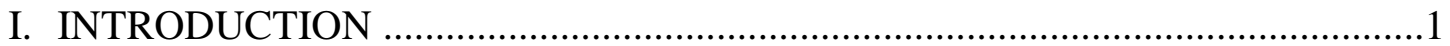

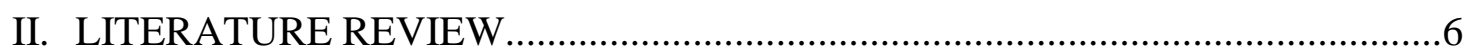

Definition of Presence and Relevant Research

News Archives in the Digital Age

YouTube as Archive: Temporal Effects

News and Memory

III. METHODS

Photo and Video Elicitation

Study Procedures

Participants' Procedure and Textual Analysis Check

IV. RESULTS AND ANALYSIS .

RQ1: The Connection with Presence

RQ2: Initial Memories of News Events

RQ3: Back in Time, Back in Mind

Episodic Anomalies Within the Interviews

V. CONCLUSIONS

Contributions to Research Literature

Practical Implications

Study Limitations

Future Research Directions 


\section{APPENDICES}

APPENDIX A - INTERVIEW TRANSCRIPTIONS

APPENDIX B - INTERVIEW TRANSCRPTIONS ........................................144

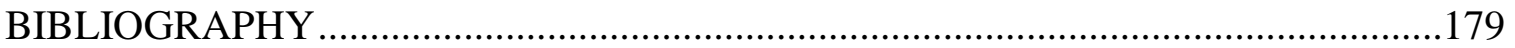

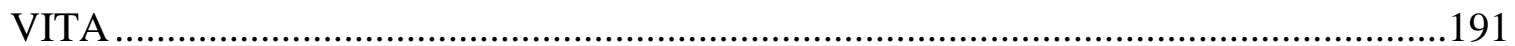




\title{
MEDIATED TEMPORAL CONSCIOUSNESS: MEMORY AND CONCEPTS OF TIME THROUGH ENGAGEMENT WITH ONLINE NEWS ARCHIVES
}

\author{
Terry L. Britt
}

\author{
Dr. Tim Vos, Dissertation Supervisor
}

\begin{abstract}
Archival news content no longer exists solely in physical collections at a limited number of public institutions and media organization storerooms. Instead, digitized and digital-native content of the past can be found online through multiple venues, including the venerable online video sharing site, YouTube. This research looks at how online videos of major news events within the past 10 years provide a chance to re-engage with memories of the news events and other memories connected to the time of the given news event. Through a qualitative research method known as video elicitation, the study uses semi-structured interviews with participants to look at recalled semantic and episodic memory content connected to a recent news event featured in a YouTube-based archival news video - one regarding the 2014 Ferguson, Missouri, protests after local police shot and killed African-American teenager Michael Brown, and the other regarding the 2010 British Petroleum (BP) Deepwater Horizon oil rig explosion and underwater oil spill in the Gulf of Mexico. The study considers the characteristics and comparative states of the interview responses in building a new media concept - mediated temporal consciousness $(M T C)$ - to understand the awareness and articulation of episodic and semantic memory content associated with past news events or the time at which the person first learned of the news event. MTC is a proposed extension of presence (also known as telepresence) theory in the sense of presence as transportation; in this case, transportation from the
\end{abstract}


present to past points in time coinciding with initial mediated dissemination of news events. 


\section{Introduction}

Internet-based, digital news archives have provided the general public with the ability to re-engage with media content from the past, including content concerning news events that took place at some point during the person's lifetime. The archival content may be of a news event with broad or general impact (e.g. the resignation of United States President Richard Nixon in 1974), or more specific, local impact (e.g. a high school football team winning a state championship). Regardless, there is potential for the archival news content to assist in retrieval of memory of both facts and personal experiences connected to the time and place of origin of the news event, and one's initial awareness, through mediated processes, of the event.

We rely on the media and the reports and programming they produce to provide us with information on events that have occurred (sometimes, as the events unfold) where we are not present to witness the events for ourselves (Shoemaker \& Reese, 2014). Additionally, much of our conscious experience of time may involve engagement with media of varying types - movies, news reported on websites or social media, etc. - and the resulting associative connection between our experience of time and the content, or activity or object, with which we have engaged results in the construction of temporal consciousness, often expressed through memory of the experience (Campbell, 2002; Dainton, 2010). Through engagement with media archives, we may not only recall or remember facts about the specific event represented in the content, but also recall or remember our personal experiences and conception of the self, at that time, associated with the time and/or place of the event (Britt, 2015b, 2017a; Hilderbrand, 2007). It is this exploration of memory associations between mediated representations of events, media 
archives, and personal experiences of the time of the events that stands as the primary concern of the proposed dissertation.

But why seek the past, whether online or through more traditional, physical archives? There are the functional reasons, such as historical research or curiosity, scholarly pursuits, or journalistic verification of past facts. However, these reasons are unlikely to cover the entire span of possible motivation, and certainly not in exploring why, for instance, a roughly nine-minute YouTube video of highlights of MSNBC's coverage of the 2008 U.S. Presidential Election Night would garner almost one million views in a nine-year period (MSNBC, 2008).

One additional motivational factor to consider is personal nostalgia, defined by Lizardi as "a yearning for the past or some past state, which results in the focusing in on the past or a past object to assuage the yearning and to reassure already held ideological positions" (2015, p. 2). Lizardi argues that the contemporary, digital-based media industry plays upon a pervasive public need for a nostalgic fix, catering to viewers or players of produced worlds that "is constructed as a past-centered consumer unwilling to relinquish lost media objects" $(2015$, p. 6). The rise of digital archiving technologies in the last 20 years, and the attendant plethora of websites and apps that host or give access to such archives, may have planted the seeds for past-based media consumption focused upon individual preferences and personally significant or connected content (Lizardi, 2015 , p. 17). The pull of nostalgia may also result in romanticized or optimal visions of the past, even one's own past, as in the case of personal photographs documenting favorable or pleasant personal experiences for the purpose of memory reinforcement of 
those experiences, at the expense of objective or wholistic views of that memory content (Chalfen, 1987).

However, it is within a consideration of human memories of events, both large and small in scale of public awareness, that a different and not as easily defined factor comes into focus. Delving into the evolution of research and concepts in human memory studies, we find a turning point in the split of a formerly unified conception of memory into two concepts, both establishing definitions for different kinds of human memory content: Episodic memory and semantic memory (Tulving, 1972). Episodic memory, in plain terms, refers to the memory of one's personal experiences in the past and the construction of self within that memory, while semantic memory refers to the facts, figures, or other information pertinent to the past event (Tulving, 2002). To draw an example, many people throughout the world have both episodic and semantic memories, to varying degrees and content, of the September 11, 2001, terrorist attacks in the United States. In regard to semantic memory, each person's memory will contain some information about the news event that was delivered through some type of media (e.g. television reports, newspapers later that day or the next morning). However, the episodic memory of that news event would pertain to memories of what that person was doing, where they were, emotions felt, or conversations with others at the moment of first awareness of the event (again, likely through mediated channels) and the immediate time that followed.

Among established media theories, a potential starting point for understanding what takes place with regard to human memory and engagement with news archives may be found through presence, sometimes known as telepresence, a media concept 
developed into its current form through a published explication by Lombard and Ditton (1997). Although originally intended to address a sense or perception of conceptualized spaces through then-newer forms of telecommunication technologies, presence should arguably also apply to a sense of previously experienced time as one might encounter through episodic memory connected with specific news events of the past. The presentation and access to online-based news archives, such as video news reports of the past on YouTube, could be conceptualized as the venue by which presence through memory of the news event is felt or perceived.

Archival news content, then, may serve as a conduit for engagement with or reinforcement of memory content that is either episodic or semantic, or perhaps both in varying portions. In this case, the motivation for seeking such archival content does not fall neatly into one of the aforementioned functional purposes, nor can it be lofted onto the saddle of nostalgia for a self-absorbing ride through the countryside of the mediated past. A different, new conceptual framework could be proposed for research examining how people might use news archives (particularly the speedier accessibility and evergrowing breadth of online news archives) to access and re-engage with memory content of both types. The proposed research for this dissertation will aid in establishing a concept as an extension to presence theory, to be known as mediated temporal consciousness, defined as:

1. The articulated awareness and recall of semantic memory content encoded at or near the time and place of events, and introduced through mediated channels. 
2. The articulated awareness and recall of episodic memory content encoded at or near the time and place of events, and introduced through mediated channels. 


\section{Literature Review}

This section will present a comprehensive review of current and past research literature relevant to the construction of the concept described above. Included will be research on the concept of presence (also known as telepresence) and its applicability in research on memory and other psychological research. Additionally, this section will address archiving of media content, particularly where it concerns digitization of older media content for presentation through new media channels of distribution such as streaming audio/video. The literature review will include studies concerning the use of websites and online collections of media content as a digital alternative to physical archives and/or libraries. The literature described above provides a basis for the proposed concept of mediated temporal consciousness by exploring how archival news, and both the semantic and episodic memory content that helps construct archives, contributes to and enables a cognitive experience of presence and the recall of semantic and episodic memory content for news audiences. Temporal consciousness refers to our conscious experience of units of time at various points within our lifespans, which may include (and often does) mediated content or information like movies, music, printed stories, and news reports, as examples (Dainton, 2010). However, we are limited by factors like proximity and the reach of our physical senses in become conscious of events, so we depend on media - be it newspapers, TV, radio, or websites - to provide an awareness outside the scope of our senses of events that are or have taken place, and to provide the pertinent information through representations of the actual event (photos, video, interviews, etc.) (De Zengotita, 2005). The proposed concept attempts to address this latter understanding of time and events presented and disseminated through mediated channels of 
communication, and how it connects to the way we consciously remember past timepoints connected to the event.

This section will continue with an overview of the primary research literature on human memory processes, as well as integral research concerning episodic memory (Tulving, 1972) and its differences to semantic memory (A. D. Baddeley, Aggleton, \& Conway, 2002; Tulving, 1972, 1985). By focusing upon literature that covers psychological processes and concepts related to studies on human memory, as well as how engagement with images assist in memory recall, we may see how the connections to episodic and semantic memories within individuals support the concept of mediated temporal consciousness in creating an awareness of past events, personal experiences related to past events, and the passage of time as it relates to those past events.

\section{Definition of presence and relevant research}

Presence, also known as telepresence, first came into the public eye as a media concept in 1980 and was defined as a sense of being physically present in a mediated, remote environment (Minsky, 1980). However, the concept came into the spotlight of media research with the publication of Lombard and Ditton's explication paper (1997), which better accounted for the concept's applicability to then-newer media technologies, such as videoconferencing and virtual reality environments. The authors established six forms, or conceptualizations, of presence within the explication, as follows:

1. Presence as social richness

2. Presence as realism

3. Presence as transportation

4. Presence as immersion 
5. Presence as social actor within medium

6. Presence as medium as social actor (para. 9-31)

It is the third form that concerns the present study most, because in presenting online news archives to research subjects for stimulating memory recall about the news event, the subject may experience a sense of transportation back to the original time the news event was first experienced. Within the conceptualization of presence as transportation, there are three potential sub-forms, including one described as "You are there" (Lombard \& Ditton, 1997, para. 15-16) - a description that certainly suggests transportation of mind and, argued here, access to memories associated with that point in time. Of the other conceptualizations of presence, most pertain to areas of communication research outside the scope of the present study, namely organizational communication, virtual reality (VR) media effects, and parasocial relationships (para. 9-14, 20-31). However, one additional connection to the foundational literature of presence theory might be found in "presence as immersion," which "emphasizes the idea of perceptual and psychological immersion" (para. 20). Although certainly applicable in mediated experiences such as VR, this conceptualization could also be extended to include perception of time and episodic memory - the sense that one is feeling or thinking just as one did during the original time of an experienced event. Whether interview responses in the present study indicate this type of presence will be addressed in the results section.

Presence as transportation is the oldest of the explicated forms of presence, having roots in storytelling traditions in which listeners, the storyteller's audience, may have experienced a sense of being taken mentally and emotionally to the time and place within the setting of a particular story, described as a "you are there" effect (Lombard \& 
Ditton, 1997). More recently, presence as transportation has been explored within research looking at cinematic techniques for virtual reality media (Mateer, 2017), effects on sense of presence in media accompanied by dubbing or subtitles (Wissmath, Weibel, \& Groner, 2009), and parasocial relationships through social media (J. Kim \& Song, 2016). However, presence as transportation works well as a conceptual or theoretical framework with regard to audience engagement with media archives, particularly digital, online media archives (Britt, 2015b). In fact, the idea of presence takes on a bidirectional quality between content and audience member:

Not only is the viewer being taken by the content to a different time and place, but also the content — produced and disseminated as news for a selected audience at the time and place of its origination - is transported forward in time to become history and cultural memory in the eyes of new viewers or viewers who are reengaging with the content for second and subsequent times (Britt, 2015b, p. 67).

The latter connection with presence as transportation plays a vital role in informing new audiences or future generations of the origins or the progression of ongoing events or issues. Conceivably, it may also play a big part in the formation of what Waterworth et al (2015) call the "extended self," a result of extended consciousness which gives humans "the ability to imagine and evaluate possible scenarios of the future, as well as to increase the sophistication of learning from the past" (p. 41). Thus, media archives may not only serve an important social role as being records of past events, but also in setting a distinct marker within time of an event or issue, by which we may cognitively process related events in the passing of time since the original event. Related to this is the ability to evaluate or re-evaluate self-perception in connection with past news events or issues, as 
was found within several interviews with college students in one study concerning perceptions of past presidential elections and of environmental issues (Britt, 2017a).

However, explanations as to why a person might experience presence in media interactions have been sparser in academic literature since the late 1990s. Kwan Min (2004) suggested that early presence literature skewed toward empirical research on the technological factors involved at the expense of a thorough examination of the user (human) factors. To this point, Kwan Min refers to "folk-physics" (p. 499) and "folkpsychology" (p. 500) models as a way of understanding why presence might occur in a mediated interaction. While the former model draws upon several studies of Byron Reeves and colleagues (Detenber \& Reeves, 1996; Reeves, Lang, Kim, \& Tatar, 1999; Reeves \& Nass, 1996) to address common human constructs of causality when responding to mediated objects on a viewing screen, the latter addresses how people “interact with virtual social actors such as computers and software agents" (Kwan Min, 2004, p. 500). Building on previous research utilizing the Computers Are Social Actors (CASA) theory (Nass \& Moon, 2000), Kwan Min identifies folk-psychology factors like reciprocity, in-group favoritism, and personality as contributing to the personal experience of presence through mediated interactions (2004, pp. 501-502). Taken into the context of online news archives, it could suggest that the cognitive awareness of presence transporting the user back in time to a particular news event may be affected by one or more of these factors, the computerized social actor in this case being the news content or, perhaps, the presenter within the archived report.

Presence has also been examined through a psychological approach and quantitative analysis of cognitive factors, such as absorption, empathy, and willingness to 
experience presence, in an effort to operationalize the concept. Findings from a convenience sample at a major university in Ireland showed correlations between the amount of cognitive resources deployed and the level to which one feels presence (Sas \& O'Hare, 2003). While this is useful research for any psychological treatment of presence theory or research on possible relationships between cognition and presence, the implementation of a devised questionnaire and scale instruments are not best suited for examining how people articulate detailed memories that may be connected to a feeling of presence across experienced time.

The study within this dissertation aims to address a gap in scholarly research, in particular, the connections between memory, experiences of events (in this case, experiences of and connected to initial awareness of news events), and presence. There have been a few published studies that involved memory and sense of presence. Mania and Chalmers (2001) used virtual environment (VE) interactions to test subjects' level of recall of episodic and semantic memory content from the interactions. In contrast to the current study, this was a quantitative study with data collected through a questionnaire measuring participants' information recall and spatial recall. The study employed a 15minute seminar presented in one of four conditions to study participants - real, threedimensional desktop, three-dimensional head-mounted display, and audio only - in a between-subjects design. Although the authors acknowledged some technological limitations at the time with the VE environments, they did not find a significant relationship between sense of presence and the memory recall tasks:

For example, presence was significantly higher for the real condition compared with the desktop condition but that was not reflected on memory recall: there was 
no statistical difference between the information recall task or the spatial recall task between the real and the desktop condition. The presence questionnaire also revealed no significant difference between the technological conditions (Mania \& Chalmers, 2001, p. 261).

The authors suggested other methods that would address some of the limitations of a questionnaire for measuring subjects' notion of presence, including self-report measures, possibly combined with physiological measures.

Among previous studies concerned with temporal elements of presence, one specifically looked at breaks, or "variations," in presence from both temporal and spatial perspectives. Participants in the study were asked to complete an immersive virtual reality simulation, depicting a bar scenario. At different points of time, the VR simulation was temporarily suspended and then reactivated. Following the completion of the VR simulation, participants were asked questions in a semi-structured interview about their experience in the simulation and about the "breaks in presence" (BIPs) (or "transitions to real") during the simulation (Garau et al., 2008). The study found that 19 of the 27 participants whose interview responses were included in the analysis reported "their sense of being in the bar changed significantly through the course of the experience" ( $\mathrm{p}$. 300) and 12 participants indicated their sense of presence was stronger at the beginning of the simulation than at the end. The authors concluded:

The analysis revealed that they did indeed perceive them as breaks in presence, likening the experience to a feeling of "waking up" or a "shock." Experimenters observing the participants' behavior in the Cave [the study's physical location for VR experiences] noted anecdotally that the first whiteout was often accompanied 
by "startle" behaviors, with participants suddenly standing still and sometimes expressing verbal surprise. In many cases, verbal and physical responses to successive whiteouts were less pronounced. This observation tallies with participants' accounts that they experienced a strong reaction to the first whiteout, but less of a surprise after subsequent whiteouts (pp. 305-306).

Although the current study does not make use of VR environments, this finding by Garau et al (2008) provides valuable insight concerning cognitive attention and its role as a factor in experiencing presence when one is engaged with some type of media content. If the whiteouts could be considered a type of distraction from the engagement with the media, then it suggests that distractions, or "breaks in presence," elicit a strong response initially, but decrease over time with increased frequency. A person's sense of presence, then, may be altered to some degree if unanticipated distractions occur. Marsh (2003) concurs with this, noting that the goal of any mediated experience "is for users to stay focused, interacting in the illusion" and adding, "Disruptions break the illusion and, consequently, break experience" (p. 538).

If, as suggested in the above literature, presence is a concept felt or perceived through engagement with mediated environments and content, and the mediated content with which one is engaged is an archival news report of a past event, it is natural to ask whether a person might be able to articulate a sense of presence through memory of the news event and engagement with the archival content; in other words, being transported in memory back to the time of first awareness of the news event. This, in turn, leads to the following research question: 
RQ1: How do subjects, after engaging with archival news content, describe the experience of presence as it pertains to memories associated with a news event?

\section{News archives in the digital age}

Gitelman (2006) suggests that it may be erroneous, or at least temporally biased, to think of "new media" as a recently developed concept particular to internet-based media technologies and features. Instead, Gitelman argues, all forms of media are "new" at some point in time and, as such, are subject to the early public skepticism, product development, and efforts at eventual widespread adoption by the public.

If we consider, as an example, the phonographic recording, it was a pristine example of a new medium being created which, in turn, caused people to reconsider their concepts of sound, speech, and writing, because the original phonographic recorder invented by Thomas Edison was intended to be used as a type of late-19th Century dictation machine for business (Gitelman, 2006). It was not until more than a decade later that sound recordings on wax cylinders made their appearance in amusement devices in large cities and at fairs and exhibitions; public conception of the phonograph favored this purpose, and the technology obligingly shifted toward one of providing entertainment in the home through musical recordings that could be purchased for use (reproduction of a performance) on a phonograph player (Gitelman, 2006). This transition of purpose is in line with Hilderbrand's (2007) conclusion that the public rarely uses any form of media in the way it was originally intended.

Disruptions by new media and transitions in the uses of old media continued throughout the 20th Century. As media scholar Marshall McLuhan wrote in "Understand Media: The Extensions of Man," (1964/2001), this process has often involved the 
enjoining of two or more established forms of media to create a new medium; for instance, television taking the sound element of radio and combining it with the visual element of the theater. One might argue McLuhan's concept served as a predictor of the same phenomenon within digitally-based convergence journalism among legacy media organizations - newspaper websites now feature online video reports and, sometimes, audio podcasts; the traditional broadcast journalism media of radio and television likewise carry a bevy of written content on their respective websites. These changes and convergences in the forms in which media content is presented stands as a byproduct of the digital transformation of media in general, and journalism in particular. Pavlik (2008) notes that digital media forms have created new opportunities and channels through which journalists can do their work, and it has also changed the journalistic culture, creating the idea of the virtual newsroom through mobile technologies that allow journalists to create and transmit their work in many different places, including, at times, the scene of the event or story itself.

The processes of transition, convergence, and creation of new media forms will likely continue in more personal and immersive fashion. Writing about 10 years ago from the present time, Pavlik even then seemed high on the future implications for media content through virtual reality and augmented reality systems (2008). More recently, we have witnessed the inundation of consumer-level virtual reality headsets like the Samsung Gear VR, taking advantage of another rapid evolution in media technology, that of the smartphone and its attendant applications. Big data and data analytics have become the current hot topics of research and social analysis; interestingly enough, McLuhan also presaged this development in written comment on the intertwining of human activity and 
media systems with the intent of recording and analyzing even the most seemingly mundane of activities (1964). And it is on this note, how humans are using the tools afforded us through "new media," that leads to the fascinating issue of memory and media technology.

\section{YouTube as Archive: Temporal Effects}

Since its debut in 2005 as a user-generated video sharing website ("A Brief History of YouTube," 2010), YouTube has gradually grown into what McLuhan probably would have considered a disruptive and transformative new medium affecting television. Barker (2018) argues that television, as a mass medium, carries a history of being always under attack and at the end of its lifespan, but continually reemerges in new forms. One of the most impactful forms of attack against television as a broadcast medium came with the consumer market arrival of the video cassette recorder (VCR) system in the late 1970s (although it wasn't until the mid-1980s that the format firmly established itself in American households) and led to a phenomenon known as "timeshifting," a term coined in a lawsuit involving Sony Corporation's BetaMax technology (Greenberg, 2010). This effect, produced by the taping of television content for viewing at times other than the broadcaster's intended time, first generated a decoupling of television content from the television that continued to evolve into the multi-platform viewing that exists in the present day (Bury \& Li, 2015).

However, YouTube and similar websites or services often "archive segments of events and then perform analysis by uncovering patterns and connections between archived data based on its relational data management systems" (Barker, 2018, p. 179). Citing McLuhan (1964), Barker goes on to argue that digital memory, ensconced in 
platforms like YouTube, frames events of the past in relational systems rather than sequential systems. Using the 2011 YouTube footage of the killing of Libyan dictator Muammar Gaddafi as an example, Barker explains that "viewers are synchronized with neither a specific time nor a specific space, but rather a multi-temporal collective of viewers, coming from different times and places" (2018, p. 184). Whereas television had always been effective at segmenting days into moments, YouTube, hard disk-based television recorders (such as TiVo) and other on-demand video services segment days into multi-temporal moments (Barker, 2018, p. 186). From this, we can consider that instead of mediated moments as segments of a particular day, time has been transformed by digital memory conduits into mediated moments as segments of a multi-temporal day, with those mediated moments originating from any number of days, months, or years. With the depth and number of video clips from the past existing on any given day on YouTube and other media archive websites, one could theoretically build a unique daily video broadcast schedule, irrespective of time and place of origination.

Online video streaming technologies, exemplified in YouTube and similar online, on-demand video libraries, have also opened pathways for digitized archival content to be repurposed for new audiences (Pavlik, 2008). Recent case study research (Britt, 2015b) shows how corporate or non-profit owners of such archival news content use online video streaming for new audience outreach projects. For instance, British Pathe, the legacy organization of what was one of the largest producers of cinematic newsreel content in the 20th century, now utilizes its YouTube channel as a free-access online library of its newsreel archives. This not only enables internet users to see newsreel-style reporting of past news events from around the world, but also presents cultural, arts, and 
entertainment features from various periods of the 20th century. In another cited case within the same research, CBS News presented an unprecedented take on anniversary journalism in 2013 with a live video stream of the network's 1963 broadcast coverage of the assassination of President John F. Kennedy in Dallas, Texas. The four days of streaming content brought the network's entire original broadcast transmissions commercials included - from Nov. 22-25, 1963, to an online audience. This essentially provided a mediated form of time travel to the assassination event and its immediate aftermath (Britt, 2015b).

The development of online archives as a whole, including the digitization of analog content from print and broadcast media sources, stands as a remarkable change in the way people can access the mediated past. Zeleny (2016), drawing upon the concepts presented by McLuhan, notes that the internet, among many things, has given rise to the idea of the amateur archivist, who, despite lacking the professional training and understanding of collecting, curating, and organizing archival content, uses online tools and websites to perform those very functions for the benefit of himself and others in the public, and often without pay or profit from any of the content being disseminated. This development of a social role for the amateur archivist is an outgrowth of prosumerism (Toffler, 1980, cited in Zeleny, 2016) as the amateur archivist finds himself at the intersection of both consumption and production. When it comes to the mediated past, represented through archival media content including news reports, advertising and commercials, photographs, or television shows, just to name a few, the connecting line from prosumerism to the present reality of cultural memory online is easy to follow: A large number of users, having been consumers of the media content at one point in time 
or another, utilize the technological tools provided through websites like YouTube to repurpose the archival content (Jin Kim, 2012).

In turn, it is our sense of cultural memory, evoked through the awareness of major news events in our lifetime or just as easily through favorite television shows of a given time of life, that drives us to seek reengagement with that content of the past (Hilderbrand, 2007). That creates a demand - a market, in an aesthetic sense - for content of the past that somehow resonates with human memory according to a very personalized cultural script. In this sense, video-sharing sites like YouTube serve as an online archive of the mediated past, although Hilderbrand argues that YouTube is not truly an archive because of the instability of the presence of the content, often owing to rights holders filing content removal requests (2007). Gehl (2009), on the other hand, argues that YouTube is an archive for the very reasons that the content is curated by one or more individuals or groups for public access. Interestingly, YouTube as a website and new media service underwent its own transformation in a relatively short period of time, starting life in 2005 as a purely user-generated content sharing site, but quickly transforming into an online archive of as much or more professionally-generated media content, either shared by individuals or the media organizations holding the rights to the content (Jin Kim, 2012). It also became the cultural destination online for users to reengage with "moments" of personally significant media content, leading to what Hilderbrand calls "clip culture" (2007). But whether YouTube serves better as a media archive than traditional media archives may depend on the type of content sought. A content analysis study by McKee (2011) in Australia found that YouTube was better than that country's National Film and Sound Archive for content from game shows and 
lifestyle programming, but that the NFSA was a better destination for public affairs programming and older media content.

The media technologies underlying sites like YouTube and media organization websites with archival content provide interesting opportunities for the repurposing of media content through digital channels (Pavlik, 2008). Case study research (Britt, 2015) has examined how large media organizations are starting to harness current technologies to pump new life into archival content or create new ways of presenting anniversary journalism content, such as CBSNews.com's 2013 live video streaming of the network's 1963 broadcast coverage of the assassination of President John F. Kennedy in Dallas, Texas. Such uses arguably perpetuate collective memory of major news events in history and establish updated methods of providing public access to that content. In some instances, the repurposing, and thus the digital transformation, of archival media content not only help to keep cultural memory of that content alive, but can present unusual ephemera that showcase a greater sense of time relevance itself. One such case is the appearance of a 1956 clip on YouTube of the game show "I've Got a Secret," in which the guest, Samuel J. Seymour, was the last living witness to the assassination of President Abraham Lincoln in 1865. The convergence of personal eyewitness account (Seymour was 5 years old at the time), television game show programming in the 1950s, and YouTube in 2012 created a sort of temporal convergence point spanning almost 150 years (Rosen, 2012).

\section{News and Memory}

Episodic Memory vs. Semantic Memory. The interview-based research portion of the proposed dissertation is concerned specifically with elicitation and articulation of 
episodic memory content associated with specific news events that research subjects would have experienced through mediated channels. Online video archives of the news events are presented as the stimuli to elicit the associated episodic memories. Before continuing with specific details of the study's interview portion and the research method on which it is founded, it becomes necessary to understand the concept of episodic memory and how it has been studied in recent psychology research.

Episodic memory essentially concerns the type of human memory that allows people to recall specific, personally experienced events within the person's lifespan (Tulving, 1972, 2002). The concept was born of a departure from the then-dominant system of unitary memory in the 1960s, when research demonstrated differences in the laws and principles governing short-term memory and those governing long-term memory (Tulving, 2002, citing Waugh \& Norman [1965], and Atkinson \& Shiffrin [1968]). A more explanatory definition for episodic memory includes its practical form within retrieved memory and its contrast with semantic memory:

Episodic memory is 'memory for personally experienced events' or 'remembering what happened where and when', whereas semantic memory is 'memory for general facts of the world.' A somewhat more elaborate definition holds that episodic memory has to do with one's 'autonoetic' awareness of one's experiences in the continuity of subjectively apprehended time that extends both backward into the past in the form of 'remembering' and forward into the future, in the form of 'thinking about' or imagining or 'planning for' the future (Tulving, 2002, p. 1506). 
Episodic memory is closely related to another Tulving concept, mental time travel (MTT), defined as the uniquely human ability to re-experience events of the past through memory of those events, or to imagine oneself in the future for events that might occur (Tulving, 1985). For the present study, we are concerned only with past experiences connected with awareness of news events in the past and the re-engagement with memories of those events through online, archival media.

The interview-based portion of the present study builds upon a similar study that examined episodic memory recall associated with news events that occurred in the recent past (within the previous seven years) of a convenience sample of college students, ages 18-23, at a large Midwestern university (Britt, 2017a). A manual textual analysis of subjects' interview responses after watching two archival news videos on YouTube - one a CNN highlights package of the 2012 U.S. Presidential Election Night and the other a Texas television station's report on the immediate aftermath of the 2010 Deepwater Horizon oil rig explosion in the Gulf of Mexico - produced the following thematic patterns:

Emotional affect within episodic memories - Most of the 39 interviewees in the study indicated memories linked to strong feelings or emotional reactions at the time of the news events depicted in the video stimuli in the study. "In the case of the 2012 Presidential Election, this connection was often expressed by subjects as, 'I remember feeling happy,' or 'I felt excited,' if one was hopeful for re-election of Barack Obama that year, and expressed feelings of disappointment or resignation if one was hopeful for Mitt Romney becoming President of the United States" (p. 96). Regarding the 2010 oil spill, "subjects remembered feeling great concern or fear for the effect of the oil spill on 
birds, fish, and other wildlife...remembered feeling anxiety or worry about the price of seafood going up at the time as a result of the oil spill, availability of some seafood being reduced, or feeling concern or sympathy for those employed in commercial fishing in the Gulf Coast area" (p. 96).

Conversations and event-related activities - Many of the episodic memories recounted in the interviews centered around conversations about the specific news event with other family members, friends, or school classmates. None of the subjects were old enough for voting eligibility in 2012, but many remembered conversations that included their intended presidential candidate of choice had they been eligible to vote in the election. Some subjects also gave detailed memories of participating in a mock election at school for the presidential race in 2012. Ecology-related discussions or learning activities at school featured in many subjects' memories regarding the 2010 oil spill, with one female subject in the study recounting how she and her family had been vacationing along the Alabama Gulf Coast at that time and actually joined other families in helping to clear a beach of the "tar balls" that washed ashore as a result of the oil spill.

One of the limitations of the research in Britt (2017a) - and in any research involving personal articulation of episodic memories - is the possibility for false memories or wholly inaccurate details of episodic memories to become part of the subject's responses. Harvard University Psychology Department Chairman Daniel L. Schacter, an authority on memory research, calls this human penchant for acceptance and integration of false memory content as "the sin of suggestibility" among his concept of there being seven sins of human memory systems (Schacter, 2001, p. 112). The term "suggestibility," as it applies to flaws within memory, "refers to an individual's tendency 
to incorporate misleading information from external sources" (Schacter, 2001, p. 113).

The creation and retention of false memory content can be sourced from media. This was demonstrated in a study by a group of Dutch psychologists, who found 60 percent of subjects, when asked if they had seen television footage of widely reported airliner crash, affirmed that they had seen the footage and provided detailed episodic memory of their exposure to the report, when in fact no television film of the crash existed (Crombag, Wagenaar, \& van Koppen, 2011). Other studies have confirmed the potential of false memories arising from media content exposure, including content from familiar Twitter authors (Griffin, Fleck, Uitvlugt, Ravizza, \& Fenn, 2017), the influence of accompanying photographs upon believability of false news items (Strange, Garry, Bernstein, \& Lindsay, 2011), emotional valence of public events in the media (Porter, Taylor, \& ten Brinke, 2008), and television advertising creating false memories for brand competitors (Sherman, Follows, Mushore, Hampson-Jones, \& Wright-Bevans, 2015). With regard to the use of online news archives for studies involving episodic memories of the news events, the prevalence of research linking media content and false memory creation suggests a careful hand of curation must be employed when scouring online media archives for content.

Memory Systems and Processes. Although an in-depth presentation of research literature concerning the physiological processes involved with memory encoding, storage, and recall is beyond the scope of the dissertation, a general understanding of long-term memory, attention, and conscious awareness will provide necessary theoretical underpinnings for the concept central to this work. This is particularly important in considering how media content might be retained and recalled over long periods of time 
from the original engagement with the content, as well as associated experiences from the original time of engagement. The notion that human consciousness could merge awareness of multiple stimuli was put forward by William James (1909/1996) in a lecture titled "The Compounding of Consciousness" with the following example:

I wish to discuss the assumption that states of consciousness, so-called, can separate and combine themselves freely, and keep their own identity unchanged while forming parts of simultaneous fields of experience of wider scope... While you listen to my voice, for example, you are perhaps inattentive to some bodily sensation due to your clothing or your posture. Yet that sensation would seem probably to be there, for in an instant, by a change of attention, you can have it in one field of consciousness with the voice (p. 182).

This idea of merging, yet identifiably separate components of conscious awareness ties into the present research in two ways: One, in episodic memories constructed from awareness of other events (for instance, activities or conversations) going on at the same time as initial awareness of a news event through mediated channels; and, two, mediated temporal consciousness itself, in the sense of awareness, though mediated channels, of events in time going on outside the reach of physical perception by the observer, such as one might experience in learning of a dangerous storm hundreds of miles from where one is presently.

Concerning human memory research, the field evolved over time from a unified model of memory systems in the brain to a short-term memory (STM)/long-term memory (LTM) dichotomy (A. Baddeley, 2002). This was initially proposed by Hebb (1949) and further developed through experimental evidence in the 1950s and 1960s (A. Baddeley \& 
Warrington, 1970; Brown, 1958; Peterson \& Peterson, 1959), and which fostered different models of STM and LTM (Atkinson \& Shiffrin, 1968; A. Baddeley \& Hitch, 1974). Work in the late 1960s and early 1970s by computer scientists trying to program machines to understand language informed new research in psychology on how humans store knowledge (A. Baddeley, 2002) and led to Tulving (1972) developing the concepts of episodic and semantic memory. Gardiner (2002) notes that Tulving's definitions of episodic and semantic memory includes processes suggesting that perceived events first have to be registered in the semantic system before being registered in the episodic system. This suggests that, when a person first learns of a news event through a mediated source, the information of the event is first processed and encoded as semantic information. That is followed by processing and encoding of the experience - the episodic memory - of learning the news event in question.

As the present research deals exclusively with long-term memory of news events, it should be noted that defining the differences and relationships between short-term memory and long-term memory has been the subject of much debate and research stemming from a model by Broadbent (1958) that suggested information goes through a linear flow from sensory storage to short-term storage to long-term storage (Cowan, 1988). In examining mutual constraints of different areas of information processing for humans, Cowan (1988) summarizes the difference between STM and LTM:

It appears that the distinct properties of short-term storage may be consequences of the types of processing that effectively keep memories in an active state (e.g., rehearsal), whereas the distinct properties of long-term storage may result from types of processing that are useful for efficient retrieval (e.g., semantic 
elaboration). Different capacity limits of short-term storage may result from the decay properties of activation, a possible limitation in how much of memory can be activated at once, and a limitation in what can be included in the focus of attention at one time (p. 166).

There is a reciprocal relationship between memory and attention (Cowan, 1995). It is the effect of attention upon memory that is of more interest here, particularly as it would concern using media-based stimuli and the attention given it to activate memory recall of the event represented in the content. It appears memory is "based upon a progression of fundamental processes: encoding, activation, decay or inactivation, retention, reactivation, and context-dependent retrieval; but attention can affect all of these processes" (Cowan, 1995, p. 243). Citing Eich (1984) and Cowan et al. (1993), Cowan adds that, although with some uncertainty, after the activated state of short-term memory is lost, there is still some trace "left on the nervous system and that if the trace is reactivated by another, 'reminder' stimulus, it can affect (memory) performance in the future" (1995, p. 243). As a result, where it concerns memory of past news events, including stimuli outside the attention given the mediated information at the original time, an archival news report on the same event may act as the "reminder" stimulus to aid and assist with memory recall.

Additional literature reviewed above provides an overview of some of the psychological processes involved in long-term memory, attention to stimuli and how that may affect long-term memory, elicitation of long-term memory content from individuals, and concepts that point to a particular interest in memories encoded and retained during the adolescence and young adult years. The act of presenting images, such as would be 
found in archival news videos online, and interviewing subjects after having viewed such content may help subjects recall and articulate not only memories of the news event itself, but associated memories of experiences at or near the same point in time, including episodic and semantic memory content not recalled before engagement with the archival news content. This also provides a venue into construction of the proposed concept through the following research questions:

RQ2: What do subjects recall through memory about a news event prior to engagement with archival content concerning the same news event?

RQ3: After viewing archival online news videos, what themes emerge among subjects' recall of episodic and semantic memory of the event, and how do they contribute to subjects' perception of that time? 


\section{Methods}

\section{Photo and Video Elicitation}

Video elicitation is simply a variation on the longer established research method known as photo elicitation. By utilizing a photograph within a research interview with a subject, the researcher using photo elicitation, versus a written or verbal interview alone, has the advantage of a stimulus activating the parts of the brain that processes visual information (Harper, 2002). The goal of photo elicitation in research is to use those images to "evoke deeper elements of human consciousness than do words" (p. 13). The

method has been used recently in studies across many disciplines, including a qualitative psychiatry study on repeated self-harm (Edmondson, Brennan, \& House, 2018), tourism resiliency among local residents (Katarzyna, Sofie, \& Dominique, 2017), international students' experiences in a foreign country (Wang, Leen, \& Hannes, 2018), and social media depictions of alcohol intoxication and gender (Laws, Hunt, \& Antin, 2018). One significant advantage for photo elicitation compared to the standard qualitative interview method is that the images provide a talking point that is mutually understood by interviewer and research subject, whereas interview questions may be of more significance to the interviewer than to the subject (Harper, 2002).

Video elicitation studies, at one time a rarity among visual sociology research (Harper, 2002), have become more common in recent years, but much of the published research using this method centers on healthcare topics and studies involving emotional affect. Media studies using video elicitation are harder to find at present; even more so for studies concerned with either semantic or episodic memory of individuals. However, 
similar to the photo elicitation interviews cited above, the use of video elicitation has the potential of drawing not only more but also different information from subjects, versus standard interview methods. With the video acting as both visual and audio cue for retrieval of memories concerning specific news events of the past, the method may also reveal associative, episodic memories similar to those outlined in a video elicitation study of 18-24-year-olds and recent ( $<7$ years) news events (Britt, 2017a).The literature cited above regarding journalism's role in constructing collective memory establishes a strong connection between journalistic works and how the news events of the past are widely remembered, even if journalism as a whole has been paid scant attention within memory studies research. The rise and evolution of online, digital news archives, on the other hand, has become more ubiquitous in the past decade and includes an ever-growing body of professionally created works that are readily accessible to the internet-connected public (Arthurs, Drakopoulou, \& Gandini, 2018; Cariani, 2017; Jin Kim, 2012). In engaging with online news archives, exemplified by the video content available on YouTube, audiences also have a direct, interactive way of articulating their memories of the past news event as well as personal experiences related to the news event (Britt, 2017a; Dynel, 2014; Hilderbrand, 2007).

\section{Study Procedures}

For the present research, qualitative interviews were conducted in which subjects ages 30-47 are asked to watch two brief ( $<5$ minutes) videos featuring reports on major news events of the past. Qualitative interview is a preferred research method in instances where the researcher is most interested in the respondents' perceptions or thoughts about a topic or personal experience (Silverman, 2005). Qualitative interviews also proceed 
inductively with open questions that allow for greater detail and elaboration from respondents (Frey, Kreps, \& Botan, 2000). Since the present study is primarily concerned with personal memories of news events or of experiences associated in time with the news event, a research method that allow for such personal description and elaboration would be preferred. The main disadvantages of qualitative interview as a research method is the inability to generalize to larger populations, and the question of whether respondents are constructing a narrative for the sake of the interview participation, rather than being direct access to the respondent's experience of interest (Silverman, 2005). However, the research questions are concerned with individual memories and perceptions of presence based upon news events of the past, perceptions of those news events, and individual memories associated with the time of the news event; these are bound to be unique to some degree, and rather than generalization, the study is concerned with emergent themes among recalled memories connected to particular news events of the past.

This study was approved by the Institutional Review Board at a large Midwestern public university as a continuation of a previously approved study proposal which led to research findings and article publication of Britt's (2017a) work on episodic and semantic memory recall among college students concerning major news events from the previous seven years. Subject recruitment for the current study included advertisement through locally posted flyers, social media announcements on Facebook and Twitter, and publication of a call for research participants through a weekly university newsletter. The age range chosen for participants in the current study was selected for two reasons: First, to compare and contrast research findings with that of the previous related research with 
18-24-year-old subjects (Britt, 2017a); and, second, to reasonably limit the field of news event content for the study to those events which would have taken place when all potential subjects for the study would have been 12 years of age or older, also coinciding with the procedures in Britt (2017a).

Subjects recruitment for the study was on a voluntary basis, and subjects were compensated for their time with a \$25 department store gift card acquired through university purchase protocols. Subjects were read a consent form by the principal investigator and verbal assent to continue in the study was obtained at the conclusion of the reading of the consent form. Subjects were informed the study would take approximately one hour to complete. Subjects also were asked to sign a consent form for audio recording of their interview session for the purpose of accurate transcription and analysis of responses.

Each subject began the interview session by answering a few demographic questions on age, gender, and ethnicity solely for the purpose of providing basic demographic description of the pool of volunteer subjects. The study did not intend to incorporate this information into any sociological examination of the responses, such as along gender identity or racial/ethnic identity. Following that, the principal investigator revealed the specific past news event for the first of two video elicitation interviews, and each subject responded to the following two questions pertaining to memory of that news event:

1. What facts do you remember about this news event?

2. What personal experiences do you remember at the time of this news event? 
Responses to these questions helped establish a baseline context of episodic and semantic memory content before viewing of an archival news video on the chosen news event, and assists in answering RQ2 in this study.

Subjects then viewed the archival news videos on a small tablet device provided by the principal investigator and, following the viewing of each video, proceeded with an interview about the degree to which they felt a sense of going back in memory to the time of the news event, which assists in answering RQ1, as well as questions regarding memories of the news event concerned in each video, associated memories during the same time of the news event, and their attitudes and/or perceptions of the same news event today, which assists in answering RQ3. The questions for this part of the interview session are as follows:

\section{Presence}

1. To what extent did viewing this news video remind you of thoughts and/or feelings you had at the time you first learned of this news event?

2. To what extent did you begin thinking about things you said or did at the time you first learned of this news event?

3. To what extent did you just experience a sense of "going back" to the original time of the news event?

\section{Semantic Memory}

1. How much did the content of the news video concur with facts you remember about the news event?

2. What facts, if any, did the news video present that you had forgotten over time? 
3. What facts, if any, did the news video present that you did not know prior to viewing the video?

4. Were you aware of the existence of this news video online or other videos similar in content?

\section{Episodic Memory}

1. Did you speak to anyone about this news event on the day/night it occurred? If so, what do you remember about the conversation?

2. What, if anything, do you remember about the remainder of the day/night or the time immediately after you first learned of this news event?

3. What personal memories did viewing the video of this news event help you to recall?

4. What personal memories do you associate with the time of this news event? The videos selected for use in the study were chosen from among available archived news videos on YouTube, as of November 1, 2018, concerning news events that were ranked among the top three news events of a given year, as selected by the annual Associated Press Editors' Poll ("Gulf oil spill voted top news story of 2010 in AP editors' poll," 2010; Nicks, 2014). To address concerns of authenticity of the original news report, only original video reports produced by one of the major news publications or news broadcasters in the United States was considered for selection. Edited "highlights" packages and retrospective reports were not considered for selection, as the study is concerned with video elicitation of memory using content at the originating time of the news event. In keeping with Britt (2017a) and in providing at least four years of time 
differential between selected events, the following videos were selected as stimuli for the video elicitation interviews:

1. "Ferguson 2014: A Protest Ignites - The New York Times" - New York Times (link: www.youtube.com/watch?v=hC9vBlgBfjY)

2. “Oil Rig Sinks, Spill Possible" - CBS News report on the 2010 BP Deepwater Horizon Oil Rig Explosion in the Gulf of Mexico (link: www.youtube.com/watch?v=fj84UmmgUWA)

While these videos are only two of the dozens, across the corpus of YouTube-hosted video content for both news events, that could have been selected for the study, they were chosen for their adherence to "traditional standards" (Peer \& Ksiazek, 2011, p. 46) of news journalism video production and, as archived news reports from recognized, mainstream news organizations in the United States, there was not the concern over a potential confound to the study stemming from authorship bias to promote particular social or political causes (May, 2010; Smit, Heinrich, \& Broersma, 2017). Additionally, these videos were selected for the respective news events because of their relatively short total runtime (4:13 for "Ferguson", 2:02 for "Oil Rig"), helping to keep the total session time for each subject at or under one hour and keeping in step with research that indicates four and a half minutes as the mean maximum viewing time people are willing to watch a video (Clossen, 2018).

Through the interview transcriptions, the study aims not only to discover recurring themes about memory of the news event within personal experiences (episodic memory), but whether those themes are similar to those of the findings in the related previous study, and thus suggests a commonality across age groups. Additionally, the 
study may provide useful analysis on the articulation of an experience of presence through engagement with media archives that stimulate memory recall, and connect current research on presence with the proposed concept of mediated temporal consciousness. The findings from this portion of the study may also contribute to research on memory recall through video elicitation, which, as noted in the literature review, seems to be lacking presently. Additionally, the findings may help support the proposed concept on an individual level through analysis of interview responses pertaining to episodic memories wherein the news event acts as a ground stake in memory, around which other memories at or around the same timepoint are more easily recalled.

The analysis of the resulting transcripts followed the constant comparative method, comparing coded incidents within a category with previous incidents in the same and different groups coded in the same category (Glaser, 1965/2008). This analysis was conducted with the principal investigator and a research assistant for the study examining interview responses from each of the subjects and coding for themes based upon the text of the transcribed interviews. Constant comparative analysis is especially helpful from the standpoint of generating theoretical properties of each category, and:

As his theory develops, the analyst will notice that the concepts abstracted from the substantive situation will tend to be the current labels in use for the actual processes and behaviors that are to be explained, while the concepts constructed by the analyst will tend to be the explanations (Glaser, 1965/2008, para. 15) From this, we may learn more about experiences of presence and initial awareness of news events that help to formulate a mediated sense of time and memory (mediated temporal consciousness). 


\section{Participants' procedure and textual analysis check}

The research study brought in 31 volunteer participants, all of whom had answered a call for participants published on social media platforms (Facebook and Twitter) and a weekly electronic newsletter at a major public university in the midwestern United States. Consent to participate was obtained from each participant following the reading of an informed consent form, and each participant signed a consent form for the audio recording of the interview portion of the research session. Each participant received a $\$ 25$ gift card valid at a major department store retailer as compensation for their time (approximately one hour per participant) given for the research study. One participant declined the compensation offer. Of the 31 subjects, 21 identified as female while the other 10 identified as male. All but four of the subjects identified as white/Caucasian. With all subjects between the ages of 30-47, the average age was 38 and the median age was 39 .

At the beginning of the research study, one session was conducted as a pilot to test the clarity of the informed consent forms, instructions to the participant, fidelity of the selected video content, and the clarity of the interview questions. After observing that there were no issues for the pilot session participant on any of these points, the principal investigator continued with the remainder of the scheduled volunteer participants. Responses from the pilot session participant are not included in the analysis below.

Prior to watching the two selected YouTube-based videos for the study, each participant was informed of the subject matter of the video. This was done to establish a baseline of recalled memory content about the news event in question. Participants answered the first two questions as listed in the method section to provide baselines of 
content for both semantic and episodic memories connected to the news event. Following this, each participant viewed one of the two videos to its completion. Participants watched each video on a Samsung Galaxy Tab A 7-inch tablet with the official YouTube app, and were informed they could watch the video in either portrait or landscape orientation of the tablet. During the participant's viewing of each video, the audio recording app used for recording the interview sessions was paused and then restarted upon resumption of interview questions. Additionally, while the participant watched each video, the principal investigator stepped away from the desk to prevent any visual distraction or otherwise influence cognitive processes with inadvertent facial expressions or body posture. After completion of the video, the principal investigator returned to the desk where the participant sat and continued the interview with questions meant to address semantic memory, episodic memory, and awareness of presence in the sense of feeling transported back to the time of the respective news event featured in the video. With the interview being semi-structured in format, the principal investigator asked specific follow-up questions, outside of the standard list, when necessary for clarification of a response or where elaboration of an initial response was likely. When the interview finished for the first video, the same process was repeated for the second video.

When all the scheduled interview sessions had been completed, audio recordings of the interview questions and responses were given to two transcribers hired for that work. The transcription text files were then uploaded to a private, secured cloud drive belonging to the primary investigator of the study. From among the total number of transcription files, the principal investigator then printed a 10 percent sample and provided a copy to an IRB-certified research assistant for the purpose of comparing 
textual analysis and categorization of content in the sample along thematic groupings, identification of statements of memory as being either episodic, semantic, or blended (translatable as either episodic or semantic), and identification of statements regarding presence as being either positive or negative for a sense of presence. The principal investigator and research assistant analyzed the sample of interview response texts separately and did not converse about interpretations until both were finished with the analysis. After comparing the individual interpretations and categorization of statements, it was found the separate analyses agreed on more than 90 percent of the content. The principal investigator then proceeded with textual analysis of the remaining transcriptions, using a constant comparative method with which to address the emergent themes from across the whole body of transcription texts. 


\section{Results and Analysis}

Following are the results, based upon analyses of the body of interview responses in the study, in answering each of the three research questions stated earlier.

\section{RQ1: The connection with presence}

One research question for the present study concerned itself with the idea of presence as transportation; here, as it might pertain to a sense of being transported back to the original time of the past news event in question. Three interview questions in the study concerned participants' articulation of this sense, or feeling, of having "gone back in time" and are connected with the following RQ:

RQ1: How do subjects, after engaging with archival news content, describe the experience of presence as it pertains to memories associated with a news event?

By far, emotional memory or an emotional connection to the news event was the biggest factor in subjects who indicated a sense of presence while or after viewing one of the archival news videos. Responses that characterized this sense of presence were more numerous for the Ferguson protest video (16 of 30 subjects) than for the Deepwater Horizon incident video (eight of 30 subjects); although the respective topics of both videos could be characterized as serious or "bad" news, many subjects expressed more detailed and more intense emotional connection to the situation in Ferguson in 2014. As textual analysis showed in other parts of the study interviews, the closer temporal proximity to the present of the Ferguson protests, and, for many of the subjects, the closer geographical or spatial proximity of the event, may have played a role in producing a stronger emotional connection to the news event, compared to the older and, for most, 
more distant Deepwater Horizon incident. However, some subjects also indicated a feeling of going back in time to 2010 and the Deepwater Horizon incident through memories of worries and concerns for the Gulf of Mexico and the Gulf Coast region of the United States, including residents and industries dependent upon wildlife and fishing for their livelihoods. These characteristics suggest that emotional affect and emotional memories connected to past news events could act as a thoroughfare for presence as transportation to a time in the past, assisting in autonoetic reconstructions of the self at that point in time, and fostering an awareness of a mediated temporal consciousness of that time. There were fewer cases in the interviews of subjects articulating a sense of being back in a physical location or engaged in a particular activity through memory of the news event. When that did occur in the interview responses, it was largely described as an episodic memory of watching, reading, or hearing news media coverage of the event at the time, or engagement in discussions and conversations with family members or other about the news event. In most cases, the appearance of such responses coincided with a response indicating a strong emotional connection through memory of the news event, suggesting again that emotions play a major role in fostering a sense of presence or MTC when one encounters archival news content.

\section{Carried back by emotion}

Many subjects in the study expressed an emotional connection to the Ferguson protests and indicated they felt drawn back to those original emotions, and the time of the news event, while watching the video about that event. Subject 020 stated, "It ties back into what I was saying about the emotional memory and having a sort of sympathy for both sides and feeling sad that there wasn't a way for everyone to connect." The same 
subject added that the video also prompted memories of fear of confrontation leading to "being a little more cognizant of where we stopped to get gas and having an awareness of where Ferguson was relative to the broader city." Subject 016 explained, "I felt my whole energy change as I watched the video. It brought back that sick feeling of watching this country and (thinking), 'How is this ever going to get better?'" Subject 021 spoke of the video bringing back memories at the time of a change in her perception of discrimination issues within law enforcement and an episodic memory of doing statistical research at the time to further her understanding of the issue.

Indications of a strong emotional component, and, subsequently, presence as a transportation back in time, tended to be fewer with regard to the Deepwater Horizon oil rig incident video. Responses to questions regarding how much the video transported the subject back to the time of the event, or to thoughts, feelings, or actions at the time, were typified by "Just a little" (Subject 002), "I think it reminded me a little bit of my concern for the Gulf and ecosystem and environmental effects" (Subject 026), and "it wasn't a significant event in my life that was actually memorable to me at all" (Subject 017). In many cases in the study, subjects indicated they could not remember the news event well enough to articulate any substantial memory content, emotional or otherwise. When emotions did feature in the responses about the Deepwater Horizon incident, they did suggest a sort of empathetic connection that provided a roadway back to the time of the news event, as exemplified in a response by Subject 009:

I just remember feeling really, you know, not like depressed or anything like that over, but just like you feel like, oh man, you know those people and their families, and when the movie came out, I remember feeling kind of the same way where 
you just think about all what those people went through, really. And what a horrible situation it was. And how much it could've been... avoided. That didn't have to happen.

Where an emotional connection to the news event was evident in responses, most subjects talked about a sense of being back to the original time of the event through remembered feelings or thoughts born of the emotional reaction to the news event. This suggests a major role for emotion in encoding and retrieving memories of events when they happen and, here, suggests that people may be able to use that emotional connection to the news event in forming a mediated temporal consciousness of that time as they experienced it.

\section{The memory of places and people}

While emotional connection to past news events dominated the responses pertaining to a sense of presence among subjects, some were also able to make a memory-based connection to the past news event through remembered places or activities, the latter chiefly being conversations with family members or others within a social or workplace group. Subject 028 said the video brought her back not only to the time of the protests but experiences with much of the debate that followed, including seeing other videos of individuals "defending the cops" and "people like standing up for Black Lives Matter.” Conversations about the protests and the underlying racial issues featured prominently in responses where subjects indicated a strong sense of being transported back to that time. There were a few subjects who shared episodic memories in pointing out a strong presence-like effect from the video, including Subject 007, who stated: 
Watching the video made me feel like I'm back in my living room at that time when it was happening, like, I remember just staring at the TV and just being mystified by this event while it was unfolding live on CNN.

Subject 006 spoke of a similar feeling of being transported back to the time when she watched the initial news reports: "It just really makes me specifically remember being in my parents' living room and trying to maintain a conversation that didn't generalize people or behavior."

As with emotional memories connected to the event, memories of places and activities associated with the Deepwater Horizon incident were fewer than with the Ferguson protests. Where at least a moderate sense of presence-style transportation was indicated after watching the Deepwater Horizon video, it tended to be connected to conversations with others, usually family members, about the long-term effects of the oil spill on the fish, wildlife, and tourism industries along the Gulf Coast. One example of this came from Subject 002, who stated, "I mean, it brought back the memory of it occurring, and questioning my dad that I knew would communicate with my uncle about it...about how it could affect things, other than that, not much." However, there were exceptions to this trend. The most notable of these came from Subject 011, who stated that the video report about the oil rig incident put her back in time, mentally, to a special visit with her brother and sister-in-law that included a road trip to Kansas City, Missouri, for a professional baseball game:

I can like see myself being kind of in those moments and that time period. You know, (in) my brother's old house. They've moved since. Going back to that hotel room in Kansas City, it was a horrible little hotel room, cheap one near the 
ballpark. (I remember) going to the museum and I remember seeing the Verdant (Mountains) statue at Nelson-Atkins (Museum of Art).

There were also a pair of episodic memories connected to British Petroleum itself. A statement from Subject 027 indicated that viewing the video brought back to mind a time of indecision as to continued patronage of BP products. "I think there was a BP station and I went to it a lot, so I remember, not very in-depth, if I should continue to go to that station or visit a different one," the subject stated. Subject 017 stated she "might have been slightly more anxious" about owning stock in BP at the time. In another interview session, the news video brought back the subject's memories of being on active military duty in Iraq, where oilfields would frequently come under attack and oil fires would be the result. However, in all three of these instances, the subjects stated that they did not experience a strong sense of going back to the time of the Deepwater Horizon incident.

In summation, the interviews suggested that a presence-type transportation back to the time of the news event was more frequently indicated through memories of feelings or event-related experiences for the Ferguson protests video. This stands in contrast to the Deepwater Horizon oil rig incident video, where presence seemed weaker or non-existent for most subjects, absent of the same emotional portent as with the Ferguson protests video, and only in instances of some significant personal connection to the event or time of the event was a sense of being transported back in time indicated in the responses. In general, subjects tended to articulate a stronger sense of presence with the Ferguson protest video than with the BP Deepwater Horizon oil rig incident video. This may have been the case for one of three reasons: emotional affect differences in the two news events, the time differential (2014 and 2010, respectively) making the Ferguson protest 
video less susceptible to forgetting due to memory transience (Schacter, 2001), or a proximity factor, given that most of the subjects indicated through responses that they were living in the midwestern United States in the previous 10 years. The findings in this chapter suggest that emotional memory plays a significant role in how strongly a sense of presence as transportation to a past event or time is perceived when one engages with archival news content. By extension, this would suggest a stronger sense of MTC - the awareness of one's self at that timepoint and ability to articulate the associated memories - where that emotional component connected to the event remains in memory. It is interesting to note, however, that both archival news events in this story elicited emotional memory of worry or concern. In the case of the Ferguson protests video, many of the subjects relied on their memories of concern for friends or family living in the St. Louis area at the time, along with general concern about the state of race relations. The Deepwater Horizon video, while seemingly not as likely to elicit strong emotional memories, nonetheless did bring back some memories of concern for the environmental impact of the oil spill. The differences between the two videos in eliciting a sense of presence taking place is also interesting because both news events, it can be argued, are negative in emotional valence - both are "bad news" and, according to Giles (2003), "It seems that whatever the source we simply find bad news more interesting (author's ital.) than good news" (p. 218). However, most of the 30 subjects in the analysis indicated, through articulation of semantic or episodic memories, that the Ferguson protests as a news event contained greater proximity to them than did the Deepwater Horizon incident. The one subject who indicated a closer residential proximity to the Gulf of Mexico (Subject 030) stated that the Deepwater Horizon incident "was more salient" as a news 
story "because I live in Texas near the Gulf." MTC as a concept of engaging with memory of past news events may, likewise, be affected by proximity of the news event. Going forward with perceptions

As indicated in the literature review, audiences can potentially use archival news content to form comparative perceptions across time and re-evaluate themselves in the context of the news event or issue. This is a different, progressing conception of presence as transportation, yet indications of it can be seen among interview responses for the Ferguson protests video as it pertains to the state of race relations in the United States presently and since the Ferguson protests. Subject 002 summarized the passing of time in stating, "It (the video) just brought back the feelings of how there is still such a divide, and how racism is still very much apparent." Subject 004 spoke of how the Ferguson protests changed her perceptions of self and how the video called to mind that transformation in thinking:

So, that feeling I had at that time is because, after that incident, then I watch and read more news about the racial issue news, on news about racism. And then I was more interested in the white privilege topic and how (African-American) people (and) Asian people was or are, treated by white policemen. And I was concerned about my status as a foreigner in the U.S.

Subject 006, who recounted episodic memories of conversations with relatives as she and her family moved to Missouri from a comparatively isolated area in Kentucky at the time of the Ferguson protests, talked about how the event changed the level of saliency of the story and the issue it represents: 
I've remembered this news event specifically where we were all of a sudden talking about this national story, and it had to do with law enforcement that affected our family and black communities that my kids were totally unfamiliar with. And (the) behavior of my own parents compared to the behavior that I expect from other people, that's my biggest recollection of this event. It was, I think, really important in moving me personally in another direction and realizing I'm going to have to be more vocal for the sake of my own kids and their growing up.

Similar responses were present within the interviews after viewing the BP Deepwater Horizon video, though not as numerous as with the Ferguson protests video. However, Subject 029 shared an episodic memory of how the oil rig explosion and large underwater oil leak subsequently affected her workplace, explaining, “...We had to make some pretty large changes to where our seafood was being sourced, specifically shrimp. Because we used a lot of Gulf shrimp in our operations and then all of sudden it was not going to be available." Subject 005 talked about the video playing a part in reminding of "the scope of the problem" and the fact that the event, having largely disappeared from the current U.S. news landscape, has spurred a personal desire to "see now what is the status of the Gulf, what does it look like?" In contrast, Subject 009 indicated the event is still in the news, despite the passing of eight years since the incident, and conversations continue on "the effects it has on the environment" along with "the fact that BP is going to be paying for centuries for their mistake." The takeaway from these interviews responses is that engaging with media archives can provide a sense of the changes and developments of an event or issue over time, the long-term effects of an event or issue on daily life or 
personal perceptions within a social context, and that the archived content provides a valuable historical starting point by which evaluations of the impact of an event or issue may be made.

\section{RQ2: Initial memories of news events}

As stated above in the study procedures, each research subject was told the topic of the video they were about to view and then asked a pair of questions regarding what they immediately remembered about the event (semantic memory) and personal memories connected to the event (episodic memory). This was done to establish a baseline of recalled memory content connected to the news event, so that comparisons could subsequently be made with recalled memory content after viewing the respective news video. It also allowed for an analysis of patterns within the pre-video responses, leading to the second research question:

\section{RQ2: What do subjects recall through memory about a news event prior to engagement with archival content concerning the same news event?}

Although the initial questions were worded to address specifically semantic memory content or episodic memory content, there were a few occasions when the types of memory crossed over in the responses. However, the analysis of responses to the interview questions prior to video viewing showed that 28 of the 30 subjects remembered both the general information and some details about the Ferguson protests - though not always correct information. Comparatively, semantic memory prior to video viewing was more generalized about the Deepwater Horizon incident, and tended to focus on the oil spilling underwater into the Gulf of Mexico more than any other detail. Five of the 30 subjects were unable to recall anything about the event. Episodic memory recall prior to 
video viewing revolved largely around conversations with others about the Ferguson protests. Some subjects spoke of feelings of concern for the safety of others. In a few of the interview sessions, a subject was able to recall a very specific, unique episodic memory associated with the time of the news event. Of everything addressed by this RQ, episodic memories prior to watching the Deepwater Horizon video were rarest; responses, if containing any memories at all, tended to be generalized about friends or relatives in the Gulf Coast area or about seeing news of the oil rig incident on television.

\section{Facts initially remembered}

With only the topic of each archival news video revealed before viewing the video, most research subjects were able to remember basic elements of the news event in question. For the Ferguson protests video, most subjects stated that they remembered the protests were in response to the shooting death of an unarmed black teenager by a white officer on the city's police force. Most subjects were also able to remember general elements of the protests, particularly some looting and vandalism of property and businesses in Ferguson. In some cases, the subject's memory of the event was less detailed, such as in the response from Subject 009:

$\mathrm{Oh}$, that it was a police shooting from a young man who struggled with a police officer and lost his life. There were conflicting stories about where he was shot...it escalated from there, which then caused riots and looting and unfortunate incidents, that people from outside that community came in and really destroyed many of the businesses in that community, which was devastating for those people who lived there. 
This same subject was able to recall hearing, at the time, that the shooting incident began as police were called to the scene of a disturbance at a local convenience store. Several other subjects articulated their memory of what allegedly took place to bring the police to the scene, in varying degrees of detail. Some of those subjects said they remembered these details from news reports at the time and a few noted they remembered seeing the video surveillance footage shown in news reports about the shooting and subsequent protests.

As for the series of protests, from which one night was featured in the video used in the study, few subjects articulated memories of any details beyond the fact that protests took place in Ferguson and the looting or vandalism that took place. This was not unexpected in the initial responses within each interview, as details of memories tend to be lost over time and the events themselves take on a more generalized representation within memory (Campbell, 2002; Schacter, 2001). A few subjects did remember more detailed information initially, including the name of the black teenager who died (Michael Brown) in the police shooting, one protest shutting down a portion of an interstate highway in the St. Louis area, and debate from the time as to whether Brown was attempting to steal cigars from the convenience store, prompting a call for police to arrive on the scene.

Initial semantic memory recall for the BP Deepwater Horizon incident was often characterized by generalized statements about the volume and duration of the oil leaking into the Gulf of Mexico. The only other detail that came up occasionally in the pre-video responses concerning this event was an awareness of the concerns for the environmental and economic impact of the oil spill, or remembered emotions of worry for the same. 


\section{Remembered experiences at the time}

As for initial episodic memories tied to the two news events used in the study, most subjects spoke of interactions or communications with other family members, friends, or work colleagues concerning the events. One female subject, who said she worked in education at the time of the Ferguson protests, remembered "consoling a lot of students" who came from the underserved areas of St. Louis, but added that her remembered experiences of the event were "mostly through friends and acquaintances and students." The same subject initially remembered conversations with her husband, who was originally from the Gulf Coast, about the Deepwater Horizon incident. About a third of the subjects in the study recalled episodic memories of contacting friends or relatives in the St. Louis area to check on their well-being during the Ferguson protests, while more than half of the subjects indicated memories of conversations with other people about the protests, the shooting that led to the protests, and/or racial issues within law enforcement interaction with the public. This finding connects with interview responses in an earlier study by Britt (2017a), where most of the younger subjects from that study also spoke about episodic memories of interactions or conversations with family members or friends at school regarding major news events during their teenage

years. It suggests that people often turn to others within their respective social groups to facilitate discussion, debate, or cognitive processing of the news events as they become encountered through media.

It is worth noting here that some news event-connected episodic memories with family members were more unusual than the conversation/discussion description. Subject 023, a male, stated the only thing he remembered experiencing at the time of the 
Ferguson protests was "marital problems going on at the time" and that the oil rig incident took place about a year before he and his wife eventually separated. The Deepwater Horizon incident, four years earlier, brought episodic associations with his then-wife having just had a baby or expecting; the subject was unsure which because of uncertainty of the exact year of the news event.

Even more unusual is the initially recalled episodic memory from Subject 011, a female, who said that the Deepwater Horizon oil rig incident instantly brought up detailed memories of a car trip from a brother's home in Omaha, Nebraska, to Kansas City, Missouri - a trip that took place because the subject had received tickets to a Kansas City Royals baseball game. The episodic connection with Deepwater Horizon came about because the event coincided with the time of that long-distance family outing and was discussed by the subject and her family members as they were traveling to Kansas City. The subject recalled:

I had gotten four tickets and my niece she was just, let's see, a little over a year old. And so, I was going to babysit my niece, and my parents and my brother and sister-in-law were going to go to the game, and I had gotten the four tickets for Christmas for them, but then we ended up getting a fifth ticket and just all went to the game. I remember that trip very vividly.

The subject went on to add that the memories included not only the baseball game, but dinner at a barbecue restaurant and a visit to an art museum. She did say the trip was out of the ordinary for the time, compared to other visits to her brother's family. "Usually if I see my brother, it's in Omaha and we stay in Omaha, and like that's the only time we've ever done that (go on a road trip)," the subject explained. Instances of highly unusual or 
unique episodic memories like these suggest that temporal associations are created when we become aware of news events while also encoding into memory these personally significant moments or experiences.

\section{Temporal and factual misattributions}

Although it didn't occur frequently in the responses to questions prior to viewing videos, in some cases, research participants exhibited a type of memory misattribution concerning the actual timeline of events. This misattribution may be characterized as a sort of temporal compression effect, wherein memories of events are ascribed to have been closer in time than when the actual events took place. One example of this can be seen in a response from Subject 028, who shared an episodic memory of black student protests at her university, following the Ferguson protests:

I do remember we got on the (university) campus, I don't remember what his name was. It was a number. And they camped out on (the university) campus as a kind of "We're going along with Ferguson" event. It kind of all happened at the same. I remember my mom worked at the dining hall and there was a Girl Scout (troop) that had come in, you know, to eat. And there were rioters that came in the dining hall...and they were yelling "Black Power! Black Power!" And the girls were getting scared and they didn't know what was going on. So that's pretty much what I remember from all of that.

In fact, the protests referenced by the subject took place about a year after the Ferguson protests. However, the specific episodic memory may have been so closely connected in subject matter that the time differential was either forgotten or misattributed to being closer in time to the earlier event. 
The interviews also revealed a few cases of misattribution within semantic memory of the events featured in the two news videos. One subject initially confused the identity of Michael Brown with that of the victim of a different shooting incident $21 / 2$ years earlier, Trayvon Martin, a 17-year-old who was fatally shot in Florida by a 28-yearold neighborhood watch coordinator, George Zimmerman, during a physical altercation between the two. Eight of the 30 subjects, when asked what facts they remembered about the BP Deepwater Horizon Oil Rig incident, indicated doubt or uncertainty if their memories about the incident were not from that of a different oil spill event in the United States. Another subject initially referred to the news event as involving "a rig off the coast of Texas," instead of the correct location, south of the Louisiana coastline. The above types of misattribution are commonplace because "people often have sketchy recollections of the precise details of previous experiences - when and where they encountered a person or object" (Schacter, 2001, p. 93). Throughout the interview sessions, several instances of expressed doubts about attribution occurred. In cases where a misattribution occurred during a response to one of the pre-video viewing, introductory questions, the video subsequently served as a correcting mechanism for the subject's initial misattribution or unclarity of memories about the respective news event.

Here, we have seen how the mere mention of a past major news event is able to spur at least some memory recall about the event, and possibly episodic memories connected to the event itself or connected to the time of the news event. There is also a suggestion that the passage of time can create forgetfulness of memories concerning the event or misattribution of details (Schacter, 2001); noticeably, semantic and episodic memories connected with the Deepwater Horizon incident (the older of the two news 
events) were fewer and more generalized than memories initially shared about the Ferguson protests. It is also possible that, once again, proximity of the event to the majority of the subjects' place of residence at the time may have been a factor in the ability to recall semantic and episodic memories. However, in responses that showed any memory recall, and that a clear majority of the subjects were able to articulate those memories, it suggests that people carry at least some level of MTC about past news events and presents a baseline level of memory about the event, with which a person can then seek archival media about the same event.

\section{RQ3: Back in time, back in mind}

The final research question in the study looks at what subjects were able to remember, in terms of both semantic and episodic memory content, after viewing an archival news video about a specific news event.

\section{RQ3: After viewing archival online news videos, what themes emerge among subjects' recall of episodic and semantic memory of the event, and how do they contribute to subjects' perception of that time?}

The most common theme found in an analysis of the responses was surprise or a suddenness of realization that subjects had forgotten, or perhaps did not know, vital details within both news events. Topping the list of facts that fell into this theme was the loss of human life from the Deepwater Horizon oil rig explosion and collapse. This was closely followed by the topic of police use of tear gas (featured prominently in the video) to disperse protestors in Ferguson, Missouri. Regarding semantic memory of the events, most subjects indicated they felt the archival videos matched what, if anything, they remembered about the news event in question. Although nearly all subjects indicated they 
had not seen online videos about the same news events as presented in the study, some subjects stated that watching the video reminded them of viewing news reports about the same event on television at the time. Regarding episodic memories, most subjects said they did remember having conversations about the respective news event, but the degree of detail about those conversations varied widely. Fewer subjects remembered something they experienced the day of the news event, or episodic memories recalled while viewing the video, but of the ones who did, the details were often vivid.

\section{Key facts forgotten or never realized}

There was a common thread of facts forgotten, with those facts being recovered with the assistance of the videos. For both news videos used in the research study, nearly all subjects stated that watching the videos reminded them of facts they had forgotten about the respective news event over the course of time. For the Ferguson protests video, exactly half - 15 of 30 - of the subjects indicated they had forgotten about or did not know previously about the alleged use by law enforcement agencies of tear gas cannisters in an effort to disperse the protestors. This was featured early in the Ferguson protests video as a protestor being interviewed had retrieved one of the empty cannisters and held it up to the camera used in The New York Times' video report. The repeated phrase of “Hands Up! Don’t Shoot!" among protestors was another bit of information that many subjects stated they had forgotten since the 2014 protests.

One-third of the subjects also noted that although they remembered reports of looting of stores in Ferguson during the protests, they had forgotten hearing or reading that some Ferguson residents banded together to halt the would-be looters from stealing or vandalizing businesses along the site of the protests. This fact was also highlighted in 
the video shown to the research subjects. Many of the subjects could not initially recall the name of the teenager, Michael Brown, whose death sparked the Ferguson protests, although most subjects were able to recount the circumstances of the shooting and that it involved a black teenager behind fatally shot by a white police officer. Brown's name was brought up by a woman interviewed in the video, and many subjects afterward indicated that the video had reminded them of the deceased teen's name.

The video of the news report about the BP Deepwater Horizon oil rig incident turned out to be an eye-opener for many research subjects as well. Most notable of all is that 26 of the 30 subjects admitted, after viewing the video, they had completely forgotten or never knew about the deaths at sea of 11 of the rig's crewmembers - and several research subjects expressed surprise and dismay at themselves for having not remembered that fact before viewing the video:

I did not remember how many people were missing or injured or presumed dead, or how many people were on the rig or what was happening, and I remember more, I think, about some of the follow-up stories where they were talking about cleanup and effect on wildlife and, you know, showing pictures of birds and things like that (Subject 006).

Many other responses reflected a similar surprise at encountering information that there had been a number of human lives lost in the incident. Subject 015 stated, "The one thing I didn't remember at all was the loss of life, which I feel kind of bad about the fact that I remember the environmental impact but not the loss of life." Subject 023 said, "I wasn't aware that the platform had collapsed, I wasn't aware that 11 people had died or been missing... I just didn't realize the extent of what else it happened besides the oil spill." 
This "reminding" function of archival news content, on exhibit in the statements above and several others in the present study, corresponds with a similar in finding by Britt (2017a). In that earlier study, video elicitation interviews revealed that subjects younger in age (18-24) than in the present study - were reminded of small, yet important details concerning the news event for which they were recalling episodic and semantic memory content. This sudden recall of details with the assistance of the archival news video occurred frequently among research subjects concerning the 2012 U.S. Presidential Election coverage:

Several subjects noted that they had forgotten about the red-and-blue light coloring of the Empire State Building in New York City in accordance with stateby-state electoral vote victories for each candidate, something that was featured among the highlights in the video used in the study. Another recurring statement from subjects had to do with the closeness of the race between Obama and Romney in the early stages ("I had forgotten that Romney was in the lead for a while," was heard multiple times in the study). A few subjects stated that they had forgotten the fact that the electoral votes from Ohio were the ones that pushed Obama over the required electoral count of 275, another item featured prominently in the CNN video (Britt, 2017a, p. 97).

Subjects in that previous study were shown a different archival news video about the BP Deepwater Horizon oil rig incident in 2010, but these younger subjects also indicated they had forgotten that 11 people had disappeared and were never found after the initial explosion on the rig. This loss of memory content over the progression of time is known as transience and our understanding of it hearkens back to self-experiments of list 
memorization by philosopher Hermann Ebbinghaus in the late 19th Century (Schacter, 2001). The fact that a mere few moments of engagement with archival news content could bring back several "forgotten" memories or details of an event may indicate that the archival content serves an important role in perpetuating awareness of event details that would otherwise eventually be lost from public memory.

\section{Video comparisons to memory recall}

What we think we remember regarding a past event can be either confirmed or challenged by archival media (Moss, 2018). So while the videos viewed in this study functioned as digital reminders of facts forgotten or information subjects missed or of which they were not initially aware when the event occurred, the videos also served to confirm, in at least some cases, the semantic memory content subjects were able to recall prior to viewing the video. The interview questions regarding semantic memory of the selected news events were cast primarily in this comparative framework. In general, subjects indicated that the Ferguson protests video correlated largely with facts they remembered about that news event. However, one subject offered a criticism of The New York Times' video report, stating that it seemed somewhat biased toward the view of the protestors and failed to capture or attempt to present the perspective of law enforcement officials at the scene. On the other hand, Subject 006 said the video brought to memory a distinctive contrast with the news coverage of the protests she remembered at the time:

I remember seeing in the news coverage kind of the lines of police officers moving through a neighborhood, I feel like I saw a lot more footage of during the day, I didn't see a lot of things happening at night or as candid as that (video) was, with conversations with people in the community, I saw a lot more traditional 
news report with a person from the news agency talking rather than having conversations with other people.

Subject 030 said the video contained segments that seemed more relevant to his memory and perception of the protests, and "what I remember was that that particular community had a lot of serious issues with not only the police but the government.” The subjected continued, "It was economically plighted. So, I was aware there were systematic problems and it was due to poor governance." Subject 031 summarized the video as "pretty spot-on," adding, "I hadn't seen that actual clip, but it was pretty much how I remembered it." The response from Subject 018 echoed that sentiment: I think the majority of it was the sort of visual that I had in my head when you asked me about Ferguson with the crowds and the chaos as a result of the police officer that shot the boy."

The BP Deepwater Horizon incident video, on the other hand, proved a bit more informative to semantic memory recall, especially in terms of what happened aboard the deep-sea oil rig to spark the long-term oil spill from the bottom of the ocean floor in the Gulf of Mexico. Numerous subjects indicated the video assisted in bringing to mind major facts about the incident aside from long-term risks to the ocean life and the Gulf coastline from the high rate of leaked oil. "Well, all I remember it was, it (video) matched," said Subject 028. Subject 023 expressed some initial doubt that his pre-video memory of facts were actually from a different oil spill (several subjects in the study doubted their memory or had it confirmed they were confusing Deepwater Horizon with another oil spill incident). However, Subject 023 noted, "when they said it was British Petroleum, it was like, 'Oh, no, that's the same one.'” With regard to both videos, 
interview responses seemed to confirm the video content's function as a statement of record and reinforcing tool for factual information that could be preserved over long periods of time and for the benefit of future generations (Britt, 2017b; Foote, 1990).

Subjects in the present study were also asked if they had ever previously seen the video presented in the research session, or if they had seen videos similar in content, as a factor in semantic memory recall. Although none of the subjects indicated remembering viewing either video used in the session, several indicated the videos brought back memories of watching other media coverage on the respective events when they occurred. A few of the subjects mentioned getting information about the respective news events through other news sources, such as newspapers and television newscasts. This may suggest that the archival media content also serves as gateways for retrieving semantic memory content from the original time of the news event, providing a pathway back to that time to either reinforce, correct, or supplement what one is able to recall about a news event. From that standpoint, journalistic content and the archiving of it fulfills a central role in understanding how individuals or societies remember (or what they choose to forget) about an event (Foote, 1990; Zelizer, 2014)

\section{Episodic memories}

Connections between the news events depicted in the videos and episodic memories among the research subjects varied widely in number and vividness of recall. However, two common elements emerged among the body of interview responses, one being memories of conversations and interactions with family members and the other being emotional states as episodic memories. 
The ability of subjects to remember with whom they had conversations about either news event and the level of detail about those remembered conversations varied throughout the set of interviews. Again, the Ferguson protests seemed more emotionally affective and likely to spur discussions with others compared to the Deepwater Horizon oil rig incident. However, there were instances when memories of conversations about the Ferguson protests were light on detail and scope, Subject 025 being an example in saying, "I'm sure it was briefly mentioned at home, you know, have you seen the riots in St. Louis? And how volatile it was and how it seemed to keep escalating." Subject 014 admitted she did not remember any conversations but said she probably had conversations about the Ferguson protests with her students, many of whom were African-American, she said, and her husband. "I know this was 2014 because of the video, and so I was like, still post-partum, and really hormonal," Subject 014 added in explaining a possible reason for inability to remember conversations in more detail. However, many of the subjects responded with very in-depth articulation of how those conversations about Ferguson played out, almost as if the response was summarizing the dialog that occurred between the subject and others in the past discussions:

This was actually a few days later that they found out that he (Michael Brown) had robbed a convenience store, and he was antagonizing the shop owner in the same way he was antagonizing the cops. But did the cop actually have the right to fatally shoot him? And that was what we discussed. Could there have been some intermediate solution? I mean I understand the guy was right in the cop's face but at the same time, it just seems like an extreme reaction, but I know the cop, I think they are taught to shoot to kill if they feel threatened. I mean what else are they 
supposed to do? They can't just wait and say wait a minute, let's talk about this civilly, that's not going to happen. That's not how the real world works. So, they (law enforcement officers) have to protect themselves (Subject 017).

Subject 006, having moved to Missouri from Kentucky around the time of the Ferguson protests, spoke in depth about memories of conversations with her university colleagues about the incident and the national debate being sparked by it:

I remember having lots of conversation. It was when I first started working on campus, and so people in my office work with schools that are in that area, and so we had lots of conversations about traumatic events in communities, and what's happening with the schools, and where are kids when this is all going on, and what happens when, you know, it's not safe for kids to be places where kids could usually be, and how were kids now were going to be perceiving law enforcement in this community. And then my husband, who at the time was working in West Virginia at the regional jail authority and has former experience as a police officer, he had, you know, some really strong feelings about feeling like we can't just vilify all police officers because of someone's bad behavior, so I think that was the theme in our conversations.

Memories of conversations about Deepwater Horizon were considerably fewer in number among the research subjects, and those that were recalled tended to be discussions about the oil spill's potential impact on fish, wildlife, and tourism along the Gulf Coast. Subject 025 was among those who did remember conversations with her family, including her children, about Deepwater Horizon and recalled all of them feeling "just thankful we 
didn't know anyone in that industry, and how hard that would be to not know where your loved one is," in reference to the initial explosion aboard the oil rig.

In general, subjects had a bit more difficulty remembering specific episodic memories outside of conversations, for both news events featured in the study. The memories tended to be more generalized, sometimes blurring the line with semantic memory content. Subject 005 remembered living in St. Louis at the time of the Ferguson protests and changing a few usual activities ("I used to go shopping at a thrift store that might technically be in Ferguson.”) out of personal safety concerns. Regarding the Deepwater Horizon oil rig incident, many subjects had difficulty remembering anything of an episodic nature connected to that news event.

Despite some of the episodic memory descriptions being on the generalized or non-specific end of a scale of content detail, there were some cases in which the subject was able to articulate very vivid and specific episodic memories connected with the news event itself or with the time of the news event. For example, Subject 011 also had a comparatively unique episodic memory directly connected with the time of the Ferguson protests: Her mother had just been diagnosed with cancer and was undergoing chemotherapy. The subject admitted that her memory of facts (semantic memory) about the Ferguson protests were vague and generalized “just because my mind was elsewhere," but that she could easily recall episodic memories connected to the news event and that time in her life. Those episodic memories pertained to conversations with family members and friends back in Missouri while she was in Iowa helping with her mother during cancer treatments, as well as the road trips between Missouri and Iowa, 
and one memory in a restaurant that, in her words, left her with the feeling of "going back in time and just reliving that moment in my head":

I remember later having a conversation with family members and my sister-in-law and my brother were like arguing with me about it. (It was) in a restaurant I remember that conversation...it was the May House. It was in Ames but, yeah, this was like a year or so later. It might have been like a year later. We had this Black Lives Matter discussion. And it was like we're in a restaurant - we can't avoid people.

In another case, Subject 006 detailed a vivid episodic memory not connected directly with Deepwater Horizon, but more in an empathetic framework after watching the video, which contained a brief interview with a family member of a survivor of the oil rig explosion. Previously living in the coal mining area of eastern Kentucky, the subject recounted an experience after there had been an explosion in one of the mines:

I mean it's a very similar event, but that was very meaningful in our community, because people did have family members or friends... who were killed who were working in the mines and (those who) weren't working and try to figure out if people were home...There's no way to find out when there's a disaster, so I think that's more. I remember taking kids out to the bus and lots of adults were at the school for parent pick-up but they were all out of their cars and having conversations, and so I think it reminds a lot of that event and at the time where we lived.

A memory such as this one again underscores the emotional connection to episodic memory of news events, which emerged as a recurring theme throughout the interviews. 
It suggests that the strength of emotional connection concerning a news event influences MTC as a vehicle to remembering the news event in question.

\section{Thinking about the time}

Although it did not appear across the board in responses to interview questions, some subjects expressed thoughts and memories in a manner that indicated reflection upon the time of the news event as they had remembered it. Particular to the Ferguson protests video, some subjects went into detail about experiencing a growing tension and sometimes-ardent debate that took place as the protests took place and national awareness grew. Subject 018 talked about the rising awareness of racial tensions in U.S. society and how the Ferguson protests put that on the national forefront. The subject said seeing an archived video report of the protests "sort of sparks something because I have teenage boys and it sparks that memory of feeling scared that even though (they are) my child, I feel almost fortunate that my children are white." Subject 006 said she remembered the time as one of transition for her family moving from Kentucky to Missouri and, as a result, one of framing the move within her own mind as positive, while other family members didn't see it that way. "So, I think the biggest thing is moving from, what I considered not a great area for raising our kids, back to the Midwest where I'm from, and I viewed that as a positive event, and I remember thinking, 'Well, you know, this doesn't change my mind at all,"' the subject recalled. On the other hand, Subject 017 expressed being "surprised that Ferguson made national news" and added, "I mean it happened in Missouri, so of course I had heard of it, but the fact that that the rest of the world would have actually heard of it and could relate to it was kind of surprising to me." Regarding the Deepwater Horizon incident, Subject 009 recalled feelings of sympathy experienced 
at the time for families whose livelihoods were affected by the oil spill. That perception of the time was reinforced by a movie that came out years later about the incident. The subject stated, "I remember feeling kind of the same way where you just think about all what those people went through really. And what a horrible situation it was." Subject 021 spoke about being somewhat puzzled as to how BP would ever clean up the underwater spill. "I had curiosity about how would they manage the oil in the water," the subject stated.

Perceptions through memory of how one reacted, felt, or contemplated a news event at that time speaks to a type of self-evaluation and self-continuity, wherein one's perception of the self in the past is interwoven with the present (Sedikides et al., 2016). The reflective statements revealed in interviews in the present study coincide with those of subjects in Britt (Britt, 2017a), where some subjects expressed differences in perceptions and attitudes toward politics and the environment (the two subjects central to the videos used in that study) from the time of the news event to the time of the study. MTC, as a concept, assists in facilitating that self-construction within episodic memory through the experienced feelings, thoughts, and actions associated with the initial time of awareness of a news event.

\section{Episodic anomalies within the interviews}

While there are several emergent themes within the total body of video elicitation interview responses, there were also some articulated episodic memories so unique within the collective texts of the interviews that they could be considered anomalous. Such episodic memories may stem from unexpected experiences or encounters directly connected to the news event being studied, or could occur as a result of a personal, direct 
connection to the news event, such as being present at the time and place of the news event or having a professional occupation linked to the subject of the news event. For instance, Subject 024, a white male, was a journalist covering the Ferguson protests in August 2014. His episodic memories of being on the scene of those protests and at protests the following year to mark the one-year anniversary of Michael Brown's death highlighted a stark difference in perception of safety as a journalist. The subject articulated this difference, in some detail, before viewing The New York Times' video report. Regarding the one-year anniversary protests in 2015, the subject stated:

There weren't as many people there, but it seemed to be a lot more mean-spirited. The first time around there was a lot of people who don't necessarily agree with everything but were there to show support. The second time it was a lot more hardcore. I felt safe the first time; I never felt safe the second time.

After viewing the video, the same subject noted that although no other episodic memories could be recalled, the video "brought back the atmosphere and the adrenaline" of being at the scene of the protests. Although the video used in the study chronicled one of the nights of protest immediately after the shooting of Michael Brown and not the postindictment hearing protest the subject personally witnessed, it was similar enough in content to evoke strong episodic memories within the subject. This also underscores the role among professional journalists as being eyewitness to events as they happen or immediately after they happen, creating a higher likelihood for strong episodic memories connected to the news event and their work as a journalist. 


\section{Reliance on non-U.S. media}

Non-white/Caucasian subjects in the research study were not numerous enough to be identified by race or ethnicity, but there were instances of subjects not living in the United States at the time of the news events depicted in the two videos selected for this study. As they indicated in interview responses, these subjects' memories and perspectives of the two news events were influenced by differences in coverage of the events through the media outlets available to them in their respective country of residence.

Subject 004, a female, speaking about the BP Deepwater Horizon incident, noted that she had difficulty remembering much about the news event because the Asian country where she lived at the time tends to shun news stories about environmental issues. She explained that "we (her country of origin) had a lot of environmental issues but mentioning about environmental issues in the media is tough, like showing that the government is doing something wrong there." The subject stated that this media aversion to critical coverage of government practices - environmental ones included - may have influenced the relative lack of coverage of the BP Deepwater Horizon incident as much as the geographical distance of the event.

On the other hand, Subject 008 spoke about following the Deepwater Horizon incident "closely" because he happened to be employed in Mexico by a company in the oil and gas industry. The subject added:

What I mostly remember in that moment was that I usually used to ask what happened if, instead of a British company, a Mexican company would have the 
same error? So, I usually think about Mexico being invaded by the U.S. because we spilled (oil)...it was my question during many days while that news continued. The subject went on to explain that the ongoing underwater oil spill from the Deepwater Horizon rig collapse dominated workplace conversations within his company for several weeks. Those conversations, he said, were partially driven by a perception among his coworkers that BP would continue relatively unscathed as a company, despite the farreaching economic and ecological damage from the spill.

Regarding the Ferguson protests, the same subject admitted the media in Mexico gave little coverage to the event or the shooting that spawned it. In fact, the subject stated that, at the time, he felt "pretty surprised that something like this happened here in Missouri, or anywhere in the U.S." However, he did admit to a certain empathy with the protestors due to experiences seeing economic protests among people in his home city. After viewing the Ferguson protests video, the subject commented:

The first things that I remembered when I saw this was that I feel like I have seen this many times in my home city and in my home country....in Mexico we don't have a mix of different kind(s) of people, it's mostly like Mexicans, but there's still a lot of differences between social classes, so basically the workers and unemployed people block the streets. They ask for the government to fulfill their needs, and they block the streets or the roads until the police arrive, and in that moment is where people start breaking, shooting, firing cars, running, It's very familiar to me.

Subject 021 said the Ferguson protests video reminded him of numerous conversations about that issue with his colleagues. "We talked about how those things happened in the 
United States and we had not expected them here. We did not expect the violence in Ferguson. I have seen that in my country, but we had not expected to see that here." Memory-based statements such as the ones in here suggest two things: First, that exposure to media archives of news events outside one's own country can bring to mind semantic memory concerning differences in native and foreign news framing; and, second, that although a person may not be familiar with a news event in a foreign country, exposure to archival news content about that event may connect with episodic memories of a similar nature, or at least somehow connected to the topic or issue of the foreign news event. In turn, these considerations - place of residence or location at the time of the news event, access to media about the news event, and framing of the news event within one's local media - must be taken into account when looking at MTC and the degree to which one can rely on MTC in remembering a news event.

In summary, through qualitative interviews utilizing the video elicitation method to explore memories connected with past news events, it does appear that engagement with archival news content spurs both semantic and episodic memory recall. The past content can serve to confirm, correct, or remind audiences of facts concerning the news event (semantic memory), but it may also spark both specific episodic memories connected to the news event or with the time of the news event, as well as providing information central to memories that may, in turn, produce a sense of self-reflection as well as reflection about the time of the news event as experienced. 


\section{Conclusions}

Accessing and engaging with archival news content can aid with memory recall associated with the news event itself or the time of the news event. Through the present study, it is shown that engagement with memory of a past news event fosters a sense of presence as temporal transportation back to the cognitive and emotional experiences connected with the news event. With the initial awareness of the news event provided through mediated channels, we have the foundation laid for the concept of mediated temporal consciousness (MTC). Both semantic and episodic memory, though not constant in occurrence or depth of detail, seem to be accessible and can be articulated through this awareness of and engagement with the mediated past. The experience of mediated temporal consciousness tends to be stronger with memories of news events involving high emotional response or interactions with family members, friends, or professional colleagues. The present study also suggests that the passage of time and the proximity of the news event to the person are factors in the amount and detail of memory, either semantic or episodic, that is immediately recalled after engagement with archival news content. This was also evident in the present study with responses, some showing less memory content detail, from subjects who lived outside the United States at the time of the news event in question due to differences in coverage of the event from non-U.S. news organizations. MTC can also provide a basis by which people reflect upon their feelings, thoughts, actions, or responses to initial awareness of news events and possibly compare those experiences to constructions of the self at the present time. 


\section{Contributions to research literature}

The proposed concept of MTC and the present study serving as foundational research work toward the development and refinement of MTC as a media concept contributes in a number of ways to established academic research literature in four main areas. First, the concept and present study add to research literature concerning digitalnative or digitized archival media content and its functions and uses for both media content providers and audiences for that content. This has been addressed in previous studies concerning cultural significance of preserving pre-digital age media archives (Cariani, 2011, 2017; Court, 2017; Newell, 2012), as well as opportunities to reach audiences and create new audiences for archival media content (Britt, 2015b, 2017b; Hughes, 2016; Pietrobruno, 2013; Shein, 2016). As noted in the methods section, both videos used in this study were accessed through YouTube channels of the news organizations which created the content at the time of the news event in question. The use of online video streaming technology has begun to lend new life and uses for archival media content (Britt, 2015b; McKee, 2011; Shohet, 2010). Engagement with this archived content not only assisted in retrieving episodic memories of varying detail, but also served in maintaining and, at times, adding to or reminding subjects in the study of key information about the respective news events. Third, the concept may prove useful in expanding and adding to episodic memory research literature from the standpoint of how media, particularly journalistic media, contributes to the encoding, storage, and retrieval of episodic memory connected directly with a given event or the time of the event, both of which are crucial to the construction of the autonoetic self in creating episodic memory (A. Baddeley, 2002; Tulving, 1972, 1985). Finally, MTC may be useful as a conceptual 
framework in encouraging more research using video or photo elicitation as a method, particularly considering the greater availability and access to such content through online services, apps, and websites.

With the proposed concept of mediated temporal consciousness carrying preliminary definitions involving both semantic and episodic memory, it offers the question whether it would be preferable to split the concept as mediated semantic memory and mediated episodic memory. The argument here, at least initially, is that both types of memory are intertwined, to some degree, in the formation of temporal consciousness (Campbell, 2002; Tulving, 1972). Drawing from Dainton (2010), someone who watches a 30 -minute local television news broadcast is experiencing that 30 -minute block of time as both the act of watching the broadcast (episodic) and the information flow disseminated in the broadcast (semantic). The information and the experience of receiving the information are both mediated. As development of this concept continues, it may be realized that dividing the concept into a dichotomous pairing is the more substantiated route, but for this exploratory work at present, mediated temporal consciousness will stand as proposed.

\section{Practical implications}

The present study and its findings indicate much psychological and social value in the maintenance of news archives and their continued longevity through digital archives and accessibility to those archives. Not only is there intrinsic social and cultural value in archival news content to fulfill one of the four main functions of media - transmitting social heritage (Lasswell, 1948) - but as has been suggested through findings here and in 
previous studies (Britt, 2014, 2015b), there continues to be audiences and the potential for new audiences for archival news content.

However, the presence of past media content has always been subject to the willingness and means of others - media companies, collectors, enthusiasts, or, within the last 40 years, people who made home recordings - to preserve and provide access to such content (Britt, 2014). This has typically been an uneven, at best, endeavor at all levels, whether the preserved media is physical or digital (Hilderbrand, 2007; Martin, 1999). This issue seems to be further exacerbated by popular misconceptions of the ubiquity of digital, online content on nearly any subject, event, or person. This attitude of the "always there" characterization of digital content archives is addressed in two previous research articles (Britt, 2017a, 2017b) as being potentially dangerous to concerted efforts to preserve content and access to content through online venues. In short, the idea that something online is "always there" dismisses ongoing concerns about cost, manpower, legal issues, and technological requirements in maintaining online archival media content and public access to it. The proliferation of this social mindset about digital media and archival content continued to be seen in responses from many of the participants in the present study; when asked if they had previously seen either video used in the study or videos featuring similar content on the news event in question, these participants answered with some version of "No, but I knew there would be videos about this if I wanted to find one."

Difficulty in maintaining archives of past mass media content has been a constant in the realm of physical media (sometimes known as "analog" media to contrast it with "born digital" or "digital-native" media) for several reasons, primary among them being 
space, cost of preservation, and deterioration or unstableness of the physical medium (Bottomore, 2002; McKay, 2018; Pierce, 1997). In some cases within broadcast journalism, there may have been a devaluation of the media content in favor of the physical recording medium; Fiddy (2001) notes that the practice of "wiping," or recording new content on a previously used studio tape, has made preserved copies of older television programs something of a high quest among media historians and television enthusiasts. In the United States, many local television stations, at one time producing several hours per week of original news, public affairs, and entertainment programming, gradually faced a dilemma of physical space with which to store and preserve that past programming (Cariani, 2011). Despite the cultural importance of the locally produced media content to the communities served by it, the space problem was often resolved with destruction of recordings:

The volume of materials created and therefore in existence from daily TV shows - particularly local news - was overwhelming to stations. From the stations' point of view, tossing it was often easier than saving it. However, much of twentiethcentury culture has been documented on TV (Cariani, 2011, p. 139).

When it came time to develop a plan for a nationwide effort to preserve local television archives, the task force created to initiate that effort found its "main challenge was to develop a way to raise awareness nationally about the importance of preserving these valuable materials and to stop the destruction of local television collections" (p. 139). Availability and access to archival media content is not the exclusive domain of broadcast media. Many newspapers around the world have a similar set of problems when it comes to storage of past print issues and may not have the funding or resources to 
invest in digitizing those past issues. Small newspapers, in particular, may keep a limited number of copies of past issues and those "might be kept in a garage, a trailer, or a nonclimate-controlled storage facility and are vulnerable to careless supervision; damage from light, moisture, and vermin; long-term degradation from the acid content of newsprint; and environmental mishaps like fire, or storm damage” (McKay, 2018, p. 51). Thus, for any scholarly research on memory that involves media archives of any type, the content being used for the study and the time element connected to the content are essentially at the mercy of efforts - whether from media ownership, libraries, historical societies or individuals - past or present to preserve and maintain access to the content. Arguably the biggest ongoing challenge to the life of digital journalism archives lies with how to pay for the various elements (staff, equipment, website space, etc.) required to keep the archive active, organized, and accessible. Regina Lee Roberts, a collection development librarian at Stanford University who spoke at the Dodging the Memory Hole 2017 conference in San Francisco, remarked, "The elephant in the room at this year's conference... was the tension between making digital databases free and the sustainability model for news organizations" (Paul, 2017a). The challenge is heightened when one considers the rapidly changing dynamic of web-based content. Although some individuals utilize digital software or apps to capture a given website at a particular point in time, this may be for purely individualistic reasons and does not necessarily get shared with other online users of the website (Kelly, 2017). On the other hand, individual archivists, often enthusiasts of a particular category or time period of media content, stand as essential contributors to the preservation of that media content in digital format. Some offer viewing of the content on private websites or other digital venues, such as a 
YouTube channel (Britt, 2014). In other cases, a helping hand may be offered by nonprofit entities, such as local libraries, historical societies, or digital preservation groups such as the Internet Archive. Although smaller news organizations may be at a resource disadvantage in preserving news content compared to larger media companies, the problem pops up at all levels, such as when The New York Times, wishing to mark in 2016 the 20th anniversary of the start of its website in 1996, had to turn to the Internet Archive for page captures of that first day online because the newspaper had failed to archive them (Hansen \& Paul, 2017).

Whether pre-digital or digital content, there seems to be no escaping the race against time, as explained in Hansen and Paul (2017):

Nitrate film used for early photographs and newsreels spontaneously ignites or deteriorates to powder. Microfilm of newspapers and television news film on acetate decompose to lumps of goo, victims of "vinegar syndrome." Early audio and video tapes demagnetize and become unreadable. And, of course, most early digital news content has disappeared entirely because no one thought to capture it or had the technology to do so even if it was considered (p. 38).

Compatibility of the archived content's form is also a major issue, both backward and forward in time. As an older medium moves outside its primary timeline of adoption and use, it may find a new purpose of use (McLuhan, 1964/2001), but for more recent outdated media forms, this can prove costly and difficult to maintain. This was illustrated in an interview-based study (Britt, 2014) that found individuals digitizing home video or digital video disc (DVD) material were, at times, finding it so difficult to keep compatible media players operating that some in the study had decided to teach themselves how to 
make repairs to the equipment. Then there is the issue of keeping archives readable in future technological platforms. Backward compatibility of future technologies is not a given (Ghosh, 2015) and there may not be the desire or funding to make archival content compatible with every new technology that gains a foothold in the marketplace (Hansen). Still, the consequences could be dire for future generations wishing to engage with the mediated past, leading to what Google's Vint Cerf terms “a digital dark age” (Ghosh, 2015), loss of content key to social and cultural identities, or remembrances of past events (Britt, 2017b), and the paradox that, "In 50 years, we may have better access to the news from 1817 than the news from 2017” (Hansen \& Paul, 2017, p. 40).

At this point, efforts toward a logical and fiscally-viable solution have not borne fruit. The starting point for most media organizations is an awareness of what stands to be lost if digital archives are lost, not only for the content's audiences, but for journalists themselves who often depend on news archives to develop new stories on longstanding issues, or to produce updates on older stories when needed (McCain, 2015; Paul, 2017b). News and media organizations must also develop an achievable plan for systematic curation of archived content. It is a critical component for creating search indexes for content, as well as determining what should be saved and why (Allen \& Johnson, 2008). The forms of media to be considered in any archive plan going forward will differ among different sizes of news or media organizations. Larger organizations who may still retain a full-time librarian or archivist must often deal with multiple forms of media content, while smaller organizations may be concerned with only one medium but lack the money and resources to go forward with sustained archiving efforts (Hansen \& Paul, 2017). In the latter case, developing partnerships with local libraries, historical societies, or other 
non-profit organizations associated with social or cultural heritage may provide the answer. These organizations may already have the infrastructure in place to assist in archiving media content, such as programs already in place in Texas and Kentucky to preserve digital copies of local newspapers throughout those respective states (DeRidder, 2016). What remains a certainty is the intangible value of what stands to be lost without sustained media archive efforts at all levels. As seen in the findings of the present study, archival media content can serve to remind or refresh memory of important details of news events, as well as maintain connections with an individual's episodic memories connected to the past news event.

\section{Study limitations}

Although the present research establishes some connections between episodic and semantic memory, presence theory, and the proposed concept of mediated temporal consciousness, there are a few limitations which may be addressed through a continuation of the research study or through other studies examining this or related phenomena. As noted earlier within the anomalous responses to questions regarding episodic and semantic memory, the present study used archived news videos produced by U.S.-based news organizations. Replication of this study in countries other than the United States and with populations from within those countries may assist in determining whether mediated temporal consciousness is a broader psychological construct rather than a phenomenon lying mostly within U.S.-based news archives, and regarding news events that occurred in or involved the United States.

A limited selection of media content with which to conduct a photo or video elicitation study always presents the possibility that responses would be different had 
other content, perhaps featuring different news events, been presented to research subjects. Framing of news events within media content is often a concern when looking at audience perceptions of the news event (Han \& Federico, 2018; Jørndrup, 2016) or, in this case, memory of the event. But, as noted in the methods section, the videos selected for this study were based on importance and, as a result, familiarity among the general public in a given year, professional production standards, and relative brevity to facilitate a reasonable duration of each session within the study. Here again, replication of the study with different archival news content would be useful in further establishing the processes underlying the proposed concept of mediated temporal consciousness (MTC). Additionally, the present study does not address the issue of memory of news events across a particularly long period of time; both archival videos depicted news reports on events no older than eight years from the time of the study. Utilizing archival news content originating from earlier points in the subjects' current lifespan might shed light on when people begin to develop MTC, as well as whether MTC strengthens or fades over a multi-decadal period.

In recruiting a volunteer sample of research participants within a reasonably large age range (18 years) and within a mid-sized city housing a major public university, it was hoped that a more heterogenous racial or ethnic profile of participants could be obtained. Unfortunately, that was not the case with all but four of the 31 total participants identifying as white or Caucasian. One volunteer who identified as black or AfricanAmerican did appear for the research session appointment, but it was then learned the volunteer was younger than the minimum age of 30 recruited for the study. Particularly regarding The New York Times' video on the Ferguson, Missouri, protests following the 
police shooting of Michael Brown, the interview responses of those who identify as black or African-American would likely have presented a valuable point of comparison and contrast to the interview responses of the largely white/Caucasian participant sample analyzed here. One potential remedy to this limitation would be to keep the present study open and change recruitment of research subjects to that of a targeted population of blacks/African-Americans within the same age range of 30-47 years. The interview content from those subjects could then be analyzed alongside the present population sample of voluntary subjects to address research questions of episodic memory, semantic memory, and sense of presence as transportation along different racial/ethnic identities.

Conducting research with media content as presented via YouTube offers some insight into the frail existence of digital-native content. The corpus of videos on YouTube are ever-changing, and what one can pull up to watch one day might not be available the next. Hilderbrand (2007) offers an analogy connecting YouTube clips of the mediated past to human memory itself:

Like memory (cultural or personal), YouTube is dynamic. It is an ever-changing clutter of stuff from the user's past, some of which disappears and some of which remains overlooked, while new material is constantly being accrued and new associations or (literally, hypertext) links are being made (p. 50).

This poses some serious problems for the researcher relying on the availability of the clips through YouTube or any other online video site, especially if the research study happens to be longitudinal in construction or, similar to the present study, remains open for an extended period of time with different subject populations. In fact, it should be noted that the archival news video on the BP Deepwater Horizon oil spill used in Britt 
(2017a) could not be located on YouTube at the time of the present study. One potential solution to overcome this sometimes-unstable population of video clip content is to utilize only clips posted by copyright owners of the content, as many larger media organizations and large- or medium-market television stations have, in recent years, started and developed "branded" YouTube channels featuring video content they have produced (Hilderbrand, 2007). These clips are much more likely to remain available on the YouTube site because they will not be the subject of a copyright takedown notice in accordance with the Digital Millennium Copyright Act of 1998 (Patten, 2007). Both archival news videos utilized in the present study were posted by the copyright owners of the video content onto their respective official YouTube channels.

Additionally, the state of media technologies at the time of a news report, subsequently archived, may present a confound in elicitation studies such as the present one. A discussion of any media content from timepoints in the past must also consider the media technology component of the production of the archived media content. As noted in the methods section, the present study utilized small, wireless internet-connected tablets for presentation of the selected videos to subjects. This was done to optimize subject comfort and privacy while engaging with the video content, and not as any influential consideration within the study; each subject was able to hold the 7-inch tablet in his or her hands and watch the video at any viewing angle or tablet orientation preferred. It seems plausible to think that interview responses might have been different in some instances had the study presented the video content through older physical media, such as a DVD recording of the videos played over a television set. As mentioned in the study findings above, some subjects spoke about episodic memory of learning 
about the news event at its time of origin through television or radio broadcasts; it is possible a similar presentation of the now-archival news content might elicit more vivid or detailed episodic memory of that initial awareness of the news event, and, by connection, perhaps more semantic memory recall as well.

Regardless, there were isolated cases in the present study where subjects talked about noticing technical and style-based differences between the Ferguson protests video and the Deepwater Horizon video. Subject 024 expressed surprise at the visual resolution difference between the two videos, stating "the (Deepwater Horizon) video looked superoutdated like it's been several years," while Subject 019, in comparing the reporting work on the Deepwater Horizon video to The New York Times' video on the Ferguson protests, mentioned about the former, “...there weren't different sides to it, it was an event that happened." Noticing differences between media content, even between two pieces of content less than five years apart in age, is not surprising, given generational changes in media technology norms and preferences (Tapscott, 2009), and the evolution of various media displacing or forcing a transitional phase within other, older media across time (Levinson, 1999; McLuhan, 1964/2001). In fact, in a focus group study involving 18-30-year-olds examining concepts of time through media content (Britt, 2015a), it was found that older media content was recognizable as such through cognitive comparisons of the visuals and social norms on display in the archival media content with those of the present time. Regarding an archival video of Richard Nixon's official departure from the White House days after his resignation as President of the United States, focus group members commented on the style of clothes worn and the manner of speech of the news commentators, whose voiceovers were heard as the camera footage 
continued, clued the subjects in on estimating the year of the video's production. This was the case even when subjects were unable to identify any of the people seen or heard on the archival video.

YouTube is not the only destination online to find archival media content, complete or in pieces, although its growth over the past decade as a one-stop shop for the mediated past is undeniable. One study comparing archival Australian television content on YouTube to that available through the country's National Film and Sound Archive (NFSA) found YouTube the superior venue for certain types of programs, like game shows and lifestyle programs, as well as being more plentiful with clips from past programs along with complete episodes, and having better cataloging of material with fewer broken links (McKee, 2011). A number of media organizations worldwide have included official YouTube channels as part of their social media content (the Ferguson protests and Deepwater Horizon report videos used in this study were from the YouTube channels of The New York Times and CBS News, respectively). In some cases, this not only includes archival news content from recent years, but also archival content stretching well back into the 20th Century; the YouTube channel of British Pathé, the legacy organization of one of the biggest producers of cinematic newsreels, contains individual films and film medleys of news events and human interest stories dating back to the beginning of the 20th Century (Britt, 2015b). Concerning television, radio, and film archives of particular interest to specific generations or people in specific media markets, a number of media archive enthusiasts have set up YouTube channels as well as dedicated websites featuring such content, although those content providers often run into 
the same conflicts with copyright takedown notices, as well as technical challenges in digitizing content from often-deteriorating physical media (Britt, 2014).

Region-based media archives online also have a growing presence through the efforts of non-profit organizations with an eye toward television, radio, and other media of the past as cultural heritage. Examples include the Tennessee Archive of Moving Image and Sound (TAMIS), which deals primarily with media archives in and around Knoxville, Tennessee, in the 20th Century ("Tennessee Archive of Moving Image and Sound,"), and the Texas Archive of the Moving Image (TAMI), which operates as a nonprofit, independent archive of film and video works originating in Texas or about Texas life ("About,"). Where the research concerns content and communities of a specific geographic area, an organization such as these may be a better source for media archives than YouTube or similar websites. For born-digital content other than videos, such as newspaper websites or other digitized text, the Internet Archive, a non-profit started in 1996 with a mission to archive the Internet as much as possible ("About the Internet Archive," 2001), may be of great usefulness to researchers and historians. This rapidly expanding website has not been immune to controversy over its presentation of copyrighted material, either. Edwards (2004), citing a site overview article on the Internet Archive's website, points out, "The directors of IA consider its activities, and its very mission, as a function of scholarship and preservation of historical and cultural material; thus, its archival activities are a fair-use exception to laws regarding access of copyrighted material." However, the Internet Archive's position on this matter has come under criticism and scrutiny from some scholars, and resulted in copyright-based takedown requests, which the Internet Archive honors as a matter of its own policies. 
Overall, though, complaints against the Internet Archive from publication owners have been minimal because the site does not provide weekly or daily archival copies of publications or their websites (Edwards, 2004, p. 5). In summary, the researcher interested in diving into the mediated past from online sources must be ready to deal with accessibility issues, which can frustratingly occur on a day-to-day basis.

\section{Future research directions}

The further development of MTC as a media concept offers multiple research opportunities to possibly support and supplement the qualitative video elicitation and interview study presented here. Given the emergent themes of emotional memory and emotional connectedness to episodic memories about past news events from this study, an in-depth survey of emotional response to past news events might provide an excellent view of this factor from a quantitative perspective. Such a study would also provide an opportunity to isolate emotional response to past news events as a research problem and enable a larger population sample to allow for analysis by factors such as gender, race or ethnic identity, and geographic location (Frey et al., 2000).

Emotional response to past news events might also be the central research problem addressed through psychophysiological measures, such as facial electromyography (EMG), heart rate, and skin conductance measures (Potter \& Bolls, 2012). Results from those measures could be supplemented with short interviews regarding the person's thoughts, feelings, and memories regarding the archival news content presented to provide a more complete picture of the intersection between neurological processes and memory retrieval and articulation. 
While the present study utilized in-person interviews as a method to examine how human memory interacts with exposure to archived news videos on YouTube, a different approach to that interaction would involve content analysis of comments posted to archival news videos on YouTube. Content analysis of posted comments would employ coding and categorization of the statements within comments (Krippendorff, 2013), which could be defined as semantic or episodic, plus a number of sub-categories (e.g. within semantic memory statements, confirming or critical). The study would also be able to look at comment "nests," or responses to primary comments or other responses, to explore characteristics of the interaction of commenters about news events of the past presented through videos on YouTube. This may shine a light on MTC as a possible influence on sharing of memories of news events with others.

While there were interview responses in the present study that suggested subjects experienced a sense of presence as transportation to the original time of the news event, additional studies could address the idea of MTC as a connecting concept between presence as transportation and presence as immersion (Lombard \& Ditton, 1997), and that of cognitive perception and awareness of time and the passage of time, rather than considering presence only in terms of place or spaces. This may also help address recent criticism of presence literature as being too focused upon technological factors in creating a sense of presence (Kwan Min, 2004) by bringing in the distinctively human matter of articulating semantic and episodic memories connected with awareness of past events and a potential sense of presence to be found by re-engaging with mediated representations of those events. Regarding presence as immersion, although that conceptualization of presence theory has primarily been applied to studies involving virtual reality spaces and 
interactions (Lombard \& Ditton, 1997; Spagnolli, Lombard, \& Gamberini, 2009), there was at least an indication in some of the interview responses that engagement with the archival news report fostered an immersion in one's emotions connected to memory of the news event, or activities somehow connected to the time of the news event. A study more squarely focused on episodic memory connected with past news events might shine additional light on this aspect of presence through media archives and provide additional depth to the proposed concept and its development.

Finally, MTC as a media concept could provide additional, informative scholarship in a human memory studies area concerned with a psychological concept known as the reminiscence bump, a distributive skew toward the number of autobiographical memories from a period of time starting at the onset of adolescence and continuing through young adulthood (Rubin, Wetzler, \& Nebes, 1986). Media consumption in the adolescent and early adult years fuels a considerable amount of nostalgic recall and re-engagement with content connected with that time of life (Lizardi, 2015). Additionally, media archive enthusiasts, in an interview-based qualitative study, stated that children's and teen audience programming from the past are among their most often requested content among visitors to their websites and followers of their YouTube channels (Britt, 2014). Both quantitative survey and qualitative focus group or photo/video elicitation studies could examine potential connections between the reminiscence bump and MTC as concepts that help define mental constructions of time through one's lifespan and memories populated along the timeline through mediated channels. 
The present study and the proposed concept born of it attempt to present a sound research-based examination into the relatively recent phenomenon and continued growth of online media archives. In this instance, the study focused upon news events within a 10-year period of the present, but similar studies would be as useful in looking at older generations' memories of news events in the 20th Century, or even how children and young adults today might react to and contemplate such archival content from events that occurred prior to their own existence. While the concept of the archive is nothing new, it can be readily argued that we live in a new age of accessibility and variety of archival content, thanks to online venues and digitization processes. The present study suggests that we can find great assistance in remembering events of the past, and ourselves, through online media archives, be it YouTube, Netflix, CNN.com, or some individual with a keen interest in the history of a particular locale or state. 


\section{Appendix A - Interview Transcriptions Video: "Ferguson 2014: A Protest Ignited - The New York Times"}

The transcribed responses are numerically listed, corresponding with the following numbered questions in the interview session:

1. What facts do you remember about this news event?

2. What personal experiences do you remember at the time of this news event?

3. How much did the content of the news video concur with facts you remember about the news event?

4. What facts, if any, did the news video present that you had forgotten over time?

5. What facts, if any, did the news video present that you did not know prior to viewing the video?

6. Were you aware of the existence of this news video online or other videos similar in content?

7. Did you speak to anyone about this news event on the day/night it occurred? If so, what do you remember about the conversation?

8. What, if anything, do you remember about the remainder of the day/night or the time immediately after you first learned of this news event?

9. What personal memories did viewing the video of this news event help you to recall?

10. What personal memories do you associate with the time of this news event?

11. To what extent did viewing this news video remind you of thoughts and/or feelings you had at the time you first learned of this news event?

12. To what extent did you begin thinking about things you said or did at the time you first learned of this news event?

13. To what extent did you just experience a sense of "going back" to the original time of the news event?

In instances where an unscripted follow-up question was asked for clarity or elaboration, the question is indicated in parentheses as being asked by the study interviewer.

Subject 001 (study pilot session, responses not included in analysis)

1. "I remember that it was the place involved, I recall they shot a colored kid or gentleman. Really other than that, I don't recall much about it I just know that it was in the news constantly about the protests and everything that came on after it, and about the St. Louis policies and procedures of how they are racial profiling and things like that."

2. "I remember my folks talking about it a lot, being kind of split on the issue. They're really big on backing the blue, and they always talk about you never get out the whole story until days and weeks later, that (if you) listen to the news after the first couple days, you're probably not getting all of it."

3. "Pretty much everything." (Interviewer: "Elaborate if you wish.")

"They were talking about the "Hands up! Don't shoot!" That was the big thing that went on, that they were talking about the Michael Brown incident where he had 
gotten shot, that ignited this situation. And then, a lot of news, there were reports coming in about how the police were, like, actively firing tear gas at people when they were (having a) peaceful demonstration. They were using a technique called corralling, where they would set up a blockade and then force people into the blockade, so even if you were just on the street going to like a restaurant, you got forced into the blockade and you ended up getting arrested. And then a lot of people were talking about how they were there to peacefully protest and then other people in the community would go out and loot. start fires, destroy cars, and things like that."

4. "I'd forgotten the instance that caused it, the Michael Brown instance. I wasn't sure if it was that one or another instance similar along those lines at that time, about how some parts of the community came together to stop looting from happening. So, you know in the video they showed them in front of a liquor store. That happened (on) more than one occasion during that instance. They were protecting their own businesses, the neighbors came together and helped and then a lot of how the police would just show up, fire tear gas and then they would leave, and that happened multiple times that I would remember."

5. "Well, I had never seen one of those tear gas canisters before. Must be used by trained law enforcement - I hadn't seen that. I've seen them explode, but I've never seen somebody actually holding one. And that made me remember that I recall somebody had actually gotten hit by one, a woman who had gotten hit and she had to go to the hospital for serious injuries from it."

6. "No, I had not seen it before."

7. "Yeah, I did, I know I spoke with my folks and some other friends. It's like a lot of it was curiosity about what facts would actually come out after reviews and investigations, 'cause time and time again I've seen and other people have seen that I've talked to. It's like day one, it's this, day two, it's this and by day three, oh, this is what actually happened. So it's like although we were getting the news story and we were following it, we've kind of trained ourselves to take it with a grain of salt until more information comes out."

8. "I have friends that live up in the area, so I was, you know, concerned about their safety and I had friends that, you know, their texts said they were going over to the protests and just, you know, hoping that they were safe."

9. "When they mentioned Michael Brown, it made me recall that allegedly that he had robbed a gas station, and then when the officer tried to talk to him, he got in a scuffle with the officer through the window and then walked away, and then the officer ended up shooting while he was, when he turned back towards him, he (was) still a great distance away. But that's, if I recall, that's when he got shot."

10. "A lot of, just, hate speech from really both sides of the... I guess it's not really both sides of the equation, but you know your white supremacists, not white supremacists, I guess your white nationalists, took it as an opportunity to, you know, talk about how blacks are always violent and robbing things, and certain black groups talked about how the police are always violent and profiling and killing blacks, and they used the situation as, I guess, their speaking point or their podium."

11. "It reminded me that, you know, at the time, like my folks, I was like 'This is what they're saying but I wanted to give it time for the full story to come out, and it ended up taking really weeks and weeks for everything that came out. And I didn't blame, I 
didn't place blame in my head on anybody. I just thought it was just a really bad situation. One that I wish hadn't happened."

12. "Probably almost immediately... why it was on the, why it was just on the news. That's, you know, when I first started thinking of talking about it. It's like, I think I was actually at my folks when I first saw it, so of course we started talking about it first, and then almost immediately some friends (who) live up in the St. Louis-Illinois area were chatting about it, so it was pretty immediate.

13. 'It felt quite a bit, 'cause I could barely remember anything and then when I watched it, it was like, it brought up everything that I had forgotten. Conversations that I had, the fears that friends of mine had had 'cause they were going to the protests, and it's like I had forgotten all about that until I watched the video."

Subject 002

1. "I remember it being an African-American teenager that was suspected of stealing from a convenience shop and was running away from authorities, and in the process, was shot by the authorities, and I.... And that developed into protesting from the unnecessary killings."

2. "I'm from St. Louis, so, it's my hometown, although I'm not from Ferguson, I know the city itself got a lot of bad attention, and so I was living north of Kansas City, and so it just kind of like hit home, I guess, and to hear people outside of the city talking about it. I was in an area that was more rural, and so they were very much in support of authorities? But I tend to be more open-minded, so, it was just an interesting dynamic to not be there but to be hearing all about it and to have different perspectives from people around me."

3. "As far as like what, what was publicized, do I feel like it matches what was? Overall, it seemed to match what I remember of it. The statement by the one guy that was talking about that's not the message they want to send out? I don't remember seeing that kind of media being publicized at that time. To where it was truly meant to be peaceful protesting without alluding.... Overall, I think that was the goal, and that's the part that I would support, but there's always bad apples that can take it the wrong way."

4. "Oh, just the chaos around it, how, the tension, they really, I think there's fear on both sides for the police side, the authority side, as well as the protestors. Both sides didn't know what was going to come of it, and so there was definitely fear (on) both sides of the situation."

5. "I didn't know about like the tear gas that they had used, the tear gas, specifically. The video to me seems like raw footage and so it seem unedited. I feel like it was a different viewpoint than what I saw on the media."

6. "No."

7. "The protesting part or the night that he was killed?" (Interviewer: "Either, let's say.")

"Yeah, I spoke with my parents just because they live in the area, and not knowing how that would affect just (their) commute to work and things like that, back and forth, 'cause I know they, there were like highways that were shut down, just want the logistics about it?" 
8. "I was engaged in what was going on, I was trying to follow and, overall, I just wanted people I know that live in St. Louis to be safe. Safety was my concern, and then, interestingly enough, the police officer who shot Michael Brown, he actually lived not only just a couple blocks from where my Dad lives, and it was just kind of an interesting like, thinking about how you can have areas so close to one another yet the difference in racism, I guess..."

(Interviewer: "From where your father lived?")

"Yeah, just knowing like that area does perceive African-American culture and things, and then they get (a blight?), although, like it's, the school is Lumberg, the school that that is the school district it's in and they have a decent amount of AfricanAmerican kids that come through the high school, and so you would think they would be more open-minded to the culture and unfortunately there's just not a mutual respect there, I don't feel like, which I think kind of drove the whole situation."

(Interviewer: "If I can ask a follow up question on that, you talked about worrying about the safety of people you knew back in St. Louis. You mentioned earlier that you were living...")

"Kansas City side."

(Interviewer: "Yeah, Kansas City area at the time, so, do you remember any experiences of like checking on people?")

"Yeah, more or less. Like, how has this affected your ability to do what you normally do on a daily basis? Did you get to work, did you have to detour and go different directions, and then it was concerns cause most of the protesting was in the evening, so what are you guys going to be doing in the evening? Are you going to be in the (Ferguson) area, which they didn't know, (but they went to support) the protesting, and so. But I do remember hearing feedback of, you know, hearsay, they would say this happened and that happened, and it was typically in a negative light, of how the protesting got out of control."

9. "It just brought back the feelings of how there is still such a divide, and how racism is still very much apparent and, unfortunately, like I said there's bad apples in every side of things, and so we hate to see that negative things like this happen."

10. "I mean I had a full time job, I had a child. I now have two children but at the time I only had one, and (not) that like I correlated it to their safety or had any concerns, but just overall like, as a parent, being sad for the state of turmoil that my hometown, you know, was under, so. And then the other, like, when you had talked about concerns, so, the statement about my Dad living just a couple blocks, I kind of dug into that like making sure that it wasn't in the media because I was afraid that there would be an attack directly towards the police office and possibly his family and that's only down the street from where my Dad lives."

(Interviewer: "Because of the proximity?")

"Yeah, so, it made me like, is that going to (affect) travel, is that going to affect that community, so, that safety issue was a real concern."

11. "Well, I did watch the video footage that they had of what they thought was him being in the convenience store, and then of course there were pictures of him holding I believe it was a gun and pictures of, it looked like he was under the influence and, so, those sort of behaviors make me more likely to understand why a police officer who felt threatened would have done those actions, because I think, I don't know, 
when you put a perception out there to people you're more likely to be taken the wrong way. Had he had a different appearance, had he reacted differently, had he, I don't know if he actually did steal that, I don't know if that was him in the video, they made it seem as if it was, but I don't know for sure myself, I wasn't there, so, yeah, I don't know. I feel like sometimes the way we hold ourselves it can affect the way that people react to us."

12. "It didn't really change as far as like, how I lived. Just more communication with my family, back home. Again, based off of like safety concerns."

13. "I don't feel like I can recall exactly where I was when I saw it. It's more of just a feeling, you know, at that time, just at, maybe some anxiety..."

(Interviewer: "More emotional content?")

"Yeah, yeah. But not like, physically what I was doing, and, yeah."

Subject 003

1. "I remember the visual of it, pretty clearly, that was pretty tragic. Kid turning around, the actual shooting."

(Interviewer: "That surveillance video?")

"Yeah, yeah. Um, I, I would say the visuals of it were what stuck most in my mind."

2. "In my personal life you mean?"

(Interviewer: "Yeah, just either connected with that news event or something that happened at or around the same time as that news event.")

"You mean things I heard from people, or...?"

(Interviewer: "Yeah, anything connected to that time point, that you remember.")

"That was the biggest news, I don't really remember any other news. I remember people's opinions about it and hearing about, about those opinions."

3. "I think it concurred pretty well."

(Interviewer: "Anything in particular that kind of reinforced your memories of the news event?")

"Not really, to me it was pretty cut and dry, I mean, the protests were, I think they could have (used?) a little more daylight footage, you know. It was hard to see some of it, and I think, I don't know if they intentionally did it, but I think sometimes when you see those (at) nighttime, it, it provokes a little more fear in an audience. You know, spooky stuff happening in the night. So, I think it kind of tended to make the protestors look a little more sinister, than if they did those daylight leadership interviews that they sometimes do."

4. "No."

5. "Hmm, (new) facts. That was a, there wasn't a lot of facts in there necessarily, that was a lot of passionate protesting, I mean. I did not know the exact incident, you know, of the cops throwing the tear gas canisters out, I don't think that ever made the news, as they drove away, as far as that incident."

6. "No."

7. "Oh, yeah, it was, lines were drawn pretty much immediately, like I said, I think from the surveillance video, everyone drew their opinions immediately, I don't feel like what anything, anybody else said after mattered, I think it was, it was a visceral, primal response when you saw that, one way or the other, so." 
8. "Oh, I thought it was just sad, tragic. Just..."

(Interviewer: "Feelings of sadness, and...")

"Just, yeah. Tragedy, just completely tragic."

(Interviewer: Anything outside of emotional content (or) emotional reactions?")

"Not really."

9. "Oh, to me, that was a pretty standard news video of it, I remember seeing a lot of footage like that. It didn't really evoke anything new."

10. "No, I don't even remember what I was doing."

11. "Oh, yeah, it brings up a lot of feelings about it, just kind of remember that lump in your gut when all that started, you didn't know how far it was going to spread. I mean, we're pretty close to St. Louis, so, you didn't know what was gonna happen here."

12. "Things I had said? I didn't really, nothing, wasn't much."

13. "Yeah, yeah, you definitely go back a little."

Subject 004

1. "So, I read news about that event, but yeah I don't think I read much about it?"

2. "So, I think at that time I was at Lehigh University and students at my school, they held vigil, how to say that word?"

(Interviewer: "Vigil?")

"Yeah, vigil, for that black guy."

(Interviewer: "Which university was this at?")

"Lehigh University in Pennsylvania."

(Interviewer: "And you remember a student vigil?")

"Yes."

(Interviewer: "OK. Anything additional about that you remember?")

"Yes, yes, because, and at that time, oh no, now I remember, when at that time then, during the class and when we had conversations, we, other people or whenever I listened to news...CNN, there are tons of news and video clips related to, yes, how police shoot black people, and it seems like there are news everyday about black people are badly shot by policemen everywhere, and people kept talking about it on the bus on my way to school."

3. "So, now thinking back, yep, looking at the video then it helped me to remember back even then, about black teenager who was shot by a policeman and the incident started as follows: the shopkeeper informed the police side, yes, somebody was stealing something in the store, and the police came and they saw a teenager who was running out the store, and when the police, the boy stop, he put the hands up like this, but for some reason the police, yeah, still shot at the teenager. I think, it was that event."

(Interviewer: "So you're saying watching the news video...")

"Yes, helped me to remember otherwise."

4. "Can you clarify?"

(Interviewer: "Let's see... You had mentioned that you, for instance, you read some news about this event. Did the news video you just watch, are you able to remember, was the same, did the content match from what you remember reading about it?") 
"Yes. So, the content of this video, very match with what I read on, or listened to in the past about um the bias, the media projected bias about the policeman towards the black men, it followed the same discuss route, the police man have a hatred for black men, no matter what they do, then, yes, police, they shoot them, they are the target for the police men to fight the force with them."

(Interviewer: "Was there anything else you had forgotten since the time of the event?")

"Hmm, yeah, so, watching the video helped me to remember just what the event was about, and that's it, and no more new pieces of information here."

5. "So, what I didn't know is so in this video it is about protests towards policemen and then, I didn't know that during these protests that the police actually, yeah, fired. I didn't expect that and I didn't know that and that there are witnesses showing everything in that the police, in fact, that they threw, yeah, armory, at the protesters. I didn't know about that."

6. "I often read, I often look at news and videos on BBC and CNN, so, I, yeah, I know that there are some videos related to this event on the media."

7. "Yeah, I did talk, I did talk with my bus driver, he was, he looked to be a policeman, and he was a white, male caucasian, and I asked him about what he thought about the incident, and from his own experience, he didn't experience any negative feelings towards black people. When I did talk with that guy, but he was...very neutral in his answers, so it didn't raise any sensitive, didn't' mention any sensitive comment at all, and show any negative attitudes towards black people. So he said I just make sure that justice is served and that I serve for other people."

8. "Let me see, so I mentioned about the vigil, yes, so, in fact, I prefer to read news in my language and in my home country, Vietnamese. We don't have, or make news a lot, yeah, so no news about this incident, this event. But I only knew about it from the vigil, and I saw a lot of people gathering in front of the square, the school, and then I asked one of them what was going on, and then I knew about it. And it shook up my interest about how, yeah, how black people, the status of black people, you know, in America, and how they actually took in the U.S., and I want to see the change in the news. I want to see in each that there is a trend that there is some bias in treatment of white people and black people in and among policemen. Do they favor white people and if they commit any mistakes like on the road, then they are easily, the mistake is easily thrown out. But for black people, maybe the story can be different, so I want to see and compare because of my status, I want to see if I can be the target as well. Like, may I be treated like black people or something like that."

9. "I don't think so."

10. "I don't have personal memories associated with this event." (Interviewer: "With the time, the same time frame as this event?")

"You mean personal memories...?"

(Interviewer: "Yeah, whether, they're connected with the news event or not.") "OK. So, it can be any kind of personal memory?"

(Interviewer: "Sure, any kind of personal memory.") "So, at that time I was taking my master's degree at Lehigh University, so, yes, this event in fact I remember that my black classmates, colored classmates, they didn't talk too much in class about this event. But my Caucasian classmates were more into 
this, they seemed to be more interested into this topic, and they seemed to be more willing to share their viewpoints and opinions about the subject. Yeah, we'd talk about how, like, how the media can influence the lens on how you see the incident. $\mathrm{Oh}$, and I remember one more thing. So, I did in fact, I did talk about this event with pretty closely with one of my Vietnamese fellow students. She came to the U.S. two years before me, and I asked her what she thought about the event, and she said that it is very understandable that white Caucasian person policeman, many times, they have negative, may have negative attitudes towards black people because they are very loud, and they, not my words, they can be loud, and they love parties. And she told me that from what she observes is many times from what she experience then, black people, they don't follow laws strictly, like other people, like Asian or Caucasian. That's why they commit more, how to say, they break more, they tend to break laws more often than other people, but when other police catch their mistakes, they make a fuss about everything. Like she told me one incident when a black woman, she was pulled over by a policeman, and rather than wait until the policeman came and ask her what she supposed to do then, she just made a fuss about everything and, yes, she said that it's understandable that maybe police have negative attitude towards black people."

11. "So, that feeling I had at that time is because, after that incident, then I watch and read more news about the racial issue news, on news about racism. And then I was more interested in the white privilege topic and how colored people, Asian people are, was or are, treated by white policemen. And I was concerned about my status as a foreigner in the U.S."

12. "In fact, watching the videos, I just focused, I tried to remember what the event was about that hadn't, yeah, just trying to find the connection between that video clip, that event with my life at that time. My mind was just focused on the event itself."

13. "What can I say here, so... So, frankly, if I don't watch the video clips, then, yes, that event, I don't think I can recall that event."

Subject 005

1. "So some of my memory about it has to do with having a friend who was a reporter and he was working for Al Jazeera and decided to, he was in Ferguson during the protests, and decided to actually leave... maybe it wasn't' Al Jazeera, it might have been somebody else. But I think he ended up writing a piece about it, about how disrespectful he felt that the reporters were being in the context of what was happening."

2. "At the time when it happened? Really not, I, I'm even blanking on what year it was... Yeah, I don't, except that...I had (a) friend in the media, yeah, but other experience, no."

3. "Yeah, that was the one that my friend had participated in, and it occurred to me that I didn't answer any questions about the events themselves because I am a little hazy still on... If I'm remembering correctly, he (Brown) was shot, he was shot in the street by a police officer and had been accused of stealing something from the store? Yeah, well, you know what that video brought back to me, I don't know if I can ask you a 
question but, was that the protest that the cops were screaming down the street, 'Whose streets? Our streets!' That the cops were chanting that?"' (Interviewer: "I don't remember if it was exactly the same one.") “OK, but if it was surrounding that incident, 'Whose street? Our street!' But it struck me that, that's what it reminded me of. And, yeah, it also brought back the memory that I guess didn't, I did have that in my recollection, but it just brought back that the looting. I had forgotten that there was looting, because my memory of those protests were that they were not particularly violent. But I guess it had gotten violent at some point."

4. "Yeah, I had forgotten some of the details about that shooting and it also just brought this, I guess this isn't a memory, but this is just a realization of just how many incidents were like this that we've had in the news and how I'm getting a little emotional, just how terrifying that is, that that this keeps happening. Sorry, this is really unexpected."

5. "I don't know, I don't know that there was anything, it just reminded me, there was nothing that was a surprise, in that video. It really had just reminded me."

6. "I had never seen that one. I had seen some other ones, but I had never seen that one in particular."

7. "I used to live in St. Louis, (or) I used to live in University City, so not terribly far from Ferguson. I feel like that surrounding there I touched base with some people about what was going on, and you know if what they knew about things. Yeah, a couple friends who were still in St. Louis."

8. "I remember in particular a friend of mine was at Washington University, and she was really shocked about the lack of response, that it seemed like very, that of all places, you know, it's a liberal hotbed and the middle of St. Louis, that the students would have poured out in support. But they didn't necessarily. It seemed like, I don't know, you know, that's just one person's side too, so I don't know if that's... an overall realistic impression. I feel like some people did go out and support, but it seemed like the majority of the protesting was internal, you know what I mean? People who were local, and there was a sense that also it was important to show support, but at the same time show respect. That it was was a certain group of people, who, you know, it was a certain demographic who were the people that should be most represented, if that makes sense."

9. “About, like, my life?"

(Interviewer: "Yeah, just anything connected or not necessarily connected with the news event.")

"It reminded me of living in St. Louis, and Ferguson, not far from home, and I used to go shopping like at a thrift store, that I think might technically be in Ferguson, I'm not sure. But it struck me how close to home that was and how important that was, that something like that, that Missouri is at this crossroads of racial tensions, and that you know, of course, it made a lot of sense that it would happen in St. Louis."

10. "I was in school. I was working on my dissertation, and so I might have still been in classes, I kind of don't remember now. What year was it? 2014, yeah, so I was (in the middle of my dissertation)

(Interviewer: "Anything else in particular?")

"No, yeah, very specific to that." 
(Interviewer: "Kind of like you alluded to earlier, it's hard enough, or hard to think about much else when you are doing your dissertation.")

"It really is, isn't it? You've got like these blinders on in your life. But yeah, honestly, and I apologize for my emotional reaction, that really surprised me."

11. "Quite a bit, yeah, quite a bit, because it reminded me of of that feeling that I was just talking, that I just mentioned, the feeling that of course it would happen in St. Louis, because St. Louis is so divided...it made sense that also Missouri is so divided, but St. Louis in particular because, even by street... I lived exactly on the south side of Olive Street, and anything on the north side of Olive Street, you know, demographically, changed quite a bit. And in University City, and that kind of stuff, it happens everywhere in the city where you go a couple blocks and all of a sudden, you're in a totally different demographic. And I wasn't old enough to really question that as much as I am now, as much as I can now, to really think. I meant I thought about it, but it didn't, I don't know, it didn't strike me... No, it did, to an extent, but I was in my 20s, you know, so all I did was, there were other things that I was doing that seemed more important, you know."

12. "You know, it's funny that a few isolated things came to my mind, but not pieces of things. So not as much, not as much as something else would have."

13. "Absolutely, yeah, a really big sense, and that did bring back details that I had forgotten. And also the profound sense of loss that this, the repetition of this kind of thing that that really brought that into focus. But absolutely, yeah, it was very much close to home."

Subject 006

1. "So, I don't specifically remember The New York Times reporting, just general news. I remember it was in the summer and I remember that it, he, Michael Brown was unarmed and the shooting occurred, I feel like the officer was in his car or something like, something about being in his car, I can't remember for sure, but I don't remember a lot about the previous, like what led up to the event. I do remember kind of some of the after events, like that his, Michael Brown's, body was left in the street for many hours after the event. I remember that there were conflicting eyewitness statements. I remember later news coverage, like after, but I don't remember a lot about what people were reporting as it happened, other than there was this officer-involved shooting."

2. "So, we, this was in our transition moving from far eastern Kentucky here to Columbia, and so, I remember people from people who are from my Facebook page, they were like 'Ahhh, what's happening? Missouri is crazy, you shouldn't be moving there,' We did not have our own house at that time, because we were really in transition. My parents live here, so it was at my parent's house that I remember seeing most of this in their living room, trying to have conversations between my parents and my, at that time, middle-school age children, and trying to talk about what like, well, you know, what are facts that we can talk about...to keep away from people's opinions because I always worry about (that). I have some concerns about views that my Dad might share with my kids sometimes, so it's like whenever there's 
conflicting news events, and I specifically remember that one being a case where I was just trying to distance that conversation."

(Interviewer: "The way you described trying to have those conversations, um, you bring across a lot of, that it was very difficult, that it was maybe frustrating to a point. Could you elaborate on that?")

"I was concerned that the kids, I mean, (it) already was kind of a traumatic event and news story and they were seeing lots of reports about officer-involved shooting(s) and, it was kind of scary, because we were new to Missouri. And it's not like they haven't lived in a place that they haven't... it was like here we are to Missouri and look kind of what's happening. This is bizarre, so instead of kind of allowing that fear or my Dad (who) definitely has tendencies towards some racist behavior, and, you know, not allowing some conversations where it's like 'Well, what (do) you expect when people are acting like crazy and then what are the police officers supposed to do?' Actually, let's just talk about what's happening right now and not a general thing and realize it's not in Columbia. It's in St. Louis, it's kind of far away, it's a big city, it's not where we are, so it was just kind of trying to put it in perspective for kids so they didn't have a lot of fear about it, but that they would realize, you know, there are things that happen and people should know about things that happen, but they should know the actual story and not just what people think about it."

3. "I remember some specific scenes, some specific, you know, language that was repeated in the video. (I) definitely remember 'Hands up! Don't shoot!' as being very prominent in all the coverage that I was seeing. I did not, I remember seeing in the news coverage kind of the lines of police officers moving through a neighborhood. I feel like I saw a lot more footage of during the day. I didn't see a lot of things happening at night or as candid as that was, with conversations with people in the community. I saw a lot more traditional news report with a person from the news agency talking rather than having conversations with other people."

4. "So, I did not remember the timeline, or the, you know, the continuing, multiple, over the course of multiple days. I just don't have the concept of how long the protests occurred, two days, five days, I don't remember. So, it was kind of making me feel like, OK it wasn't an event that was a day, it clearly was an extended period of time."

5. "I can't say that I didn't know that there were additional measures, like tear gas distribution into the crowd. I don't specifically remember that, but I don't think it's a surprise to me. I did not realize, you know, from the report of the person who was talking like that kind of changed some dynamics during that period of time between members of the community who would maybe typically not be cooperative, and then kind of, you know, not having a common problem. So, I thought, you know, it doesn't surprise me but I don't remember hearing that conversation ever, and some of the very specific intentionality of saying we're actually trying to convey a message and, you know, being here and we have to not let people engage in looting behavior, because that's not we're trying to say."

6. "I don't remember seeing a lot like this, yeah. I've never seen that one before, and for the most part, I remember newspaper coverage and more like news anchors or other people reporting and talking rather than community conversation." 
7. "I do. I was speaking with my family, my parents and my kids, and I think there's a lot of, I don't necessarily remember specific conversations except trying to say, well let's just listen to what they're saying and we'll find out all the information. My husband, I do not think (he was with us), I think he was still (in Kentucky). He visited a couple of times in the summer, but he was still living in, well, I know he was still living in Kentucky until November. I don't remember if he was here during that time, I remember conversations later with him and our kids, but I don't know if it was at that time."

8. "I remember having lots of conversation. It was when I first started working on campus, and so people in my office work with schools that are in that area. And so we had lots of conversations about traumatic events in communities, and what's happening with the schools, and where are kids when this is all going on, and what happens when, you know, it's not safe for kids to be places where kids could usually be, and how were kids now going to be perceiving law enforcement in this community. And then my husband who, at the time, was working in West Virginia at the regional jail authority and has former experience as a police officer, he had, you know, some really strong feelings about feeling like we can't just vilify all police officers because of someone's bad behavior. So, I think that was the theme in our conversations."

9. "I had forgotten about some of the comments from the conversations we had in, just the comparison of the conversations that we had...with my current co-workers, who at that time were my new co-workers, and kind of the idea of community and education and... idea of what should be happening for kids in this situation compared with comments from where I had lived and teachers I had worked with saying like those people are crazy and like, you know, they were focusing much more on the adults. And we were thinking about what about the community and the kids."

(Interviewer: "So kind of a comparative framework, from where you had just come from to where you were then?")

"Yeah, I had forgotten that that was, all that time was kind of in our transition period."

10. "So, I think the biggest thing is moving from, what I considered not a great area for raising our kids, back to the Midwest where I'm from, and I viewed that as a positive event. And I remember thinking well, you know, this doesn't change my mind at all. I think it's, I think there are people who use bad judgement and do awful things no matter where you are, but I do remember kind of, you know, my mother-in-law, of course, then said, 'Well I don't know why you would take your kids to such a terrible place.' That, it was mostly the transition of moving."

11. "I think at that, quite, if I think now, that was really an event and the conversations that followed it that have kind of moved me more towards advocacy, where living in far, I mean far, far eastern Kentucky, like Hatfields-and-McCoys country, is literally where we lived, where it's very isolated and...people don't care much about what happens outside that region. And so, I've remembered this news event specifically where we were all of a sudden talking about this national story, and it had to do with law enforcement that affected our family and black communities that my kids were totally unfamiliar with. And behavior of my own parents compared to the behavior 
that I expect from other people, that's my biggest recollection of this event. It was, I think, really important in moving me personally in another direction and realizing I'm going to have to be more vocal for the sake of my own kids and their growing up. But also, if I'm going to come out of teaching this tiny little county and here to a state initiative to realize who I am, and what I intend to represent."

12. "I don't know by watching it. Well, maybe, it just really makes me specifically remember being in my parents' living room and trying to maintain a conversation that didn't generalize people or behavior."

13. "I think because this one is really so different than the coverage that I remember seeing, I don't feel like as much reimmersed in the situation as like I appreciate that this is a perspective that I didn't see. So that's really interesting to me right now and what it's actually making me think about is last month, I was at a conference. Our annual conference is in Chicago, and it was on the day when they were releasing the verdict for the Chicago police officer who shot and killed a black boy. And, so, the behavior of the community and the news coverage and the way people were really watching, and I think were prepared then to behave in certain ways like they were really concerned about the outcomes. And it was funny because it was the day we were coming home, and so we had been staying downtown for the conference and trying to get on the L to get to O'Hare (Airport). Luckily, we got on at kind of at downtown, but then as we were moving out into the suburbs, people were just swarming the train. People clearly had gotten out of work and school early and there were reports of plans for school safety and stuff. That's really more of what this (was) making me think of, that more recent, what I consider kind of a comparative event. I'm thinking, I don't know, I'm reading some things about how people in the community were urging behavior, but then it makes me think, was someone talking to people in the community like this, and I just don't know it. I don't actually know."

Subject 007

1. 'It's about, it's like an aftermath of a murder of a black kid, I can't remember his name exactly, but it happened in St. Louis, which is like outside of, it's like suburbs of St. Louis. And it's an aftermath of the results of the case where it was supposed to be the cop killed the black kid, was not acquitted."

2. "It's just dense, just the racial tension in the air, even if we're like two hours away from where it happened. Yeah, that's about it."

3. "I think it matches well. That's exactly what I remembered it about. It's like, it's about the results of the case against that cop who shot Michael Brown. Now I just know the name of the victim. Yeah, I couldn't think which one was it, there's a lot of cases back then."

4. "I forgot that they used like a mini-militia to stop the rioting, like it's something of a national security threat, so to speak, and I actually have some additional memories now, now that I've seen the video. Like, I remember this had been going on for a few weeks. It's always on the news at night, and I actually remember the night where the results of the case were announced cause they broadcasted it live on every news station locally and on cable."

5. "So, no. Yeah, no." 
6. "I've seen other news videos, and like I said, I've seen it unfolded, live, cause they broadcast it live, after the verdict, it actually like immediately started."

7. "I mean like me and my fiancee were already living together at that time, and I remember her mentioning to me that she, she's like she didn't know the scope of how bad it is for minorities, until that event. I thought that was interesting because I always thought that she's the most, like, open-minded person, but then it made me realize that even an open-minded person has yet to experience some things. That's the, that's the most vivid memory I had of that conversation."

8. "It was a consistent topic, or discussion, because at that time I'm still going to the community college and I am, I was taking actually a sociology class at that time so we were discussing that in class almost every time a new story came out for it."

9. "Just remembered how I was mesmerized with the visuals I was seeing, as the new discovered event, as it unfolded right in front of me."

(Interviewer: "Just to clarify, kind of both emotional and psychological state of mind of just bewilderment?")

"Yeah, like, it's like 'Holy crap, I'm witnessing history right here.' Some sort of thing, like this is something that will be discussed, in like sociology books in the future."

10. "Since I think this is the beginning where, of like, how people are becoming more aware of like, cops shooting minorities, just, we, me and my fiancee, we started being uneasy because being a minority myself, you never know when and where it would happen, that sort of thing."

(Interviewer: "To elaborate, maybe, you know, kind of a change in direction in your...?")

"Yeah, I think the right word, aware? I don't know if that's the right thing to say?" (Interviewer: "Conscious?")

"Conscious, of like, my surroundings. I've become more careful of what I do, especially of when I am in public, because you never know how people react to my actions, and being a, I'm a minority, you never know just what's going to happen."

11. "For the most part, that feeling is still here. It just never went away, I'm still cautious, because, you know, how the political climate, it is, right now, with all this racial and culture divide, because of the kind of administration. So, at most, it just intensified, remembering the root of it, you know."

12. "Watching the video made me feel like I'm back in my living room at that time when it was happening. Like, I remember just staring at the TV and just being mystified by this event while it was unfolding live on CNN."

13. "Oh yeah, it, it brought me back to that time, pretty much, like just the feeling of, I don't want to say horrified, because I wasn't horrified. Just, I don't know how to explain it. Just, there's, like I was glued to the TV. That's how I can describe it."

Subject 008

1. "If I remember any facts about that? Probably, I cannot remember any specific fact because, as I told you, I come from Mexico, so I heard about shootings back in, people of color, is that the way you call it? So, I cannot honestly differentiate between what happened, in Missouri or New York, so, no, I don't know any specific facts. 
(Interviewer: If I can ask a follow-up question, as far as you remember, the media in Mexico did not give much coverage to the (event)?")

"No, they did not give much coverage."

2. "2014, okay, so let's say four years? Is that correct? So, in that moment, I was moving from Mexico City to another Mexican capital state, so it was not a difficult time but it was a moment of change in my life, since I have finished the master's degree in that moment. So, I really remember that time, I was pretty excited because I was getting a new job. I was feeling less stressful regarding the way of living compared to Mexico City and to Queretaro City, that is much smaller compared to Mexico City, so yeah, I think that's the general context of that."

3. "About the news event? Should I answer based on this specific news, or news in general?"

(Interviewer: "You can, I think it would be OK to speak more generally, and to that extent, I'll rephrase the question. Did the content of that news video match things that you had heard about or maybe read about the situation with law enforcement in the United States in people of color, black people?")

"Yes, for me, it's very difficult to separate this event from what we have in Mexico, especially with the protests....Most of the time they are finished the way, exactly the same, this one ended with the police trying to dissolve the protest and people stealing from the stores, especially the liquor stores and computer stores. So, even if I didn't know about this specific protest and the people in this specific news, I know a lot of cases like this one in Mexico and a lot of different places in Mexico. So, the first things that I remembered when I saw this was that I feel like I have seen this many times in my home city and in my home country."

(Interviewer: "So, to follow up on that, even if you don't remember that specific news event, there's a sense of familiarity about what took place?")

"Yes, there's a lot of sense of familiarity, but that case is not. In Mexico, we don't have a mix of different kind of people, it's mostly like Mexicans, but there's still a lot of differences between social classes, so basically the workers and unemployed people block the streets. They ask for the government to fulfill their needs, and they block the streets or the roads until the police arrive. And in that moment is where people start breaking, shooting, firing cars, running. It's very familiar to me."

4. "No."

5. "Yeah, actually, I didn't know that this kind of protest occurred here in the U.S., because for us, there in Mexico, everybody is happy here, everything is under control here in the U.S. So, I am pretty surprised that something like this happened here in Missouri, or anywhere in the U.S. I mean for me, that's only for Mexicans, people from Latin America, but not people from great, people from here."

6. "No."

7. "No, we didn't comment. We didn't have that coverage over there."

8. "Not really."

9. "Yes, but again, like I told you, all those memories are in Mexico. Probably you don't know, I don't know right now, but in 2006, the entire city where I used to live, that's called Oaxaca, experienced a popular discontent, expression, just like this, but not for, let's say 100 people. It was thousands of people who went against the Mexican state and government and these were, I saw in this video that they were clearing in the one 
street. They (Mexican police) cleared the entire city for two months. So when I see this, of course, I remember because I was in the university at the time, so we stopped classes a lot. Services were interrupted because people took control of the public transport, took control of the public school, took control of the public offices, and also took control of the, what do you call them, like Walmart stores?"

(Interviewer: "Large, supermarkets?")

"Supermarkets, so they focused on supermarkets because they said, 'Oh no, part of our problem comes from corporations like Walmart,' so they closed Walmart and those big corporations, and they only kept open small and local farmers. So, they were like kind of this thing, that's what I remember."

10. "Yeah, as I told you, in that moment, I was moving to another city, so in that city, government, the state government, has much more control over people. So, when I arrived there, I really felt relieved from, not feeling my home city when you never know when someone is going to and go take the streets again. So, in that moment I felt really comfortable knowing that I was living in a city where those situations are much more controlled. So, that's what I can relate from that specific date to my personal life."

(Interviewer: "Yeah, alongside just the act of moving, and everything involved with that?")

"Yes, so it was...personal feelings is that I felt that I had moved to a safer place, a well-organized place."

(Interviewer: "Do you remember anything about the move itself? Did the move go smoothly, did you run into any problems?")

"No, I didn't run any problems, I had some friends that helped me find a house where to move. I think, in general, the feeling in that moment was about wellness, finding a better job, a better place to live, better city."

11. "I think basically the feeling of being at home, when at my hometown, I remember that moment was a relief, and here I feel very identified with them, the protesters, but also with the people who were not affected in that moment. I had been in a place for 20 years that suffered many social expressions like those."

12. "Yeah, I think as well, really it's strong, especially because I didn't expect something like that, like this, here in the U.S. Because one of the reasons, because I moved from my home city, that movement...people were discontent, and you never realized so many people are discontent with the government, with their whole lives, until something like that happened, when so many people went to the street, and they destroyed anything that they found. That was one of the reasons why I moved to another city, but that's one of the reasons why some people are trying to move from Mexico."

13. "Yeah, I mean it was really strong because I've lived personally in a situation like that, not being a protestor, but being a witness, is the way to say when you watch. So, I watch directly something like this with the police and the helicopters and the people running and the gas."

(Interviewer: "So the images transported you back to experiences of a similar nature that you...")

"Yes, similar nature. I didn't know honestly that this happened, that something like this happened, I'm sorry, because you grow up and you see everything is very quiet. 
There isn't anything wrong, everything is good here. You want to summarize what I felt was surprise, so, come back strong feelings of remembering my home, hometown."

Subject 009

1. "Oh, that it was a police shooting, from a young man who struggled with a police officer and lost his life. There were conflicting stories about where he was shot. I can't tell you why. I do know that he was.... a man at a convenience store and was trying to steal cigars or something like that, is what prompted the police to be called to the scene. And it escalated from there, which then caused riots and looting and unfortunate incidents that people from outside that community came in and really destroyed many of the businesses in that community, which was devastating for those people who lived there. But, and I understand it was devastating for the young man who lost his life, their family, but also for the police officer. I think it was devastating for him and his family."

2. "My niece lived in St Louis at the time and she had to drive through Fergusson to get to work. So, I remember being worried for her. Plus living in Columbia, there were protests and things of that nature but nothing violent, but I was concerned for Erica. (Interviewer: “Anything else?”)

"I mean other than just saying it was a really bad situation."

3. "It was pretty typical. I remember watching a lot of protests and (scenes) turning violent. Not sure how much I agreed with it all being the police officer's fault. But let's see, there was a lot. A lot of emotions going on in that situation and I'm not going to pretend like I know what that would be like, but that was pretty typical of what you saw on the news back then."

4. "Nothing. Yeah."

5. "I hadn't seen the part where it showed the tear gas. Yeah, I hadn't, I hadn't seen that, where the two gentlemen were speaking with tear gas."

6. (Inaudible response)

7. "I remember speaking to several people but always maintaining that we needed to hear from the police officer. That we were hearing a lot from that community, but also realizing that there were a lot of people from outside that community that were speaking very loudly, and I always felt like that police kind of (got) a bad rap, honestly. Because when the truth and the facts did come out, I mean he was, I'm not saying there aren't police officers that are shady if you want to say that, but I don't believe that man intentionally took that young man's life. It's kind of hit pretty close with Erica being there, but also my best friend in college, her husband is a or was a Kansas City police officer for several years. And once these events started occurring and police shootings started happening, he retired from the police force. He was fortunate that he started out at 18, so he retired fairly young, 50-something. 52 or something."

8. "It was all over the news. It's all you could watch. There was nothing else. It was just constant news reports. The looting, about the protest that ended violently for one reason or another, regardless if it was the protesters or the police incited more violence you know, and it was for days it was like that." 
9. 'I guess just the feeling of being anxious for my friend's husband (for) one and for Erica, my niece, who worked close to that area to get to work so she could teach at an inner city school."

10. "Ferguson would have been like four years ago? I would have been switching jobs at the time. Would have been going from...starting with technology services."

11. "Well, it just reminded me a lot really with all that went on. How desperate people were and that young man's family, how desperate they were for justice for him, and the police officer who, unfortunately, was put in a tough situation and did what he had to do. But it's still doesn't change the fact that he took a life. That young man lost his life. Both families, probably both devastating I would imagine."

12. "(I) was very, very careful about what I said. I think everybody had to be very careful about what they said, no matter what your what your race was.

(Interviewer: Connected to just to the emotional content?") "Yeah, well, and you don't want to be unfeeling but you also don't want to be unfeeling towards it. (It) was a lot of racial divide, I mean, because the police officer was white and that young man was African-American. So, I think it really caused, I think it incited a lot of racial tension, Unfortunately because, and I know there's still racial tension and I know there's still issues on both sides. For me, that, who's somebody that that doesn't make a difference, that it doesn't matter to me like what color someone's skin is? It was still really difficult because you don't want to offend anybody."

13. "Just anxiety over the whole thing, really. It was a very anxious time.

(Interviewer: Is that to say that the sensation of being back in that time period was strong while watching the news video?")

"Yeah."

(Interviewer: "But it was anxiety?")

"It was anxiety, yeah. A type of, I mean, I'm not having heart palpitations or anything like that, but, yeah, that was so bad, horrible situation. And then you think about the situations that happened afterwards, situations really on both sides. Cops that weren't and then cops that were falsely accused and then you know people who lost their lives that shouldn't have on both sides."

Subject 010

1. "A lot of riots. I remember, you know, what it started with was a kid getting shot by the policeman. Hearing that it started with him attacking a policeman while he was sitting in his car and somehow, he got shot down the street, I think. I remember a lot of people flew in for the riots. A lot of local people for the riots. And I remember the verdict saying that the officer was not guilty and that causing more riots."

2. 'I don't remember any personal experiences. It didn't really affect me because my office is on the other campus. So, we weren't here when the other riots or, not riots but protests, were going on. We were away from all of that."

3. "I remember all that stuff. When you asked me before we watched the video, I'd forgotten about that it was a big deal with the excessive police force during the rioting and protests. But that reminded me of all that. How it became a big deal that they had been using like army equipment. Tanks." 
4. "That reminded me, I think I saw like (a) segment on TV. About how they looked at the emails in that particular department. They were pretty racially charged emails going between those officers and well before the protest happened."

5. "That particular example I wasn't aware of was where people were protesting, and the police came by and just threw tear gas on them. I just knew in general there were excessive but didn't know of specific examples."

6. "Just what I saw on TV in general, on CNN, but not that specific video."

7. "I had a roommate, so I know we talked about it, but I honestly don't remember what we talked about specifically regarding it."

8. "I remember it going on for a very long time. I don't remember much else I think."

9. "The example I gave about the other segment about the emails. (I) can't remember any specific ones."

10. "Just the protest that happened on campus here that weren't exactly about Ferguson but were also racially charged."

11. "I mean, I don't remember any feelings. Just reminded me of like seeing all those newscasts about it for so long, several days and weeks I think, other specific newscasts like the one I mentioned. That's pretty much it."

12. "I remember having a conversation around Christmas time that year. One of my friends from California came in and asked me to recall what I saw on the news from my perspective. He was asking several of his friends on the area what they thought of the protests."

13. "Out of 10, probably just a two."

(Interviewer: "Very little?")

"Yeah."

Subject 011

1. 'Let's see, I remember it happened in August. Kind of emotional. My mom had cancer and she was, trying to remember, I wasn't completely focused on the event, but I was aware of it. So, my memories on it aren't as complete as other people, just because my mind was elsewhere. So, I remember there were protests. I was in Iowa at the time, so it was interesting, you know, because it was a national news story breaking out back home. You know, like, 'That's in Missouri. What's going on?' And just family members, 'What's going on in Ferguson?' And having to communicate with people back in Missouri. Figure out what's going on. So yeah, I guess I remember it happening and being aware of it. But it wasn't specific. (Interviewer: "Would you characterize your memories of it as a sort of generalized?") "It was probably pretty generalized."

2. "I remember like the station they set on fire and I remember the protesters being... the police, kind of just the antagonism of the police I guess. The troops and the... (Interviewer: "Is there anything else in terms of personal experiences you remember at that time?")

"I'm not sure what you mean."

(Interviewer: "Anything you might associate with that same time period?" "I mean I just remember ... and I remember coming back, because I came back to Missouri for a while. Kind of shuffling back and forth between Iowa and Missouri for 
like a couple of months. So, I remember that time period was sort of...being on the road back and forth.

3. "I think it concurred with what I remembered. I don't think I remember seeing that specific video or footage but like the general sense of remembering that."

4. "I think maybe the tear gas, I remember the tear gas. I don't know if I realized like they had that scene of the people at the liquor store keeping people from looting. I don't think I knew about that."

5. "Oh, OK, that's new information, yeah...Yeah, that would be one thing I didn't know. Blocking the looters, yeah. I didn't remember some of the memorials like in the street."

6. "A little bit. I had seen a documentary after the fact. I wasn't watching too much video at the time. I was really reading more coverage of it than actually (watching)."

7. "I think I had general conversations with family members who just, politically speaking, were on different sides of the fence. And so, they were just like, 'Why are they doing this?' And trying to explain to them... like stay back... more of the political side. But we didn't discuss it extensively just because (of) the situation. So, like, yeah, more very casual sort of background noise for us."

8. "I'm trying to remember exactly when. I remember Michael Brown being shot but I'm trying to remember how soon after that the protests started after that. Pretty sure I was still in Iowa. When they were starting, I was there. I'm pretty sure I was at my parents' house.

(Interviewer: "What town, if you don't mind me asking?")

"A pretty little town, Radcliff. They live like two miles out, it's north of Ames about... north central."

9. "I guess just sort of took me back to that with my mom and with her. It was just a general sense of (the time)."

10. "Yeah, I mean I was just going back and forth to Iowa with my mom and kind of, I don't remember any work stuff or personal stuff besides family.

(Interviewer: "Well, would you say given the situation that maybe everything else kind of became trivial?")

"Yeah. Did Robin Williams die around that same time in August? Like, it was in a few weeks or maybe September? It might have been September, like a month later. Like, I remember that because I remember also being at home, the month of August and September kind of blur together."

11. "About the news story or just in general?

(Interviewer: "Any thoughts or feelings, specific thoughts or feelings, whether it's connected to the news event or anything else. So what I'm asking is kind of how strongly did viewing this video bring back those thoughts and feelings you had at that time?")

"I think it did because sometimes I just bury some of those feelings from that time period. I don't know (that I) thought of that every day. So, I think it did bring some of that."

12. "Yeah, it was kind of thinking as I was watching this, like do I remember this? Like how was I thinking about this and interacting with my family about it? Feel like it was one, no, no, I think that was later. It was related to sort of, it was the Black Lives Matter grew out of this. I remember later having a conversation with family members 
and my sister-in-law and my brother were like arguing with me about it. In a restaurant, I remember that conversation.

(Interviewer: "I'm sorry, were you going to add something else?")

"Oh, I don't know, did you want the restaurant?

(Interviewer: "Sure, continue.")

"It was May House. It was in Ames, but this was like a year or so later. It might have been like a year later. We had this Black Lives Matter discussion. And it was like "We're in a restaurant. We can't avoid people."'

13. "Yeah, I did. I think even as we're talking, especially now, when I'm talking about that restaurant incident. Going back in time and just reliving that moment in my head. So, yeah, its bringing back stuff I kind of haven't thought about in a while."

Subject 012

1. "So, the actual protest after Michael Brown was shot? So, a lot of it was not from first-hand information but I did have students that went to the Ferguson protest. I know that it was protesting police brutality and racial discrimination and profiling of black individuals in Ferguson, in St Louis, Missouri. I know that they shut down the interstate at one point, but that actually wasn't in Ferguson. I do remember the protest -- not the protest itself -- but there were side groups during the protest that started destroying property in Ferguson. There were tear gas issues. Trying to think of what else I remember from that time period. Funny, because it was running hand-in-hand with the university, the university protest, too. But I do remember a lot of my students that had come from the North County area of St Louis being really upset about it and so they were talking about their community really being misrepresented. Can't think of anything else off the top of my head."

2. "I just remember consoling a lot of students. So, I work with a program on campus that serves underrepresented groups and so a lot of our students actually come out of the St Louis area. And since our students are also usually low income, we do have a significant portion who are from the north county area in St Louis, or even St. Louis County as a whole, that were really feeling connected to those events and understood that police brutality issue. And so, watching kind of their community of peers selfdestruct was difficult for them. So, a lot of working with them, trying to get them to resources on campus that could help them kind of unpack those emotions that they were dealing with. And I also had friends that lived in the Ferguson and Florissant area, but they were removing themselves out of the protest. Because they didn't want to be, they wanted to be part of a solution for moving forward and unifying the population and fixing the issues versus actually being the protesters. So that's kind of the personal connection but it's mostly through friends and acquaintances and students. It wasn't anything from me personally being there."

3. "Well, I think the protest on campus ended up happening a few months later, but that I definitely had a lot of personal interaction with. And it was kind of an almost, but it was really a direct result of it because those protests on campus happened because of the protests at Ferguson. And so, that I did have a lot of direct experience with, but as far as there were other events that were occurring at the same time? I mean the most distinct thing that I can remember with situations in the classroom, from people who 
actually had direct connections to Ferguson, but I can't remember any other like personal events, aside from what was happening with my job."

4. "So, partially, yes, but I do know there were more organized protests as well and so the video appeared to be really focusing in on more of the chaos that happened on some of the nights. The Ferguson protests lasted for an extended period of time and so I know that not all of those protests were chaos. I do know in the first couple of nights they did do the tear gas and then people were looting, but there were more organized events that happened as well. So, I think that it really neglected to show that piece of it, but I don't know what the time frame the production of the news was anyway, because if they're doing it on a short period of time and not there for an extended period of time then that makes sense, too."

5. "I knew the tear gas. I knew the looting. I knew the protest. I knew that they were coming in in SWAT form to take care of the protest, to try to take care of the "protestors." I did think it was interesting that some of the protestors actually started blocking the looters from coming in - and I vaguely remember that from when it originally happened, but I didn't think about that when I was initially talking before I played the video. And so that was interesting of itself. It's not, I don't think there is anything really surprising or revealing about it that I had really forgotten except for that one piece. Just think that there were pieces that were left out of the protest."

6. "None, no."

7. "Yes, so the ones that I usually watched were through the St Louis Post Dispatch or the St Louis news stations. Because I always hope that if I'm doing local news, it's more accurate. A picture of what's actually happening at the event versus watching something that's being produced in New York or something like that."

8. "The next day, yes, but again it was more talking with students and I don't remember exactly what was said, but the conversation really surrounded around the fact that what was being portrayed about Ferguson as a community that Ferguson was actually a strong diverse community and they were only displaying on those videos certain pieces. And that, at least from my students' perspectives, a lot of those people probably weren't even community members of Ferguson. They were actually coming in from the outside to loot. And so, I do know those were kind of the conversations I was having and how their community would rebuild because really a big section of their financial kind of district - right where all of their businesses were, really did get trashed. And so how their community was going to be able to come back when they were an under-resourced community to begin with, (how would they) be able to rebuild?"

9. "I was slightly worried, I guess, about the potential of violence becoming a bigger issue in other areas of St Louis and other areas in the state of Missouri, because this wasn't really the only area that started seeing protests and then violence related to protests immediately after...I wasn't super concerned for my home, (my) personal community. I didn't think that really that violence would spread over into the Columbia area or onto the university campus. But I was also, I was concerned for my students because it was happening towards the fall. They were going to go back over Thanksgiving break. So, what would their community look like when they went back. But I don't really remember thinking much else. But then my job is kind of a major focus of my life. So, it makes sense that at that time, that's what I was really thinking 
more so, but then a little bit of that these issues were going to continue to spread the course of the United States. And not that the police brutality issue isn't something that should be discussed, but there would be people that were protesting and then there would be people that would be coming in that would take a violent turn instead of actually participating with the main leaders of the protest. Because the people that originally headed up the protest, they didn't have any spin towards violence, right? They were just really there to protest and create change. Whereas others kept coming in around them and then they started violently acting out. And so, it was challenging, I think, for the original protestors. Because I did watch some interviews with the original organizers of the protest."

10. "I mean it just kind of re-emphasized the piece of it that the chaos that was occurring. And it was almost like a domestic battle against the police and the community members. I mean it was something I already knew previously and had remembered."

11. "Not outside what I have already mentioned. I think it did bring up a little bit of the irritation that I saw originally that was captured and what was displayed in the news wasn't really the full picture. And so that really just kind of re-emphasized what I originally felt when I was watching the protest on the news the first time. It didn't really bring up the feelings of worry because I know that we've moved on past that. And there's actually been a lot of forward movement in Ferguson and Florissant, according to my friends that live there. But yeah, it just seemed like the community members were being portrayed in wonder. Or the people that were there were supposedly protesting even though I know that some of the people that were there were not actually protestors and were never intended to be protestors in the first place. I think it did bring that back up, so it's like, ah, yeah. Like it's very like skewed one way."

12. "I think watching the video it was just, like, it was a lot of reinforcement of what I knew to be true but like I had, it was a little bit more, faded out. Like I'm pretty sure this happened. Even when I mentioned the tear gas thing, I was pretty sure that it happened, but I mean there had been a lot of protests that had occurred since then. So, it's, you know more of a foggy memory but re-watching it..

(Interviewer: "You're not sure if you're mixing things up?") "Yeah, like other news events that had happened but then re-watching it I was like, OK, yeah, I was remembering it correctly. Like these things happened. That the looting happened. That the protest happened. That it was the SWAT coming in. I think it just really, as I was watching it, I kept thinking about comparing to see like what I knew to be true, and thought to be true, and whether or not I was accurate. And then being able to acknowledge, yeah, OK, I was right. I was right here."

13. "I think it was a, it kind of goes with the previous question. It was this constant comparison of me sitting and watching news events back at that time and then comparing it to watching it again to see if my own recollections and memories were accurate from what I sat and remembered watching the first time to when I sit and remember and watch now. So, I think it was more of a reflection of, OK, when I was watching these originally, what was I seeing and am I still seeing the same thing. And can I compare that in my own head with what I've heard from people that were actually at the event. Or who lived in the community where the event was occurring." 
Subject 013

1. "I'm just familiar with the chaos, the passionate actions by particularly the AfricanAmericans and members of that community. The conflict between law enforcement and the citizens of that community. I remember it being a national if not worldwide story. A lot of looting. Businesses were damaged significantly. Theft from those businesses and injury to people."

2. "No real personal experiences. It is notable that I am married to an African-American and so conversations within our household of perceptions of that event. At the time I was a board member of the United Way, I was the president and so I used that event as an opportunity to deliver just some education on microaggressions, on racism, discrimination in our community and our world."

3. "All of it did. Other than I failed to mention about what prompted the protest. That being the killing of Michael Brown. Looting was present. The conflict between law enforcement and the citizens. Just interesting seeing again it was not a very unified effort except for the people mentioning the gangs coming together, suggesting some solidarity among normally opposing groups coming together against the law enforcement. I was interested in what I didn't see as fear in some of those. It would have been a more fearful moment for me if I had been in that setting. Some of the protesting seemed almost happy. That actually that was a very small that was just a segment of the folks on the video."

4. "Actually, the year which is sad for me to say. I noted on the video it was 2014 and I thought it was more like 2015 but it was a year before the protest delivered on the Mizzou campus."

5. "Nothing in the video surprised me from what I previously understood."

6. "I've never seen that video and, honestly, I haven't seen video online other than the videos I watched during normal news cast. I have not gone back to revisit."

7. "Just conversations with my husband and he is, interestingly enough, very law enforcement-minded. Always very cooperative and promotes cooperation with law enforcement and believes that if individuals, regardless of your race or your locale or within any community, that if you just show cooperation with law enforcement that that's always better suited for you. That he hasn't witnessed either any law enforcement adverse action."

8. "Just sadness about what those people in the community are going through. Worried for both the community and the law enforcement because you don't want any additional deaths to occur. Sadness for the business owners. That people in the community, it was really good to see the part of the video where a group came together to stop the looting because I agree with their perspective that it doesn't do anyone any good to be damaging our own community and selves."

9. “Just being respectful of other people's opinions. Talking about this because we all come to the table with our own experiences and background, and it easy to make assumptions and it's easy to criticize. But really unless you ever have been in a situation like that you really don't know how you yourself would react. And so that was part of the conversation I remember having with people who were very critical." 
10. "My son was in, just starting high school. And I remember that this prompted a lot of conversation with him because obviously it was heavily discussed at school, in the social sciences particularly. And so, him being a bi-racial individual, it prompted conversations with my husband, him saying, you know you've got to act appropriately. If you're ever pulled over, cooperate. That's all you can do."

11. "The pain and the sadness that you feel for those folks. Sadness that racism, treatment of others still exists to that extent. The hope that law enforcement isn't discriminatory in their work. Racism has gone on, it's just shocking how long racism has gone on in our country. In Missouri, I find to, I think, protests in 2015 and also 2014 is, in my opinion, just reflective of us having a neutral state. Very conflicting in that way and I have this sense that racism is even more prevalent in the south. You don't see these kinds of protests there because that's just more accepted there, it seems. Whereas here, with Missouri being a neutral state as far back as the Civil War, there's greater conflict, there's a greater pull."

12. "I tried to be very respectful and not debating. Think that it's worth a lot of dialogue and discussion, but you've got to be careful in how you do it and you can't just automatically assert your beliefs into the conversation. You've got to be willing to listen and consider, which takes some time. So not be too abrupt in responding to what people share with you as their opinions."

13. 'You know it doesn't cause me great stress or anxiety it's just, it does dampen your mood to think that even in 2018, four years later, that we probably don't know enough from those types of events."

Subject 014

1. "The protests themselves? So, I believe the protests started either the day of the shooting or afterwards, and probably continued several days, and then on and off for at least a couple of weeks if not months. I think they were localized mostly in the community around Ferguson. I think that might have been some buildings burned or something. I don't know if it's in the immediate aftermath or a little bit later."

(Interviewer: "Anything else?")

"The facts?"

(Interviewer: "Yes, the facts about it.")

"You know, I do remember the governor got involved and called in the state, National Guard or something. And that was obviously controversial I would say. And there's the question of who should be talking to the protestors; what's the best way to address their concerns. And, or, repress the protests."

2. "Personal experiences at the time. So, this was 2014? Yeah. I know I was working. I have students that I work with, so I know I discussed it with them. It was 2015, so I had a one-year-old, or a zero-year-old, so I was probably sleep deprived."

3. "A lot, but not 100 percent, obviously. Because I do remember all of the attacks that the police put against the protestors. It made me remember that, I think, there was a media person who had been arrested at some point, which was controversial. And there were no burning buildings at that time. I know at some point there was some." 
4. "Yeah, the rubber bullets and the tear gas canisters. And I think broadly, I remembered that is a very tense police versus community, and still is years later. But yeah, it really brings it to the forefront."

5. "I think so. I think the comment that the gang members were all coming together, maybe. I don't think I knew that specifically."

6. "I think I've seen something similar. Probably not that one; but I think that was kind of, one of the earlier protests that had the social media, like 'everybody's there' kind of coverage, if that makes sense. So, lots and lots of those stories, and individual perspectives coming out."

7. “Sorry, I'm thinking. I do not remember any specific conversation. As I said before, I think I talked with my students because I work with students of color, and I'm sure I talked to my husband about it, maybe? I know this was 2014 because of the video, and so I was like, still post-partum, and really hormonal. I remember that summer, there was this mini-war in Palestine and Israel, and I remember crying all the time about that. So I imagine I probably had some emotional response to this event."

8. "No, I was sleep deprived at the time. Although, I just don't have good memory, too. It's just not part of my thing. I feel like I would have seen it on Facebook. I have this vague recollection that there were probably solidarity events happening in town. I feel like probably UU had one. And that's my recollection of interactions like, can I go? And I remember a friend of mine definitely went to St. Louis to some sort of solidarity rally. But yeah, I had a baby, and I was not, I didn't feel like I could do anything."

9. "No, I was just remembering more the Palestine response. I think a part of my response to this was, 'Ugh, another tragedy,' You know? Another case of us killing a child, and just the wrongness of that."

10. "I feel like it happened in August, (inaudible) no, I can't say I have any."

11. "It definitely helped those memories as far as, like, jogging [the memories]. The actual response in the moment as opposed to just recalling them. The sense that there needs to be some sort of response; that there needs to be solidarity with the community, and a push towards preventing (inaudible) impunity. I think the video helped recall the urgency around the response."'

12. "I don't recall anything specific. Part of the reason is, I link more with, I don't remember if it was ' 14 or ' 15 , but I talked to my students more about what was happening on campus, yeah, that would have happened in 2015, and it took a whole year for that, and a lot of the students really mobilized around the case in Ferguson. And you saw that, and I talked to my students about that extensively." (Interviewer: "So not really at the time of the Ferguson protests, but the longer aftermath?")

"Yeah, I'm sure we talked about it at the time, but I just can't remember anything specific."

13. "I want to say that like, moving myself back there, to a certain extent. I'm not going to say that I had any sort of like, out-of-body experience. I don't think it was like 9/11 where I can tell you what I did that morning. This was not that big of an event for me." 


\section{Subject 015}

1. "There was an African-American male, Michael Brown, and he was shot by a police officer in Missouri and there was a lot of social unrest related to that, a lot of protests and controversy because he was believed to be unarmed. The police officer felt that he had a weapon and shot him and it was a very long, drawn-out affair, the indictment with the police officer, it caused a lot of social unrest."

2. "I was living in Illinois at the time. So that was like 2014 or 2015 , so my one daughter was just a couple of years old and I might have been pregnant with my second and I was working at the VA there."

3. "All of it."

4. 'Yes. The 'Hands up! Don't shoot!' All the looting and destruction of the businesses and the severity of that came back to me, and I guess some of my emotions from that time came back."

5. "I had never watched that specific video before so the individuals they were interviewing, I had not seen before. But the general consensus of events are what I remembered."

6. "Plenty of the local news coverage of it and the national news coverage of it, just not that specific one."

7. "I don't recall on the specific night it occurred, but I probably heard about it within a day or two after. I would have discussed it with my husband."

8. "I can't remember a specific conversation, no. But we definitely talked about it."

9. "I can't remember specifically what happened that day like I can with $9 / 11$. So, I mean I remember it was on the news and very widely broadcast for days and weeks afterwards, it was all over the news for the longest time. I'm just going to speak in general terms, but I just remember being upset by it, just from the way all of the protesting was handled because I did not feel that was a productive way to get your message across, by destroying other decent people's property. That part may be really upset. So from that general standpoint, that's what I remember."

(Interviewer: "Any other memories?")

"More of the specific details about the event that I had kind of forgotten because I remembered it in general terms of the protests and everything like that, but I didn't remember the specific mantra of 'Hands up! Don't shoot!' and all of the major destruction of Ferguson. That all came back to me, so it helped fill in the details."

10. "In 2014 or 2015, I was pregnant with my second daughter and I was not in a great place with my job at the time, I just had a supervisor that I didn't get along with very well, so work was very stressful at that time, on top of being pregnant. And then this happened like late in the summer, I think it was like August or September, and we had a new resident starting at my job, because I'm a pharmacist, and I was the residency program director at the time. So, it was a really busy time getting their new year started, just a lot of stress, I was preparing for an accreditation survey. So, I was under a lot of work-related stress at the time."

11. "Oh, quite a bit." 
12. "I guess when I was watching the video, it was just initially, oh yeah, I remember these details now. As far as other things go, that didn't come back until you directly asked me."

13. "Well now that we've gone through all these things, I not only remember the event, but everything else going on at the time. Yes, I would say that I did. To the best of my memory, it's not 100 percent."

Subject 016

1. "I remember seeing it on the news. I lived in Wisconsin at the time. I remember being concerned about the students on campus, and how that was going to play out.

(Interviewer: "The students where you were at the time?")

"I was wondering how it would play out here in Missouri. So, I thought it was interesting and I thought it was great that the students were getting involved. But my employer is at the time said that some of the news that was coming out wasn't actually accurate, so it was hard to tell what was true and what was not."

2. "No personal experiences, other than talking about it on campus in Wisconsin."

3. "It seems pretty accurate about some of the events from that time."

4. "I forgot how emotional it was. It was a heavy couple of weeks around that time. It did bring back memories of the students that were upset at UW in Milwaukee. I think the Black Lives Matter movement came out of that and that was big. There were lots of angry people and it was justifiable anger."

5. "I guess none, I remember all of those things happening."

6. "I would say that I'm aware that if you want to watch anything you can find it, so I wasn't aware of this particular video, but I would assume that it is out there if I wanted to find it myself."

7. "Yes. I remember reaching out to my friends of color, in case they needed support, or listening to their stories of hurt and anger and confusion. At the time I was a leader of a women of color group, and it was held every other week and around this time it was the one thing that the women wanted to talk about. It was so powerful, I remember feeling really privileged that they were able to speak about their experiences with me in the room. We talked about that and I remember a lot of expressing empathy and sadness."

8. "I think everyone was scared and waiting to see how this was going to play out across the country. There were some protests in Milwaukee as well. You know, just wondering what was going to happen and if there was going to be any sort of good outcome."

9. "I remember thinking about the individuals that I spoke to that were people of color and not people of color but just the sadness and the confusion in the anger, a lot of the emotions came back after watching the video."

10. "I know that this was just one of the multiple events that started blowing up and becoming incidents each day regarding police and black men being shot. I remember there being a lot of conflict online on social media between police lovers and (other) people, I'm not sure, there just seem to be a lot of conflict. I know personally I have people on one side of the aisle and I was on another side and it was really hard to navigate that." 
11. "A big extent, definitely. And now I'll probably keep thinking about it."

12. "A great degree. When you asked me originally it had been so long since I had thought about it that I hadn't remembered all of those things that were troubling."

13. "Moderately. I felt my whole energy change as I watched the video. It brought back that sick feeling of watching this country and how is this ever going to get better. It makes me hope the next video is more cheerful, but that's not likely."

Subject 017

1. "I remember the media made a bigger deal of it than anyone thought that it was. It seems like the media, yeah, I remember that there was a protest about an AfricanAmerican male that was shot by the police in St Louis, or Ferguson, I guess. I remember that his parents, from the news, that his dad actually initiated the, either initiated or escalated the protests, and I also know I remember that he was seen robbing, the boy who was shot, was seen robbing a convenience store I think, earlier in the day. I think that's all I remember that are facts about it."

2. "I remember discussing with people whether it was, you know, in St Louis there is a lot of racial tension in St Louis in general. And you do hear about black-on-black crime, and I guess this was cop-on-black, but there was discussion as to whether or not, they said the guy was kind of antagonizing the cops. So, there are both sides, the guy shouldn't have been antagonizing the cop, the cop was fearful, but maybe his reaction was too extreme. I remember both sides of the argument, I didn't really have an opinion on it one way or another because, first of all, I was geologically, geographically very distant from it, Columbia, but from St. Louis, I was not in the St. Louis area or anything so I wasn't really affected by it, I wasn't affected by the increase in tension or the increase in crime. It was just a discussion, and we know there's a lot of tension like that in St. Louis, and especially North St Louis. A lot of areas in North St. Louis are just not good areas. There's a lot of black crime there, anyway. So, it wasn't a huge surprise when one was shot by the police. So, yeah, I just didn't understand why it was, I mean they said he was innocent, he didn't have a gun on him, but I don't know."

(Interviewer: "Anything else as far as personal experiences at that time?") "No, I was really too far away from it to have any personal experience with it. It was more, you know reflecting on it."

3. "I have to admit that I have never seen that particular video, but it concurred with what I recall in general. I mean I never saw that specific aspect of it, but their description of the way people were behaving concurred. It aligned."

4. "His name. I had forgotten Michael Brown's name until they said it. Most of the other stuff I didn't know, I didn't know specifics, his name was one I had forgotten."

5. "Not that I wasn't aware of it all, they told me some information. I think I've actually heard about them gassing them, but the specifics of it and those pops I saw at the beginning, I guess that was a gas canister, I was not aware of that. But then again, I didn't know how a gas canister worked. They talked about them looting like four stores or something and I remember hearing on the news that they were looting but I didn't know where or what or how many or when it went on. They said they stopped 
around 4 a.m., I didn't know the time specifics, but in general there wasn't anything that surprised me."

6. "I had not seen this video before, but most of the videos I saw actually were about the subject, but there was a lot of videos that were taken after the fact of the street where he was shot and the area. They interviewed neighbors, I saw his parents, but not like civil conversations with this. There was just a huge crowd of people, and in any of the videos I saw did not have so many people in the background. It was usually a lot fewer people."

7. 'I don't know if I talked to anyone the day that it occurred because I don't know that I was watching the news on the day that it occurred. But in the immediate few days afterwards, yeah. I did talk to people about it and it was similar to what I mentioned before where there was just like, on the one hand, he was kind of supposedly aggravating and antagonizing the cops. And he had previously, and this was actually a few days later that they found out that he had robbed a convenience store, and he was antagonizing the shop owner in the same way he was antagonizing the cops. But did the cop actually have the right to fatally shoot him? And that was what we discussed. Could there have been some intermediate solution? I mean I understand the guy was right in the cop's face, but at the same time, it just seems like an extreme reaction, but I know the cop, I think they are taught to shoot to kill if they feel threatened. I mean what else are they supposed to do? They can't just wait and say, 'Wait a minute, let's talk about this civilly.' That's not going to happen, that's not how the real world works. So, they have to protect themselves."

8. "I used to have family that lived in North St Louis, so I was wondering about how close it was. That was one thing, but it turned out it wasn't all that close. I did MapQuest it, I do remember MapQuesting Ferguson to see if it was near anything that I'm familiar with, but it wasn't. But I think that's really the only thing."

9. "I don't think I had any personal memories of the event other than recalling his name. I had a more gentle feeling with this video then I recalled. There was one interesting thing, I had a co-worker who was from Africa, and she had to go over to Africa to renew her visa because she was a student, and she was over there while this happened, and all her family was over there, and she was staying with them and they all said, "Oh my gosh, you are from Missouri. Aren't you scared about Ferguson?" And she didn't have a TV when she was over there, so she was like "What happened in Ferguson?" But that's pretty much all. They didn't realize that it was so far away from Columbia, that it's not really relevant. So, I don't have really any personal memories of that, it just didn't affect me."

10. "I saw the video said 2014, so other than that, I was just working and going through life, I didn't have anything specific, I think that was it. I think Adele was getting big. I do remember, and it's not immediately afterwards, over several months the tension increased in racial relations and I think it might be worse in Missouri. I actually do remember, I was surprised that Ferguson made national news, it was like on late night shows and stuff like that. I think there was a South Park episode or something that referenced Ferguson, and I had no idea that it was that big. I mean it happened in Missouri so, of course, I had heard of it, but the fact that the rest of the world would have actually heard of it and could relate to it was kind of surprising to me. Because I mean, in Missouri, you know, in North St Louis, you hear about crime all the time 
and you don't think, it's just crime, you know, and it's just maybe callous for me to say, 'That's St Louis for you,' but I just didn't think it was big enough to be nationwide news."

11. "It refreshed my feelings. It made me reflect on them again, but my thoughts didn't change from what I recalled. It didn't change anything, it just re-engaged me."

12. "I had brief snippets pop in my head. Like how my co-worker went to Africa and that was kind of an interesting story, and just the discussions about the police. I remember after this that Black Lives Matter and Blue Lives Matter started, or was created, and there was an ongoing debate about who matters, which is still going on it seems."

13. "Well, I didn't really experience a sense of me going back in time. I kind of, I didn't really relive my life outside of that video, there wasn't anything, it was only because the video said 2014 that I knew it was 2014, otherwise I couldn't have told you what year it was. 2014 doesn't really stand out, it's just another year that I was plugging away trying to get through my little goals or my big goals."

Subject 018

1. "I tried not to watch too much. I remember that there were just a lot of protests regarding the boy that was, isn't that, the police shot a boy? I think it was a white police officer, and a black kid that got shot and it caused a sort of domino effect, which sort of spread nationally. I remember that there were businesses that people were destroying and a lot of property damage and just chaos. That about sums it up."

2. "I'm not sure."

3. "I think the majority of it was the sort of visual that I had in my head when you asked me about Ferguson with the crowds and the chaos as a result of the police officer that shot the boy."

4. "I forgot the name of the kid that was killed and then whenever I saw the guys that were kneeling with their hands up it reminded me of the incident that sparked it where the police officer had shot the boy that they said was armed and there was a lot of controversy about that. I had forgotten exactly what happened with that and just generally remember that it had to do with a young black kid and white police officer. That's sort of sparked that memory."

5. "I didn't know about the tear gas and sort of as they were presenting things the police officers were doing to sort of disperse them, I hadn't realized that it was, that those things were going on."

6. "No."

7. "I remember having some general conversations just about the discussion of seeing it on the news and sort of, since I work in the sort of occupation I have, I remember hearing a lot of talk of protest downtown since we have a pretty large AfricanAmerican community. I just remember these protests sprawling all over the country and the discussion of that more so than the facts of exactly what happened there in Ferguson."

8. "I don't remember specifically that day or night."

9. "The only thing I can think of is, it made me think about any times I see things like this, it's sort of sparks something because I have teenage boys and it sparks that memory of feeling scared that, even though it's my child, I feel almost fortunate that 
my children are white. I remember feeling glad I don't have to worry about it, and feeling sad that parents do. So, emotionally, I feel like that's part of it."

10. "No."

11. "Like I answered earlier, just the feelings of it being someone's child and thinking about my own and sort of going back to that place and just feeling sad and concerned."

12. "It did make me think about where I was when we were discussing it. I've changed a couple of jobs positions since then, so I started thinking about, OK, I remember being at my desk in my previous office and just sort of saw my co-workers and me talking about it just generally. I can't remember any specifics, but I did have that image in my head of just sitting there and talking about the incident."

13. "When the video started, as soon as I saw the riots, I was just picturing it on my television and wondering if that was, I remember watching a very similar video on the news at the time of the incident and it sort of felt like I was sitting right back there."

\section{Subject 019}

1. "Yeah, I know, it's terrible though, because like I'm trying to think why it happened, and I don't remember what sparked all that. I mean, I think it was about police brutality, maybe, like, with minorities, and I remember that there was a lot of like stuff on the internet with like people protecting their businesses with automatic weapons, or whatever. Scary guns and, yeah, it was definitely about the cops, and the police force being racist. Yeah, that's what I remember. That's terrible. I feel like since that's something that happened local, I should be more keyed in on that. It was in my state!"

2. "Like what was going on in my life?"

(Interviewer: "Yeah, whether connected with the news event or otherwise.")

"I don't know, because I don't even... I couldn't even tell you exactly when that was. I didn't feel like it was 10 years ago, but I have no... I don't know...but I also tend to block on things that are unpleasant, you know what I mean? Like that's just a thing I do? Like if you ask me about a baby giraffe being born, I could tell you every detail."

3. "Yeah, it had reminded me of the situation because I had forgotten, although really I couldn't remember, I knew it was Trayvon Martin, I believe, is that the right name, was in Florida, and Michael Brown was in St. Louis, and I couldn't. That's unfortunate that that kind of thing happens, has happened enough times that I can't keep them straight? That's not good. But I remembered a lot of the stuff that happened in that video. 'No peace, no justice,' 'Hands up! Don't shoot!', all of that stuff."

4. "Probably most of it, just because, and that's like white privilege right there, you know, it's not affecting me, so I don't have to keep it in my mind, which is also sad."

5. "That people defended businesses that weren't their own, and weren't allowing, tried not to let people loot because that's not what it's about. That was something I didn't know."

6. "I mean, I hadn't seen that video before, so I guess no, but I mean I'm sure, I knew, like, the incident happened, and I knew that there was stuff on the internet about it." 
7. "I remember talking to my husband about it a lot, because this is the kind of thing that's very, he's very aware of things. I'm usually not, but just because we had a lot of conversations about was it justified or not, because it took a long time for the kind of details to come out, and like what was true and what wasn't, and we talked about that a lot."

8. "I remember that they, I don't know what, I don't know when in relation to the event happening, but I know it was because of it, people, they shut down the highways, as a form of protest, they shut down interstates in St. Louis. People like parked on the highways to draw attention to it, I remember that happening."

(Interviewer: "Do you remember that happening via news reports about it?")

"Social media mostly. Mostly just the media."

9. "Yeah, I mean, just talking to my husband about it, and I had, I mean, I had kind of forgotten about it. Of course when you said 'Ferguson,' I was like that's near and but, if you had said, if you had tried to, if you had asked me about it another way, I don't know where and what I would have come up with it, like, so, kind of buried."

10. "Like, not from my personal life, not really."

11. "It reminded me a lot, because I had totally forgotten, so definitely remember like being upset, you know. I don't know it's just so, it's hard to watch people in positions of power not behave the way they're supposed to? You know, like disrupting a peaceful protest is not appropriate."

12. "I guess a lot?"

(Interviewer: "Anything in particular or anything you might be able to elaborate on?") "Mostly just because I really feel like this was kind of where they, because now I feel like the news is a little more like aware of presenting their bias, but I feel like this is kind of where that all started, or kind of started to shift maybe, like away from being overtly biased around people."

13. "I would say medium."

Subject 020

1. "My memory is that an African-American young man was shot by a police officer and there were protests about the police targeting and using excessive force, particularly against African-Americans. I don't really remember more of the details."

2. "The only personal experience I remember that ties me to it is that I had a friend whose daughter lives near Ferguson, and my friend was worried about her daughter, who tends to be a social activist, which she supports but still worries about her being involved and putting herself in danger."

3. "There was more than I remembered initially but everything I remember was correct based on the news clip."

4. "I had forgotten that the person who was shot was named Michael Brown. I forgot about that the people protesting did the 'Hands up!' which made me partially remember but they didn't discuss it in the video, whether the boy did have his hands up when he was shot. I had forgotten that the officer was not indicted or at least wasn't indicted by when the riots were, and that's part of what got the riots started."

5. "I didn't know that the police used tear gas on people protesting and I didn't know that some of the protesters looted local stores." 
6. "No."

7. "(I) really only remember speaking to my one friend whose daughter lives near Ferguson. I don't remember talking about it with anybody else."

(Interviewer: "Anything more specific come back to you about that conversation, I know you said his daughter was an activist?")

"I remember that her daughter did the 'Hands up!' to police and that was one of the things that worried her, her level of activity."

8. "I don't remember the day I learned of it, so I would say nothing in particular because I remember that specific conversation, but that was way afterward."

9. "It did help me recall or remember just being really sad that I felt like both sides were really trying to do the right thing and had merit, but they just couldn't connect."

(Interviewer: "So it was an emotional memory?")

"Yeah."

10. "No, it's hard for me to remember exactly when it happened."

11. "It ties back into what I was saying about the emotional memory and having a sort of sympathy for both sides and feeling sad that there wasn't a way for everyone to connect."

12. "I do remember when driving to St Louis being a little more cognizant of where we stopped to get gas and having an awareness of where Ferguson was relative to the broader city."

13. "I would definitely say that I felt that. It's a little hard to describe, but especially how I was saying I remember how I felt about it. I would say that that's the part where I remember going back."

Subject 021

1. "It is about racial discrimination between the local police force and the community. I remember there were a series of people on strike and there was (inaudible) debate. It wasn't even a national issue, it became a very hot issue in international politics about the rule of policing to the local people and some of the arguments about the racial discrimination of the police against the black community. Especially where Ferguson looks like a dominantly black community and there were more white police officers and the local newspaper in the media at that time argued that the white police are discriminating against the black people with traffic stops and domestic violence more than they do with white people. And then you had the people who thought he was innocent and something like that echoing through the media and the local newspaper. Then there was a jury from the government side and the police officer wasn't indicted, and after that there was a strike that happened against them not giving any punishment to the particular police officer, and then there was some destruction of and people breaking glass (in) people's homes and the business complex. It was kind of chaos at that time and everybody was reading the newspaper and watching television. Also, how the police treated the community depending on color, there were a lot of different articles about the sentiment of the police force and how they interacted with the community."

2. "I had not been there, but I was here in Columbia and we also had some discussion about it and we talked about it. And I tried to find some more detail about those 
things because, at that time, I did not believe that the police would discriminate based on color because personally I did not get involved in those kinds of events. That's why I could not figure out if it was real or not. That was my understanding at the time, but I also had conversations with other folks about Ferguson and I looked into some statistics about domestic violence and (inaudible) in the black community. It seems like more people of color were being harassed by the police force... and then there was a counter argument that, no, that was not the reality and that actually our police force is discriminating based on color."

(Interviewer: "You mentioned a class that you were in, do you remember which class it was?")

"It was a class on Organizational Studies. At Mizzou. At that time, my professor was travelling, and he talked about how it was national news. We talked about what the organization should look like to handle those kind of issues."

3. "I can't explain all of those things, but my understanding of the events match."

4. "No."

5. "When I heard some of the folks talking about the Civil Rights movement and (inaudible) I had not expected them to talk about things like that."

6. "To be frank, I have not watched a lot, but I had a snapshot and had seen clips on TV, but nothing long, just a few things."

7. "Yes, I had conversations with my colleagues. We talked about how those things happened in the United States and we had not expected them here, we did not expect the violence in Ferguson. I have seen that in my country but we had not expected to see that here, we expect to see it in a movie like "Saw.",

8. "I came to know about the event on that day by the news on television."

9. "As I mentioned earlier, I found those young folks talking about civil rights based on race in their country. I did not notice those things earlier. I didn't know about the early racial discrimination."

(Interviewer: "To make sure I understand you, are you saying that this news event you feel like made you aware of racial divides and discrimination existing here in the U.S.? In other words, did it kind of change the way you viewed things or change the way you were aware of things?")

"Actually, no. I already had an understanding but I noticed the young people who I saw on the street also talked about the Civil Rights and discrimination and I thought only the police or political leader could talk about those things, but even young teenagers could talk about it."

10. "No. It gave me an understanding of something in the United States that I had never seen...The scene was very terrible. People in the street against the police force, they did not follow what the police were saying and there were some that looked uncomfortable."

11. "This event has given me some indication of the discrimination within the police department and now there have been several other incidents with similar racial issues. This showed a lot of evidence of racial discrimination."

12. "Well, after the event I tried to find some of the statistics to understand what was really happening and how we treat people based on color when it comes to domestic violence... The data shows that those folks are more frequently involved in those kind 
of activities, but my understanding is that there is some sort of implicit bias that the police have."

13. "This was a very thoughtful sort of event and it put me in a very different sort of situation. It gave me a sort of reflection of other events." (Interviewer: "Is that not only to say that it reminded you of this particular event, but similar events that occurred across time from that point?") "Yes."

Subject 022

1. "A black man was shot in Ferguson by an on-duty police officer. It was on a weekend in August. Soon after there were protests and there was looting and fires and destruction of police vehicles. There was a large police presence in the Ferguson and St. Louis area. Then that kind of snowballed into other protests around the United States."

2. "My husband and children were coming home from a family reunion that Sunday near Marquette State Park in Illinois. So, we were coming through North St Louis. We weren't far from there. We heard about it on our way back on I-70. There was a protest within that next month and I remember being on high alert."

3. "It seemed pretty accurate. It was kind of one side of the news event."

4. "I don't think any."

5. "I didn't know about the tear gas that was thrown without any warning."

6. "I had seen live news videos of the Ferguson riots online. I had never seen this particular one, I don't believe."

7. "Yes, I remember talking to my husband about it. We were discussing getting the facts and usually the facts were one-sided, and we didn't get the whole picture of what actually happened. Sometimes it was more people forming opinions about what happened without knowing all of the facts."

8. "I had cousins living in Ferguson at the time. They couldn't leave their house, I don't know if they chose not to or if they were encouraged not to. North of Ferguson are some other suburbs and that's where some other family members live, too, so there was just kind of a heightened sense of safety for them. And then I know some law enforcement in the greater St. Louis area and I was concerned for them as well."

9. "Well, Ferguson was the beginning of a dialogue nationally about police brutality and Black Lives Matter. It was an investigation into the whole justice system and I work for the court so (inaudible)."

10. "Just coming home from that family reunion and . . what year was this?"

(Interviewer: "I believe it was 2014.")

"So, then I had a 3-year-old and a newborn."

11. "A lot. I still have questions about what actually went on and who knows the actual facts, not just their opinion of what they perceived. It kind of stirs up a lot of questions."

12. "A lot. I mean these events, thinking back on how these events have affected my work and how I perceive people of a different race and if I'm treating everyone on my caseload the same. It kind of reminded me of how I bring up my kids and how they view people of a different race or ethnicity." 


\section{3. "100 percent."}

(Interviewer: "Can you describe that feeling?")

"Just the feeling of the frustration those people were having with what they perceived was going on and how they were being treated. The memory of having some people there to protest to actually get justice, but then also seeing some people on there laughing and running around like they were just part of a crowd. Just that crowd mentality of 'I'm going to do what everyone else is doing and we're having fun.' There were people that were there that were serious, that didn't want anything bad to happen, and there were other people that just wanted to be a part of something at all costs."

Subject 023

1. "I remember Michael Ferguson, was it Michael Ferguson? Or was it a different case? Anyway, he was in an altercation with the police and the police officer shot and killed him and it resulted in many protests and riots in Ferguson, Missouri. And as the facts came out, it seemed that the seemingly innocent young black man was actually strong-arming a convenience store owner and had stolen cigarettes or something. Then that's why he was being stopped by the officer and then he had actually reached in the police officer's car window and tried to take his gun, and then they struggled for the gun. The cop was in the car and the gun went off several times and broke the window of the cop car and then the cop got out and Michael Brown came back towards the cop and the cop shot him seven times, I think, and killed him. So, there was a whole thing about why was the police stopping him and was it necessary to shoot him and that he was just this poor kid trying to walk home from school."

2. "I don't even remember how long ago it was, like what year that was or what time of year."

(Interviewer: "I believe it was 2014.")

"That was a year before my wife left me, so there wasn't anything major going on other than marriage problems."

3. "I have seen news videos of the event but I didn't remember seeing the people in this video. But I do remember that there were peaceful protests, but I did see in the video there were people that just seemed to be out there to cause trouble. They weren't helping the movement of the peaceful protest. Then I do remember that there were people trying to loot stores during the protest, and other people in the community tried to stop them from looting, like the guy said, that wasn't what they were trying to accomplish. I didn't remember that the guy with the tear gas canister where that was something that had happened, that apparently law enforcement had showed up and tear gas the peaceful protesters and then drove off. I remember the 'Hands up! Don't shoot!'. That happened here in Columbia and I was actually working security. We were contracted by Harpo's, but we weren't actually inside Harpo's, we were outside to keep the streets clear. There was a night when the 'Hands up! Don't shoot!' protesters stood in the intersection and blocked traffic for probably 15 or 20 minutes. And you had people that were obviously very educated and passionate about the movement leading the protest, but I saw firsthand here in Columbia, people that were just there to get attention and be anarchists, if you will." 
4. "The 'Hands up! Don't shoot!', that was the first thing they came up with."

5. "The guy they were interviewing, he said that was supposed to be a peaceful protest. I'm (sure) the only thing that I had ever heard about was that there were protests and riots in Ferguson. It was never said that there was a peaceful protest going on, it was always set up as a violent situation from the get-go. Like anything I had seen on television or Facebook, or internet news things, was always like there are riots in Ferguson."

6. "Similar videos, yes, but I had never seen that one."

7. "I mean, yeah, I was working security at the time. I remember the reason they were protesting in Columbia that night is I guess some guys got kicked out of a different bar in town, because the people that own the bar had made light of the situation and the rule to get in the club, which might have been Field House, was 'hands up, pants up.' I think it was happening before the situation, but the rule for coming into the club, was if you put your hands up, and your pants don't stay above your waist, then you're not dressed properly to come in. And then there were people that thought they were making light of the 'Hands up! Don't shoot!' movement. And then also because of the way that young black men dress, you're profiling people, you're being racist without being racist because this is how we wear our clothes."

8. "I actually had a buddy that was in the National Guard, I think, and he had to go to Ferguson. He is now CPD, he went through the training academy with the Columbia Police Department, he's an officer now, but he went with people that got called to handle the Ferguson protests and riots. He was there for like a weekend. We kind of talked about it, and from his perspective, as a cop there, it was really uneventful. They were there with their riot shields and stuff, and they were out there all night standing around, and he goes nobody threw anything at them. There was yelling back and forth, and there were groups of people protesting, but there was no shooting, there was no looting where he was at. There was concern for his safety, but he came back, and nothing really happened. It was boring."

9. "I remember working security at Harpo's and the people blocking the intersection right there in front of it, all four ways. Like they were in the crosswalks in a big circle, and they weren't militant black people but, like, they reminded me of the Black Panthers, they had that look about them. They were educated, but very much wearing fatigue bottoms and black coats. But still speaking intelligently and one guy had a megaphone and he was talking about they want this, and they want that, and they're not taking us seriously. They were doing the call and response of 'Hands up! Don't shoot!' They were there for a while and then CPD came around and they dispersed. Like I said, you still had the people that got in with that group that probably wanted to be taken seriously, and they were just there, blending in with those trying to cause trouble. They didn't care about the kid that got killed, they didn't care about race relations. They were just there to hang out I guess. And cause trouble, nothing better to do on a Friday night."

10. "Like I said, that was right before my wife left me. So, I was working downtown, like on a Friday and Saturday night, and we would discuss these things in the morning. So, in a marriage where there wasn't a whole lot of communication going on, the news was something to talk about. The back and forth of do you think the cop was wrong or do you think the kid was wrong, and my wife and I are both from pretty 
sketchy backgrounds growing up, and so when there are shootings in Columbia, or shootings like this, a lot of people get freaked out, like, oh, there's random violence, and I'm like, no, that dude took two rounds to the back of the head, that wasn't random. Like he had done something to somebody. So even though we are divorced, we get it, we didn't grow up in nice neighborhoods, either. So even though I'm white, when the cops told me to pull over and keep my hands on the wheel, I would do it because I know what neighborhood I live in. I don't mouth off the cops, and I don't reach for the gun. and we have conversations with our kids, the older one is 15 now, and it's like don't hang out with these people or when a cop pulls you over and they tell you things, and my older daughter is multiracial, she's Mexican, Filipino, and white, but she's brown. So, she's been raised that it doesn't matter what color you are, when a cop tells you to do something, you do it. That's the safest way out of any situation."

11. "I'm reminded a lot of the negative people, like the guy said, we're trying to have a protest, we're trying to make a statement, we want justice to be served. But then all I'm ever reminded of is the criminal elements, the looting (of) stores, and there were people out there that were actually concerned because there were children at these protests, but when the tear gas was thrown, there were guys in their late teens and early 20s running around with their shirts off, bottles of liquor, like they weren't out there to protest, they weren't even involved. They were standing on the side, hooting and hollering."

12. "Yes, immediately. Before the video you kind of reminded me, but then as soon as the video started, it was like, and I saw the 'Hands up! Don't shoot!', it was like, oh yeah, I worked at Harpo's and there was a protest in the street and this is why there was a protest and this is what went on with that. It's hard being a security guard with all of this going on and at Harpo's you had to start having two forms of ID, one of them being a student ID from somewhere in Columbia, and they we're profiling because you had black guys from St. Louis. They didn't want to party in St Louis, so they were coming to Columbia to party. But Harpo's was concerned that you had criminal elements coming in with that, and that this was a college town bar. So, you had to have a driver's license and a student ID to come into Harpo's during that time."

13. "A little bit, with thinking about my time at Harpo's and working security, and having to, like, I can visualize them coming down the street and what they were wearing and that the cops had to start clearing them out. That reminded me where I was in my relationship, that I was working security until 2:30 in the morning, and when you're working security with another guy, and the things you talk about and what you think about when you got time to just stand around."

Subject 024

1. "I remember it happened in Ferguson/St. Louis. Michael Brown was killed by a police officer, and it was August '14. It started off with smaller protests or a memorial, and then it turned into basically a riot against the police for a few days in August and then again in November, when it was decided not to indict the officer in question. It led to massive protests, which I covered myself, and it was interesting. There were media from all over the world. There was so much attention but there 
(were) not that many protestors relative to how much coverage it got, and it was some of the protestors were out to cause trouble, and others were there to quietly protest. There was a massive police force there, and the National Guard was there. And I remember it was in front of the police and fire station in Ferguson, and it was right before Thanksgiving, so there was this sign across the street with 'Seasons Greetings,' which created a great visual scene with the armed police and the Molotov cocktails flying around right under the 'Season's Greetings' signs. That went on for a couple of days and it was freezing cold. Then Thanksgiving happened and after that, the massive protests were over for then. Then they came back the following year. I can't remember if it was in August for the one-year anniversary of when he was killed, or the November protests. No, it was the one-year anniversary, there was another set of protests that was covered. There weren't as many people there, but it seemed to be a lot more mean-spirited. The first time around there was a lot of people who don't necessarily agree with everything but were there to show support. The second time it was a lot more hardcore. I felt safe the first time; I never felt safe the second time."

(Interviewer: "And you were at both?") "Yes."

2. "Being tear-gassed and shot with rubber bullets. And then I remember for the first time, while it was crazy, there was togetherness. Every time I talked to the police or a protestor or anything like that, the conversation ended with, "Be careful." When I got tear-gassed, it was no more than a few seconds before they were giving us the stuff that provides relief. Everyone was helping each other. Not everyone, but there was a feeling like we were all in this together. And I talked to so many as a journalist that told me that it was about police brutality and them needing to be accountable for their actions, and that it wasn't necessarily a race thing and we are on the same side. And I wasn't there to protest, I was there to cover it, and then the second time I was there on the anniversary of his death, I felt threatened, and I was threatened, many times by the protestors."

3. 'It does to a certain degree. I don't think there was anything incorrect in there. There was nothing in there I found inaccurate, but I don't think they necessarily covered a complete picture. It was wonderful to the guy and his friends who stopped the looting of one store, which happened, and there were many good Samaritans there, there's no doubt about that. But I think that what they covered there maybe does not emphasize enough how much destruction was made by protestors. I also don't think that it's necessarily fair, and I'm not sure when this video is from, to include the statement from the woman say, "They were just looking for any excuse to kill him and they were never going to charge him with murder." Not that I know if he's right or wrong. But there's definitely the other argument that Michael Brown didn't obey orders and that he had been strong-arming the storeowner earlier. So, I know many felt like he felt, but only having that side, and not having the response from those being criticized is problematic and doesn't paint the whole picture of how it happened and was perceived by some others."

4. "No, there were a few things I should have mentioned before I watched, but it wasn't like I forgot that there was looting. I don't think there was anything like that." 
5. "No, only the micro-facts, like the specific people, but nothing relevant to the broader story, but I hadn't seen those specific people before."

6. "Not this specific video. I knew there were videos about Ferguson."

7. "I spoke to a lot of people about this. I spoke to the protestors; I spoke to some police officers as a part of my profession work. I spoke to radio hosts in (inaudible). I spoke to family and friends."

(Interviewer: "Anything specific that stands out from those conversations?")

"Just how strong the opinions were, especially in the beginning. It was so focused on it being wrong and how can the police kill an innocent black man. There was outrage about the racism form everyone I talked too, or the perceived racism. And later there was more, OK, there are two sides to the story, and some I talked to said, yes, it might be wrong, but it's also not OK to loot and burn down stores, or to attack police officers. Those were the sentiments I heard."

8. "It snuck up on me in the sense that when it first happened, I wasn't there for it, I was in Denmark. It was only for the indictment and the first anniversary that I was actually in Ferguson. So the initial stories were something that I read online, about the protests, but I didn't think much of it, and the first stories made me think that it was unfortunate, and it sounds harsh, but like, things happen, and I'd heard horror stories about the police before so I wasn't surprised by the first reports. And it wasn't until I was asked to go on Danish TV to comment on it that I realized I really needed to read up on it because it must be a big story. It was probably some tweets and Facebook posts that I saw at first. It took a while to register that it was a big deal."

(Interviewer: "You said you appeared on Danish TV to talk about it to a news program?")

"Yes, and that sounds odd, I realize that I wasn't in St. Louis, I was in Denmark, but I was a guy from Missouri who could talk about it. So that was it."

9. "The tension from the protests from the August event. And the immediate reactions to that, but it was similar to the November protests I was at, where we heard gun shots, not live fire, but probably rubber bullets or something else. There were a lot of rumors of shots and people being armed, so it brought back the chaos of that, and also the togetherness that I talked about before because there were people looking out for each other and that was the beautiful part of it. It brought back the atmosphere and the adrenaline."

10. "Not that I can think of."

11. "It brought back some strong feelings."

12. "I had already been primed to some degree because of your initial questions, but the video did bring back some new memories, if that's what you were referring to. It brought back some sensory memories Where the question brought back some factual, the video brought back what it felt like to be there."

13. "There was a strong feeling of that."

Subject 025

1. "It happened in Ferguson, Missouri; north of St. Louis. It stemmed from racial bias I guess you would say. The police were involved, heavy protesting nationwide, on the 
interstate even. Businesses were lost, there was looting. It was over the murder of a young man, in a convenience store, trying to leave. That's about it."

2. "Nothing major in my life."

3. "It definitely seemed one-sided, to the public versus what was happening on the ground. There was no other side given. The police were not interviewed. The law enforcement at the time were not interviewed."

4. "His name was Mike Brown. And how the community came together...whether it was the right way or the wrong way interpretation."

5. "That guy's opinion was that the police just shot the tear gas. Whether that's a fact or not, is all up to interpretation. But the tear gas, yeah. I knew that the police action spurred it all."

6. "Not that one, but videos similar to it, yes."

7. "I'm sure it was briefly mentioned at home, you know, have you seen the riots in St. Louis? And how volatile it was and how it seemed to keep escalating."

(Interviewer: “Anything else?")

"Not that night. My brother-in-law was actually working in that area when all of this was going down."

8. "Just how fast it was escalating. I mean, it was LA (Los Angeles) all over again. We had national broadcasting from there, people on the streets from New York and California on the ground."

9. "Where I grew up, we grew up with a high population of Native Americans, so it made me consider their viewpoints and outtakes of different things."

(Interviewer: "So the video elicited memories of when you were younger, and growing up? Tell me more about that.")

"I went to school with them, through high school, the settlement was right outside town. This was right outside Toledo, Iowa. We have a high population that at that time didn't have their own school. So, they were integrated in our school and they felt very ...mistreated sometimes. They felt like outsiders, they were not respected. Their viewpoints and culture were not respected at different times."

10. "I remember my brother-in-law working there, and telling us what precautions he had to take to stay safe, and what they had to do. Otherwise, not much."

11. "That it depends on who is doing the news story, what spin they're going to do on it. Whether it's going to be both sides, neutral, slighted one way or the other." (Interviewer: "Media bias, in other words?" "Yeah."

12. "I was shocked how fast it escalated, you know, that the town was under curfew and that these poor shop owners were ruined, some other them could never reopen. They lost everything in this incident."

13. "A little bit, yeah."

(Interviewer: "Was there any aspect of it in particular that kind of transported you back?")

"The way everybody came together. Like if one was feeling biased, that was a big thing when we were growing up, you knew it was never a one-to-one fight. They always showed up together." 


\section{Subject 026}

1. "I remember hearing that a black teenager had been shot by a police officer. I don't recall a lot more than that initially. As it kind of became more than a news story, I heard a little bit more. That's all I really knew about it."

2. "Well I work in the college of education, and they do. We do have some affiliation with some schools in North County in St. Louis because every once in a while, we were concerned with whether the schools were still wanting us to come to the building at all, or how the community was feeling at the time. And then I also remember I was flying, I don't remember what I was on the east coast for, but I was flying back from the east coast when the protests really started happening. And right after my plane landed, there was a no-fly zone over St. Louis. I was, I didn't know what was going on."

(Interviewer: "It sounds like you were fortunate to land when you had landed. Before that temporary ban.”)

"And then I was waiting on the shuttle to come and pick me up so I was sitting at the airport and getting these news alerts, like, I didn't really know what was going on at the time."

3. "Pretty accurately. From what I can remember."

4. "Honestly the biggest thing was the date. I forgot what year it was." (Interviewer: "Anything else?”)

"Not really, it wasn't anything new that I didn't know."

5. "I think I knew pretty much everything as presented. Once I had flown back, I realized it was all kind of going, since we do work in St. Louis. I was following the news as it was coming. there wasn't much new."

6. "No, I don't think so."

7. "I mean I did, so when I was on the east coast, I was visiting my boyfriend. I don't remember exactly what we would have talked about. But I know after landing I would have texted or called him and said this stuff was going on." (Interviewer: "So, you may not be able to recall specifically, but you probably did." "It was highly likely I talked to him and probably a couple other people, thankful that I landed and (wasn't) rerouted."

8. "I mean, I remember discussing with co-workers what was occurring, what, any effects it was going to have with us working with the schools. I don't even think right away with the protests themselves we realized the magnitude of what that event was going to be."

9. "Not really."

10. "Other than flying into St. Louis, nothing sticks out."

11. "I think it definitely reminded me of I was angry about the situation. It just seemed senseless and I felt like there was just a lot of physical force being used instead of conversation. And there was nothing I could do."

12. "I don't really think I did anything." (Interviewer: "You didn't get a sense of mentally going back to things you said?") "Not really, no." 
13. "It definitely brought some stuff back. It feels like it was a lot longer ago than it really was, so it kind of reminded me it wasn't that long ago. It feels like a lot has happened since them in the new cycle."

Subject 027

1. "I remember that they happened after a police shooting of Michael Brown. They were in Ferguson, Missouri. And that there was a lot of riots and a lot of businesses that were broken into and destroyed. Do I say things if I'm not a 100 percent sure they are true?"

(Interviewer: "If they are in your memory content, then go ahead with what you think, what is in your memory."

"I believe the National Guard was called in. That's all that comes to mind."

2. "My personal experiences that some protests were happening here in Columbia. And I work in the student center and a lot of protests would come through there and so we would always have to pause work for that. Or I went to dining, so we'd have to make sure we didn't get involved or they didn't involve us in any way. I had some friends that lived in St. Louis - not in Ferguson - but I remember talking to them and making sure they were safe and in the clear enough, out of concern."

3. "I believe almost completely."

4. "Some of the details like what the chants were by the protesters. That there were people who tried to stop some of the looting. Things like the police did engage with the crowd like throwing tear gas and things like that."

5. "No."

6. "No."

7. "Especially since it affected this community, I spoke with several people about it, but I don't remember any details of what we discussed."

8. "Nothing I can remember. it was far enough away that I personally wasn't too worried."

9. "Nothing more than what I remember from the protests that happened."

10. "No."

11. "Can you give me a scale or?"

(Interviewer: "You can quantify it or particular thoughts and feelings you could elaborate on that were reactivated by this video.")

"It just reminded me of the controversy over whether the police officer should have been jailed or not. It reminded me of the national debate we had on that."

12. "Not very much."

13. "Some. Something that hadn't come to mind recently for me. Seeing it reminded me that was a big that happened those years ago. And I remember what experiencing that felt like."

Subject 028

1. "It was the riots were started by, there was a black man that was killed by a white police officer that they thought, the community in Ferguson, the death was uncalled for, unnecessary. I don't remember for sure, but I believe he was unarmed. But I've 
also heard stories that he was attacking the police officer. So, there are two different sides to the stories. So, basically, the riot started because black people believed they were being targeted by the police to make a statement that that was wrong. I do remember the black guy that was killed that he was robbing, I thought he was robbing a convenient store. But I could be wrong, too."

2. "I do remember that it almost there was rioting but there was looting. They were destroying their town, burning things. Almost an excuse to steal. I remember there was a YouTube video of a black lady that caught her son. I don't know if it was Ferguson or maybe somewhere else that riots were happening, she was mad at him for like being involved with the looting. And there was a video of her yelling at him. I do remember we got on the MU campus, I don't remember what his name was. It was a number. And they camped out on MU campus as a kind of 'We're going along with Ferguson' event. It kind of all happened at the same. I remember my mom worked at the dining hall and there was a Girl Scout (troop) that had come in that, you know, to eat. And there were rioters that came in the dining hall Plaza 900, and they were yelling 'Black Power! Black Power!' And the girls were getting scared and they didn't know what was going on. So that's pretty much what I remember from all of that."

3. "Well, there was looting. I, that was the first time I've seen that video. I did not, you know, obviously I knew his name now. Mike Brown. I did not know about the cops throwing tear gas. I did also know, I did like that some of them were trying to stop the looters. I didn't realize the gangs had come to together to fight against the police. It didn't show any fire. And I vaguely remember seeing fireworks in the news, so maybe that's what I was thinking of. It didn't look like they burned anything down. That was inaccurate."

4. "The boy's name. Yeah, Mike Brown. And I think that's the main fact I've forgotten."

5. "I would say also, the people who were trying to stop the looters. I vaguely remember that maybe."

6. "I think there was, I don't know about videos on YouTube, I bet there was stuff on the news. But I didn't know there was stuff on YouTube."

(Interviewer: "You maybe remember news reports? Video footage on television?") "Yeah."

7. "I just spoke to my husband. I think it was around that time my parents and there was a video of Mike Brown on the news. It showed him attacking the police officer even though he was unarmed. And I remember thinking well if that guy was attacking me, and I had a gun, I want to protect myself. Like he was a big dude. Like even if he wasn't armed he could really hurt me. you know. I remember thinking that. And I think that's what the cop was thinking. I remember he had just like I could be wrong, but I felt like he had just robbed a convenient store and left. And the cop like, they called, and the cop found him. And that's when everything happened."

8. "I think I just remember thinking like I heard this was Ferguson was a predominately African-American community and they had had problems with the police for a long time. So, it wasn't a huge surprise something like this had happened. But I think it was surprised that it spread across the nation. It kind of started the Black Lives Matter in all the U.S. I kind of remember thinking this might be a problem, but I feel like 
they could be making it worse, causing more division between black and white people. And making it harder for the cops to do their job."

9. "Probably just the division that was going on at the time. There was a lot of tension everywhere."

10. "Personal feelings, is that what you said?"

(Interviewer: "Any personal content you connect with the time of the event.")

"My husband had to go to St. Louis to visit somebody and he told me not to come because he was like 'It's not a safe area right now."'

(Interviewer: "Was that business related?"

"It was actually, he was going to it was like a personal, he was going to help a friend who worked in St. Louis."

11. "I think I just thought, I'm sure I don't understand everything that's going on, like how they feel. But I also felt like it was kind of getting blown out of proportion. Yeah. I kind of felt like they were kind of making it worse, you know?"

12. "I think it just brought me back to conversations about the whole like, police, you know hurting black people. Then like how it's not always true. And then there was videos of like, I just remember people defending the cops. People like standing up for like Black Lives Matter. Such division of it."

13. "Do you remember what the date was? Can I ask that?"

(Interviewer: "I believe it was 2014.")

"OK, because I think the reason I asked that is that I had that previous question wrong about my husband going to St. Louis. Because in 2014, we were going to St. Charles for the Christmas thing. And they had Krispy Kreme in Ferguson around there and my husband's like 'Don't go there, it's dangerous.' I just realized it was totally wrong what. Because I was like 'What!' And he was like 'Don't even. Who cares about them?' I'm sorry."

(Interviewer: "No, that's fine.")

"I just remember him telling me to stay away."

(Interviewer: "I figured it was a different reason.")

"Yeah, because I was pregnant then, too."

(Interviewer: "With your younger one?")

"Well, we have a 3 1/2-year-old and a 16-month-old."

Subject 029

1. "I remember it involved the killing of Mike Brown. I don't remember the officer's name involved. But it was a white officer who, whose, who reported he felt under, under threat by Mike Brown charging in his direction. And then after that, there was a lot of unrest kind of built by his family saying he was not that kind of person. And you know, there was a lot of pictures of high school graduation associated with that. I actually don't recall if Black Lives Matter started then, before, or just after. But it was kind of the kickoff in my mind."

2. "I personally, my grandmother lived in Ferguson. A long time since has passed, she passed long before then. But I have visual images of that area would go through my mind quite a bit. There were following like student center-based protests that I recall because I work in the student center. I was working. And then I had to go to Atlanta 
for a conference, not long after that, and there were citywide protests regarding the outcome of the hearing or whatever it was."

3. "Oh, pretty well exact."

4. "I had forgotten. I remember what happened with the looting part of the protesting being a lot more focused on than what I saw. It seemed between compared to that video. It seemed a much bigger deal, that part of it, like what was going on was ruining the message like what was going on in the video."

5. "No, I don't think anything comes to mind."

6. "I have never seen any of them. I can't say I knew specifically of any. But I am sure they exist. I have not seen that one."

7. "Again, probably more related to the outcome of the hearing, because I happened to be in another city at the time. So, you know the group of people I was with generally more conversations were a little bit of a sense of surprise that there was seemingly almost no consequences. That the officer was held, regardless of you know what kind of threat may or may not have been present. There had been enough people around. So that was kind of the conversation we had. And also, whatever protests we were witnesses to, just trying to give it a wide birth because we didn't want to be involved in any kind of escalation or anything."

8. "I again kind of remember people made — they held onto the part about looting and whatnot. And kind of twisted it into being something only about causing a ruckus and making trouble more than actually trying to have justice for a person. So it kind of, there was a lot of negative comments about what happened after, in regards to the people who were protesting, not even in regard to the incident itself."

9. "Since I wasn't there, it tends to associate with that trip to Atlanta where there were you know, I don't believe any tear gas was going on. But there were helicopters flying overhead. You know just trying, lights shining down in kind of watching kind of aspect. It was a little bit surreal because it seemed like we were in some kind of, this is exaggerating, but some kind of almost war-zone-like. Like what is going on? All these flyovers. Like someone was waiting for something to happen."

10. "Nothing super strong, in terms of time. Because most of my memories are associated with when my children were born. You know, about how long after was my first son born."

(Interviewer: "Kind of using your kids as a stake in time.")

"Yeah, and also, because I work the dining services here, we get moved around to different units and so I always think of where was I, which place was I working in. And you know we talk to a lot of students. And so, a lot of my associations were who was I working with at that time, too. At that point, I think working with a more liberal group of people than I do today. So, I kind of remember having a lot of interesting conversations in the months following after that."

11. "To go back to that, walking from one place to another in Atlanta with all these things kind of going on around me. You know it was probably not as intense as what the video showed, but it was learned terms in volume and like the level of passion of people involved. So that's what I remember thinking about every moment through that video. And like the whole chant of "No justice, no peace." That was in the student center quite a bit as well."

(Interviewer: "Perhaps another way of saying the video quite easily transported you 
back to that time to the student section?")

"Yeah, I was imagining the whole thing as I was watching the video."

12. "I don't necessarily have a lot of exact things. I feel like if one of my student employees, for example, wanted to, was talking with a group of other student employees and I came across that conversation, sometimes people would get quiet because they never know what you're going, what kind of opinion you're going to have. So, my whole thing with them was trying to encourage the discussion, not like shut it down. Because I didn't want to be personally viewed as someone who was on any one side, but certainly not about finding out what happened, which was a general feeling at the time."

13. "A little bit more into that how, how it seemed, the protests I personally witnessed. Even what the weather was and that kind of stuff."

Subject 030

1. "The Ferguson protests, I remember quite a lot. Because that was right before I arrived at Mizzou. The key thing that I remember was that it was obviously caused a very severe public reaction. And it resulted in some rioting and chaos. I wouldn't say very bad rioting, but enough to cause issues. I also understand that the there was a lot of controversy shooting. I recall reading into the story the shooting was in fact authorized. The officer complied with the law. The suspect did charge him in an aggressive manner and commit an assault immediately before the incident. And then I also remember after I had arrived in Missouri. I started looking at Ferguson as a speed trap on steroids. So, this town had a really toxic type of environment, which would obviously make people hostile towards the police. Like I would certainly be hostile towards them under those conditions, too."

2. "Well there was the, it fed into the, fell into, the protests we had here at Mizzou. I don't know if there was a causal relationship, but it definitely contributed to it. I just remember what I read in the news reports about it. And I also remember there seems to have been a Ferguson effect of some sort. The FBI has been able to prove just deeply that it [inaudible]. But I'm from Texas, so we don't have these kinds of problems. Police shoot people all the time in San Antonio and they are all legit and nobody ever riots about it. You know, investigate it properly. We just don't have these problems, so."

3. "It's hard for me to say, it's probably about 50 percent. I had never seen that video before. So, the gas grenades, the police tactics were new to me. The parts that were relevant to me, were what I remember, was that that particular community had a lot of serious issues with not only the police but the government. It was economically plighted. So, I was aware there were systematic problems and it was due to poor governance."

4. "I don't think I forgot anything, but it did show me new information."

5. "Gas grenades." (Interviewer: "You mentioned that.")

"The other thing I didn't know, I saw the police in their convoy and having to disperse the crowd. I wasn't aware the tactics there were specifically using at that time."

6. "No." 
7. "Well, I mean I've been in riots. I tended to judge it to my personal experience. I mean I've seen plenty of videos of riots. Rioting is like a national sport in Paris. They are burning cars. So, by European standards, this riot was very mild."

(Interviewer: "I would not have known that.") "By my standards, this riot was nothing more than left of temper-tantrum. But that's how I perceive it. This is very mild."

8. "I remember talking to people here at Mizzou about it. Because I didn't really understand much about Missouri and how it worked. I was a very I guess I was very, it was very perplexing to me. Because on one hand, you have Kansas City, which is clearly thriving, I've spent a little time in Kansas City when I was in the military. It's a thriving place. Economic, lots of jobs, it's growing. On the other hand, St. Louis which is it's almost in a slum status. So how do you have within one state, two cities that are diametrically opposed to each other? I know there's African Americans in Kansas City, and they don't seem to have problems like that. But I'm not that knowledgeable about this, so I don't have authority to claim. But I was trying, at the time, I was trying to have discussions, like what was the dynamic, what caused that. I also remember talking to people about when I was back in Texas, some people asked me about Ferguson and what they thought. And I explained, from why I understand, it was just like the city was I compared it to a city in Texas called Selma, where they have speed traps all over the place. And they are just notoriously bad. Everybody hates them. So just imagine Selma, but five times worse and that's Ferguson. So people are going to be pretty mad about it. People are not just getting speeding tickets. they are getting everything."

9. "It was a little more relevant to me because I knew I was coming here. At the time, I didn't really know much about it. I mean at the time, I've been involved in active shooting situations myself. So, at the time, I'm inclined to side with the police. But you know, I don't, what's first reported is often not accurate, a lesson I learned the hard way in the military. So I was really hesitant to accept any opinion at the time. Not just this event, but I mean I had memories about my first riot in Kosovo. But I mean I was thinking, Ferguson police have it pretty easy if that's the worst they gotta deal with. I mean because they're you know, the first day of the riot people were throwing hand grenades. I mean, luckily, they were communist hand grenades. Communist hand grenades are really bad. They're basically fireworks, but they are still throwing hand grenades. So, it struck me as not kind of blowing that out of proportion, but that's just really my perspective. And it's an unusual perspective, so I can't really generalize to other people."

10. "Well I mean, I had my son was just born. I was getting ready to come here. It really wasn't, it wasn't, in the grand scheme of things. It was really just an event that happened. It may have some impact on me in the future, but it really wasn't that significant."

11. "I got a feeling that this is was a political situation in this country is gone full unhealthy. And I felt this was one more step in the perpetuating a dangerous and unhealthy situation nationally. But I didn't necessarily this incident in and of itself at the time was extremely dangerous. It's dangerous in the sense it contributes to other things." 
12. "About the news event?"

(Interviewer: "Or at that time.")

"Well, I just confide, I talked to my friend and I said, you know, at the time because coming to Missouri, I wanted to study communication. So, it reemphasized the importance of what I was trying to do."

13. "It was hard for me because this particular not that significant to me. But it triggered other emotions. I mean it triggered other memories of other events that happened. I tend to view these events in relation to what I've already experienced. I had some friends you know being down in Texas [inaudible]. So, half the people in my neighborhood own an AR-15. Some of my neighbors are saying come down here and get blown away. Good thing that's never going to happen here because rioting a good way to get yourself shot. And you know I ignored that. I said ok, yeah. I agree but at the same time, they have a different culture down there. It's not something they would do. This is very odd and strange to them. I counter that this is more common in other parts, they just don't have the frame of reference. Compare those two, so sure. I just kind of go along with it."

Subject 031

1. "Well, it happened in Ferguson, Missouri, a suburb of St. Louis. Basically, it was a giant protest about the handling of law enforcement of a black male, I want to say he was around 19 years old, I want to say somewhere around there. And how he was shot and killed by police under circumstances where it seemed the police basically mishandled the situation and the suspect did not have to die. I remember there were riots and blocking the interstate. And it was a big mess. And then I remember the victim's mother ran for a local government eat. I can't remember if she won afterward. She became an activist. I don't know, it became a really polarizing event. It also spurred certain things at this university. So it was a major historic moment, not necessarily a good one. But it definitely brought racial tensions to light."

2. "You know, being a Missourian, I'm not from the St. Louis area, but being a Missourian, it was not great to have your state cast in this light. You know I also joined the university in November of that year. kind of in the middle of the controversy starting here and the Black Lives Matter movement. You know, personally, was kind of with others in the state and nation, kind of horrified by the events that went down and just kind of wondering what is going on. And not just that event, but other events in the past, you kind of sometimes give the police the benefit of the doubt, we weren't there, we don't know exactly what happened, but we had too many in a row come to light under suspicious circumstances. As a Missourian and not just a Missourian, but a human being, but as a member of the white race, it was a shameful moment, where you just hoped that you weren't judged. Where it kind of made me uncomfortable, you know I hope African Americans don't think I'm the image of the top. So as where you know before I felt very comfortable, I kind of felt uncomfortable after that, even though I had nothing personally to do with it. It was just awkward."

3. "It was pretty spot on. I hadn't seen that actual clip, but it was pretty much how I remembered it." 
4. "Not that I'd forgotten specifically, but I didn't, I mean I'd heard, about the police throwing smoke bombs and various things into the crowd. But the clip was more specific about it than I'd heard. So, from before, from the news, it was kind of ambiguous whether the smoke bombs came from the crowd or the police because each side was disputing it."

5. "No, I don't think so."

6. "Somewhat, this one I thought was, how do I explain it? I had seen video clips just on the regular news. This one seemed a little more, grassroots isn't the right word, I don't know what the word I'm looking for. I guess it was it a little more real. And the fact they brought the smoke bomb out and was actually reading the label of, rather than just innuendo, or each side saying this did and they did that. It kind of was like evidential is what I'm looking for, here is the smoke bomb we just picked it up and it says it was used by so and so."

7. "Yes, definitely. It was a huge point of a conversation I think so a lot of people. My husband, in particular, is a big newshound, so we watch a lot of news. I remember at first, we didn't know what to believe. But as you know, the news went on for quite a while, so we weren't sure what to believe. But as time went on, it became clear there were some misactions by the police or at least it became clear to us. So there was a lot of discussions. And like you said some of the stuff we talked about earlier, it kind of made us this is the image we want of our state. You would think St. Louis, in particular, would be a little more progressive than this. I think I thought this was something you'd see in Louisiana down in the 60s and 70s. It was kind of like going back in time. I was telling my husband this kind of reminds me of the LA riots when they were looting the stores. I remember talking about how it's a shame that this affects a certain group of people but yet the rioting and all that is making it worse for those people and it's ruining their businesses and livelihoods. But at the same time, you kind of have to understand like, the feelings that we have to do something people are going to notice. I guess it's hard to understand unless you were there."

8. "I remember when they started showing kind of the riots and breaking out, riot may be too strong. Riot and looting and all that. And you know blocking the interstate, it kind of made me nervous when talking about bringing out the national guard. I actually was really nervous because it kind of made wonder, like I said, it kind of made me uncomfortable as a white person to be walking around, I hope they don't think I have this hate or bigotry or whatever. You know, also, OK, this is like a major movement, which is great, but I don't want smoke bombs being thrown by the police. And I don't like gunfire from either end. You know, so it made me a little nervous for a while."

9. "Just kind of like the shame and just the realization that there's a large population of African-Americans who really aren't heard, aren't heard authentically. Like I thought this video was very authentic. Like it's on the ground, people actually in it, not just politicians, or black community leaders. You go right there in the middle of it and I was personally affected."

10. "Like I said, I started my job with the university in November. And that was when Black Lives Matter on campus was heating up. And I remember the then system president refusing to get out of the car at homecoming to speak to the crowd. And I was like man, did I pick a good time to start at the university. And I work for UM 
system, too. And I was like we are penalized by the legislature and I remember thinking this is not how the majority of us think. Like I get it that people are angry, but it felt unfair that such a big population of us were being negatively affected by something the leader did."

11. "It was a pretty big stint and it was pretty long ago and especially being here at the university where they're trying to change the atmosphere for the better, it's kind of, it kind of hasn't been forgotten anyway. It's obvious strides to be more diverse. I don't know if that answers your question. Nothing has changed much but my opinion of the situation."

12. "It made me second guess other similar situations that had happened where I had tried to give the benefit of the doubt to the police and it just still makes me second guess it. Because I do believe it's hard for the civilian at home to know what happened without being there. So, it's kind of hard to know sometimes, did the police believe they were physically in danger? Or not? So, I have to be fair to both ways. I wasn't there. I don't know. However, watching this and even more so more events that came after this. Even after this specific event. Like the kid being shot in Chicago and being left in the street. Things that were really blatant. It kind of made me wonder what view I had of police. Like maybe they hadn't been heard and they need to be heard more. Cops aren't always right."

13. "I didn't only go back to that time 100 percent. But it definitely made me remember it. I know more than even watching the video. Just talking about it, it's making me remember it was just a couple of years ago. It was really fresh and you really did feel uncomfortable. Like does that person want to talk to me, or do they think I'm a racist? Like I think it's kind of dissipated now, but it's definitely still there. It's something to be aware of." 


\section{Appendix B - Interview Transcriptions Video: "Oil Rig Sinks, Spill Possible"}

The transcribed responses are numerically listed, corresponding with the following numbered questions in the interview session:

1. What facts do you remember about this news event?

2. What personal experiences do you remember at the time of this news event?

3. How much did the content of the news video concur with facts you remember about the news event?

4. What facts, if any, did the news video present that you had forgotten over time?

5. What facts, if any, did the news video present that you did not know prior to viewing the video?

6. Were you aware of the existence of this news video online or other videos similar in content?

7. Did you speak to anyone about this news event on the day/night it occurred? If so, what do you remember about the conversation?

8. What, if anything, do you remember about the remainder of the day/night or the time immediately after you first learned of this news event?

9. What personal memories did viewing the video of this news event help you to recall?

10. What personal memories do you associate with the time of this news event?

11. To what extent did viewing this news video remind you of thoughts and/or feelings you had at the time you first learned of this news event?

12. To what extent did you begin thinking about things you said or did at the time you first learned of this news event?

13. To what extent did you just experience a sense of "going back" to the original time of the news event?

In instances where an unscripted follow-up question was asked for clarity or elaboration, the question is indicated in parentheses as being asked by the study interviewer.

Subject 001 (interview pilot session, responses not included in analysis)

1. "I know some very horrible explosion, I think I vaguely recall that it was safety, it was a safety issue or something involving like safety mechanism didn't kick in which caused the accident to happen a lot of people went in the water people were rescued, but, if I recall, a lot of people died, too."

2. "I just, really glad it wasn't me and I had a friend who was actually a geological engineer for the oil fields and had worked on rigs and made me think, wonder what it would be like, you know, for him if was ever in something like that."

3. "It didn't cover a lot of information that came out later on that I recall now, but it was on point."

4. "How many people had died, and that it had actually sunk. I had forgotten that point, too."

5. "How many ships were involved in the containment, I don't ever (remember) hearing that specific number before." 
6. "This particular one, no."

7. "Yeah, basically I remember everybody was worried about gas prices going up, cause of the loss of the production of, from the factory, or the platform. Not so much about the loss of life and things like that, but, what was coming out of our pocketbooks."

8. "I remember wondering a lot myself personally about how much ecological damage was going to be done... There was a lot of people make their living from fishing down there, and that could have destroyed them, and actually did do quite some damage."

9. "Stuff that came out later on...but I think what happened is they hit a methane pocket and it caused pressure buildup, which caused the blow, and the decision that caused them to hit or drill, it was actually somebody from BP corporate office, not somebody who worked on the rig. So, basically, a backseat general, you know, he was looking at the numbers, he wanted profit, and people on the rig that said we shouldn't do this, you know, that's what it came down to."

10. "None that I really recall. I like couldn't even tell you the date of when it happened or exactly the year."

11. "Quite a bit. The, you know, it reminded me about what, being worried about the oil spills, reminded me about the missing people that were never recovered, adn then how it was going to affect people's jobs and money's and gas prices, things like that. That all brought it back."

12. "Probably quite a bit, cause, you know, I wouldn't have been talking about the ecological disaster, what we would worry about gas prices, at the time if I hadn't heard about it no more than normal, and then different types of facts, like what the response would be to that, I wouldn't have thought about that if I hadn't heard about it in the first place."

13. "Quite a bit, because I couldn't remember hardly any of it, and then I was starting to remember a little bit before. We hit play on the video and a lot of it did come back through the video. Stuff that's not covered in there, but came out in subsequent news reports and stuff, but that jogged the memory to it."

Subject 002

1. "It was near Houston, I believe, and again I relate it back to family, I have an uncle that, and his wife and his cousins live in Houston. He actually works for an oil company, there's kind of concerns about that. Past that, I can't really remember too much about that. I know that overall just contamination of that area, the water is concerning."

2. "Nothing in particular."

3. "I remember the environmental concerns, but I don't remember the human missing, that element of it, there were actually people on the rig, people missing,"

4. 'No, I just don't remember, I don't think I ever knew anything that was, never something that I thought about, more like how is the oil going to affect the area and the water."

5. "I think in general, I wouldn't have remembered it unless I saw something that had triggered it. It's not something that I think about, whereas the Ferguson one, when issues come up, it still triggers that memory." 
(Interviewer: "That, you think that that pertains to the closeness in the personal sense to the news events, one like, you know, hit a little closer....")

"Proximity of it? Or, the actual situation?"

(Interviewer: "Yeah, I mean the actual physical proximity of it, but also like, you know, kind of personal attachment in a sense.")

"Yeah, I'd say both. Proximity definitely just because it is close to home. But then also there's still lingering issues and I feel like even in Columbia we see them on the daily of there's gang violence and things like that. And there's still this whole mistrust dynamic that is still very apparent, that I feel like there's definitely room for growth and improvement and so it's still, like, I still think about that. Whereas (with) the other one, I wouldn't have thought anything on it."

6. (inaudible)

7. "No, not the day or the night of, but probably a few days later I talked with my dad..." (Interviewer: "Kind of the aftermath about it?")

"Yeah, is that..?"

(Interviewer: "What do you remember about that?")

"Another question, well, I was asking him, being that my uncle works in that industry and he has an inward perspective of how this could affect things down the road, so my questions were are gas prices going to skyrocket, and all this fuel that has been like (inaudible), and is that affecting where he lives, are they having any issues, but, other than that, no, I don't remember much else."

8. "No."

9. "Some, no. I mean, seeing the oil spill in the water and I remember that, um, not much else."

10. "No, I couldn't even place around what year it happened. I know I was on the adultish side, but yeah, I wasn't a child."

(Interviewer: "You were kind of...")

"Yeah, like young 20s, maybe 19, 20s? Like, I couldn't tell you exactly what year it happened."

11. "I mean, it brought back the memory of it occurring, and questioning my dad that I knew would communicate with my uncle about it...about how it could affect things, other than that, not much."

12. "I would say that was the only thing I can really remember of it, yeah."

(Interviewer: "Was that inquiry with your dad?")

"Yeah."

13. "Just a little, just that conversation that we had."

(Interviewer: "Not a great sense of you know, boy, I just remember this like it was yesterday?")

"No, I was worried about gas prices increasing I'm sure, money was tight at the time, so that was one of my concerns, but, yeah."

Subject 003

1. "Well, there were a few explosions, right? This one was the biggest, this was the biggest one, you're talking about? It's the biggest, biggest one, and it basically wiped out the Gulf? That's what I remember then, that it wiped out the Gulf." 
(Interviewer: "That there were actually a few explosions, but this was the big one that sank the... Yeah. I didn't mean to fill you in on that, but you remember hearing about a lot of explosions in the Gulf?")

"Well, I don't know necessarily explosions, but wasn't there another spill? Some sort? Wasn't it an explosion? I know what you're talking about, if you say it's the big one."

2. "No."

3. "It concurred."

(Interviewer: "Anything in particular?”)

"It was pretty generic in my opinion."

4. "Nothing really."

5. "No, I just think they were focused on the 11."

6. "No."

7. "No, I don't remember."

8. "No, I hate to say it, it was just another bad news story."

9. "No, I mean, I mostly remember the aftermath of that, the explosion was horrible, and the people, the people on the rig when it exploded, and then I know the days after that were really hard they couldn't contain the spill, and isn't that the one? Yeah, the environmental impact after that."

10. 'No, I can't remember. I don't know why I can't remember what I was doing during any of these! Yeah, I don't."

11. "Well, I mean, I remember it, it was pretty actual new video." (Interviewer: "Nothing specific?") "Nothing out of the ordinary, yeah."

12. "You know, I don't watch the news a lot. There's the way I watch news is I just come across it, I purposely don't watch news because, I get really emotional about anything, so when I talk about the news, it's with a couple of people, because I just don't really watch it, so, I probably call my mom, you know? This is what I do."

13. "I mean, other than just remembering it happening, no, not really." (Interviewer: "Not a kind of firm sense of...") "Yeah, wow, there it is. No. I don't remember what I was doing."

Subject 004

1. "I think that event it happened a long time ago, and maybe at least 10 or 12 years ago, right?"

2. 'I don't think I remember anything about that event. What I can remember is at that time, I have seen in the media... because I have the habit of looking at when I saw news then, I prefer to look at images rather than read the whole news. So, and I often did the Google Image search, and I remember that I did that search and I saw a lot of pictures about the animals covered in oil in that event. The only thing that I could remember about what I did when I heard about that, when I knew about that event."

3. "At that time, I don't think I read, I remember I heard, read only one news about this event, and my boss at that time, he talked about this event and that is the only thing that I could remember. But I am not interested in politics or economics on this, the topic like that... or environmental things, so that's why this kind of news, normally I skip it. I just look at the title, because at that time I was leaving Vietnam, the things 
happening, the environment thing happening in the U.S., I was like OK, it was not my business."

4. "In fact, the video, it is a very first time that I know this event in pretty details, like I read something, like I listened to something brand new to me."

(Interviewer: "In other words, what the news video did was more present things you

did not know already about the (event) rather than things you did know or had forgotten since the time it occurred?")

"Yes, because I didn't read the news. Yes, so it didn't reshape any new information for me."

5. "I didn't remember anything about this incident, especially at that time because at that time I was new in Vietnam, and in Vietnam, then we had a lot of environmental issues, but mentioning about environmental issues in the media like showing that the government is doing something wrong there, they are wicked. That's why in the media we don't talk, we don't read, we cannot see news about what the government is doing wrong, we only see good news about the government, and it's weird that all the media talk about is...no issues. That's why this kind of video...I didn't see."

6. "No, for this event."

7. "So, at that time, I remember that I was due in my home country, and in fact I remember that it was my boss. I didn't follow public news and I didn't know the news by myself. It was my boss, he often read news, and he showed me the stories and the images.

(Interviewer: "OK, may I ask what work were you doing at the time?")

"So, I was a teacher in Vietnam at that time and my boss was my principal. He didn't have to teach so he had more time to (read news).

(Interviewer: "What classes did you teach?")

"High school students."

(Interviewer: "Ah, yes, in language, or math?”)

"Language."

8. "Because this was new, it was not something relevant to my context and not an important event in my home country at that time, so I cannot find anything."

9. "Wasn't the memories, I cannot remember anything because I just (had) nothing very special, just normal life happened at that time."

(Interviewer: “Just normal day-to-day?”)

"Yeah, nothing exciting."

10. (No answer).

11. "I think when I look at the picture and I say, wow, I had never seen anything like this before with my own eyes, that was vivid, that thought coming to my mind, when I saw the wildlife in the Gulf of Mexico, that was covered in oil."

12. "I don't think really."

13. "Nope. I wish I knew more!"

Subject 005

1. "If I'm remembering correctly, that's the one that after the explosion, millions of gallons flooded, of crude oil flooded the Gulf of Mexico, trashed fisheries, you know, fishing, trashed tourism, trashed the environment." 
2. "Nothing really in particular, I feel like I have friends who were kind of down in that area, but I, yeah, no nothing, nothing really in particular."

3. "It was, yeah, it was pretty spot on."

4. "Yeah, actually, I had forgotten that it was actually staffed, you know, so the loss of human life was not something that I had tracked at the time, I was more engrossed in the ecological disaster. That was really more on my radar."

5. "Honestly, yeah, I hadn't tracked that there were 11 people, just flat out missing. The actual number of the people missing. I had forgotten what kind of vessel it was exactly, until they got into the little bit...those are the main things."

(Interviewer: "That it was an offshore platform?")

"Yeah, I guess I did pretty much know that, but you know what I had forgotten? I

don't go to BP anymore, and now I'm just in the habit of not going to BP and that's what started it."

(Interviewer: “Oh, your BP boycott.”)

"I mean, yeah! I had just, I just started not doing it then, and then I've just never gone back and it, and now I don't."

(Interviewer: "You stopped trading with BP stations before the...")

"No, when that happened, yeah. But then..."

(Interviewer: "I just wanted to make sure I had the timeline figured out."

"Yeah, so when that happened, yeah, I stopped using BP, and the reason why faded, has faded from my immediate consciousness, you know?"

(Interviewer: "And it was brought back by the video?")"Yeah! Yeah!"

6. "I've seen others like it, but I've never seen that one."

7. "I might have had a social media conversation with a friend of mine who is at the University of Louisiana-Shreveport about impacts because I think her family is even closer to the Gulf, but I don't really remember any details about it...I don't remember what she said about it."

8. "No, nothing."

9. "The boycott, yeah, absolutely. That helped me remember that part. It reminded me of the scope of the problem and that it did occur to me that it was in the news down the road. But then at some point, things drop out of the news, and so, I'm actually going to see now what is the status of the Gulf, what does it look like? And, you know that's something."

10. "It strikes me that I might have had that conversation with my colleague in person at a conference. That seems vaguely familiar. Oh no, she's in Lafayette, she's in Lafayette. I said Shreveport because it's on my mind, but Lafayette is where she's...it does, it shocks me that maybe it did come up at a conference that she and I were at."

11. "I mean, no, not really."

12. "Not a lot, except for the boycott, thinking about that."

13. "No."

Subject 006

1. "I first remember thinking when I heard Deepwater Horizon, I thought that it was a science fiction movie, like what are you talking about? Like, what is this, like Stargate? What is it, and so because I just was, that's when I was really focused on 
just becoming a teacher and I didn't attend to a lot of things that didn't have to do with my life. So just kind of, if the TV was on in the background or if someone was talking about it, I do remember thinking what are you even saying, how is this important in the world,. But then my husband also, he just keeps cropping in all the stuff, but he lived for several years when he was in the military in Texas and then he became very interested in this story. And he talked about people he had known working on oil rigs and I remember seeing, I feel like seeing people on news stations, like showing... graphics, like here's a model of what it looks underwater and here's what probably happened, so here's what people need to do, and setting up different scenarios. I don't remember a lot of the news coverage other than, that's all that stick out in my mind. I feel like I saw modeling of what happened."

2. "Not that I can think of. I think at that point I was pretty much, my kids went to the same school where I was teaching. All I ever did was go to school and work and hang out with the kids and I was not attending to a lot of news, and in the area where we lived, neither was anybody else. So, it wasn't that unusual to not have like, living here it would be very unusual to not have conversations about news events in my daily work life. At that point, in where we lived and what we were doing, it would be weird if people were talking about the news."

3. "I think it, nothing on there was surprising to me, but I don't remember a lot at all. I did not remember how many people were missing or injured or presumed dead or how many people were on the rig or what was happening, and I remember more, I think, about some of the follow-up stories where they were talking about cleanup and effect on wildlife and, you know, showing pictures of birds and things like that. But I don't remember a whole lot about the coverage of that. It just wasn't a big topic of conversation in our area."

4. "I think, I didn't remember, like, the degree to which it was an explosion and the giant fire and stuff. For some reason I thought it was more of a, and maybe it's cause I'm remembering the graphics, I thought it was more of a failure, and not, I really don't remember explosion things."

5. (No response)

6. "So, I don't remember seeing or accessing anything myself like during the time the event was happening because it was interesting to my husband. I think he (and) I watched, that's how I saw some of the follow-up videos because he would be watching it and I would, you know, see it while making dinner or doing something else. But I just remember not a whole lot about it, because I wasn't watching it."

7. "I just remember asking him if he was talking about science fiction, like what are you even saying."

8. "Yeah, I feel like I can place it. I mean my kids were littler, I was working and not attending to too much news or things outside, because I was also working on my graduate degree at the time, so I'd teach and work all day and come home and feed kids and do my, you know, homework all night."

9. "I don't really remember anything around that time or for my own life but it reminded me again, why, like I think that's what's happening, why it's reminding me of other situations. Because I do remember when I was working at that elementary school in a very similar situation with the Upper Briggs mine explosion, and so that, I mean it's a very similar event, but that was very meaningful in our community. Because people 
did have family members or friends who had, who were killed who were working in the mines and weren't working and try to figure out if people were home. So some of the conversations with people saying, you know, what did he say to you, or what are you doing and we're just waiting. There's no way to find out when there's a disaster, so I think that's more, I remember taking kids out to the bus and lots of adults were at the school for parent pickup but they were all out of their cars and having conversations and so I think it reminds a lot of that event and at the time where we lived, it was the home of Massey Energy, so it's not just Upper Briggs branch that was concerned with the mine explosion. Everybody and their brother worked for Massey within 200 miles of where we lived, so, it was not at all concerned about the environment, but concerned about jobs, safety, and who was responsible and what was going to happen."

10. "Just being really, we were fairly new to West Virginia at that. Well, we lived in Kentucky, but I worked in West Virginia, so we were fairly new to that area and I was just trying to understand Appalachia. It was really different to me, so I was very preoccupied with our environment, my work, and not really tending to other things."

11. "It reminds me that my husband was very interested and I know we had conversations about it at dinner, I can't really remember any of them, but he loves the news, he always turns on the news and, oh, this happened or that happened, so I remember him talking about it."

12. "So, I think mainly what it made me think about later was the other unrelated event but was similar, and just feeling like, wow, this is crazy and tragic how, you know, all these things are so different, like there's all so many things going on, but then there are, you know, some things where people have the experiences that you are having are, is exactly the same."

13. "I a little bit remember just kind of seeing some like the guy from the Department of the Interior and stuff, and it's like, OK, I remember this being in, it's very clearly a different administration, and I can remember just kind of having more confidence that people would do the right thing. And that certainly that there would be just having a lot of confidence in people in positions of authority."

\section{Subject 007}

1. "I actually don't remember that much, all I know is that it's like, it's a tanker that spilled oil it was carrying in the gulf, but that's about it."

2. "Not me personally, but I know my fiancee at that time, because she's a, like, an environmentalist-type of person, she was really mad that the company let it, let that happen."

(Interviewer: “Anything specific or just her general demeanor?”)

"I think her reaction was more of the aftermath of it, not the actual news event, like how the company is not taking the blame or not, not taking actions for what it's tanker did to the gulf."

3. "Actually, I might be thinking about another oil spill. It's not what I was thinking. I might have been thinking about another oil spill."

4. "I forgot that there was a lot of workers who lost their lives in that incident. It was that, I forgot that it was actually an explosion, not an actual spill (oil) spill." 
5. "I think that covers it, that it was an explosion, and lives were lost.".

6. "No, I actually don't know about this."

7. "No, I don't."

8. "No, I don't."

9. "Well, it helped me to think that it might, might be a different oil spill that I was talking about."

(Interviewer: "As far as like, the, any personal experiences?")

"Yeah, I really don't remember, just that story."

10. "No, yeah."

11. "There's nothing really, because I don't remember hearing this story at all."

12. "No."

13. "I wish I heard that before, I wish I remembered that that happened, but no. But that was a fascinating story, and I wish I had heard about it, because that would have been something I would have followed."

Subject 008

1. "Yes, I did remember, I mean I do remember that news, especially because when I moved to that city where I was working for an oil and gas related company, so we followed that news more or less closely because that was our business and so, but what I mostly remember in that moment was that I usually used to ask what happened if instead of a British company, a Mexican company would have the same error? So, I usually think about Mexico being invaded by the U.S. because we spilled, we produce and spill in the Gulf of Mexico, so, but it was my question during many days while that news..."

(Interviewer: "Sort of what if the situation had been reversed and it was a Mexican company?")

"Yeah, if that was the case! Of course, we would have, you know, very huge trouble, but yeah, UK, they took it very well... I don't know how to explain it, but it was a problem between two economic doors, at the same level let's say, so that's why the problem didn't go beyond the technical issue."

2. "Personal... The only thing personal that I remember was that some of my colleagues at the refinery company were planning to travel to the Mexican Gulf because of the spill, the project had to, how would you say, be lost? Because we didn't know exactly what was going on in the Mexican Gulf, so they could change the plans, some plans, big trouble, something."

3. "Like I told you, it matches many facts because I was working at, as a chemical engineering, engineer in Mexico at that moment, so, we followed that news because the company was oil related, and I also remember that in that moment the Mexican government was trying to start with the, with some energy reforms with the laws, so, many people and politicians took advantage of that oil spill to say hey, that thing about taking oil from the ocean is very dangerous, so we should start reforms to the Mexican private companies. So, at that moment, the government was trying to get the program through from the energy related to oil, that's what I also remember." 
4. 'I don't know if I forgot or not, but I didn't know that there were some people were dead? Or that there were dead people? We followed more the control of the spill more than the people lost or missing in the explosion."

5. "There about the dead people. Yeah, we knew that the spill and that it took many days or weeks to re-control it, but not about the dead people."

6. "I didn't know about this specific video, but I knew about some other videos online, yes."

7. "Yes, I remember that we talked about oil and gas platforms, every time we saw this video on the news because a lot of my colleagues or partners on the job, they had already visited similar facilities in the ocean, but on the Mexican side, so they used to tell a lot of stories about those facilities, especially related to the safety of those places. Those places are really famous in Mexico because they are very, extremely dangerous, so, since they are owned by the Mexican gas company, most of the accidents and fatalities are not spread in the media, they are kept very secret. The only people who know about those fatalities are the people who actually work on the..."

(Interviewer: "So, in that sense, eye witnesses to what happened.")

"Yes, so in that moment I knew about a lot of people who (were) dead... so a lot of conversations about the details of the stories by my colleagues."

8. "Probably the first thing that I thought was what I told you in the beginning, what would have happened here if a Mexican oil company should, or could be the responsible one for this? That was the first thing that I thought about. In addition to that, I don't remember anything else."

9. "Yes, I personally remember that I was shocked when some of my colleagues told the story that in a similar facility but belonging to the Mexican oil and gas company (caught) fire, but the part of the platform that caught fire was the living room, how would you say, the place where the workers used to live, so not the processing part of the platform, but the living..."

(Interviewer: "Not the living room, the living quarters?"

"Yes, the living quarters caught fire, because they couldn't escape, the workers got trapped in their dormitory, and most of them you could call dead and burned, and their bodies were thrown into the ocean, and that was the end of those workers."

10. "Not really, it was just, I was probably remembering that in that moment I was thinking on going to the master degree program, going to graduate school to move (from) Mexico City, because that was what I was planning to."

11. "I think it's also, it reminds me too much because I was following the news closely because of my job. But I normally, no, I related it more to what I heard about similar accidents, but in Mexico, that's what I produced, produces more feelings than."

12. "I think about, right now, what I usually do in that job. Until now, I'm remembering that we, well, we take a train, I took a train to get on board those facilities, and I received a card, it's something like a passport, but it's a passport used for ship and ocean activities, that demonstrates that you are capable of getting onboard of a ship, or one of those facilities. So, I never use it because some other person, so the company...but I was really excited about having that card. But once I heard about the numerous accidents and that we knew about the British Petroleum, I felt really, really happy at the end not to have to go to those really dangerous places." 
(Interviewer: "OK, that's interesting. I did not know that you, you know, had to have like a certification card.")

"Yeah, a certification card that they stamp every time you get onboard a ship and get on the platforms."

13. "I think I felt just a little bit less than the previous video because I, they are only related to stories that someone else told. Let's say from the first video, let's say, what, 10 ? And for this one, it should be like, 7 probably."

(Interviewer: "On a scale of 1 to 10?")

"On a scale, yes."

Subject 009

1. "BP totally jacked that up. People lost their lives and they shouldn't have. Watching all of that oil spill into the ocean and the plant life and the animal life that was destroyed over it. And I don't remember how many people lost their life, but it was several. That was so bad. Bad situation."

2. "I don't remember anything personal. I just remember, I do remember watching them cleaning animals and all that kind of stuff. And just the days of watching that oil spill into the ocean and had a camera on it and it was just gushing. They made a movie out of it."

3. "Quite a bit. I had forgotten how many people had lost their lives. So being reminded of the 11 and it didn't show, because a lot of the video showed where the oil was gushing out, that video didn't show it. I remember that so vividly."

4. "How many people. Yeah, how many people. And the impact that the rig sinking would have on the oceanic environment."

5. "Maybe the scaling back of looking for the missing people."

6. "Yeah. Not that particular one, but I do remember a lot of similar ones."

7. "Yeah, we talked about it. That was about 10 years ago. 2018 we would have been moving here to Columbia. Yeah, I talked to my mom and dad. I remember watching it at my parents' house and just talking to my parents about it. How awful it was. And my brother trying to think about when (Hurricane) Katrina happened.

(Interviewer: "Katrina was a few years before, actually.")

"Because my sister, my brother and sister-in-law had lived in Louisiana and her dad had worked on an oil rig. He was an engineer for those oil rigs. So, I remember, you know, talking to them. I can't remember if they were here or still in New Orleans. But Katrina was a few years before that. That makes sense. I remember talking to them about it. My sister-in-law's dad was called in to inspect and stuff like that."

8. "I just remember just feeling overall sadness for the people, the survivors and those who lost their life. And then for the ocean life, too. I realize that - well I realize that human life is more important, but there was a lot of ocean life that was affected, too, and I know that even today BP is still paying money to people for, for that catastrophe because it was a disaster. A disaster."

9. "Probably just, you know, the time of when it happened. That was 10 years. That would've been about the time we were moving to Columbia."

10. "Yeah, Parker would've been turning four. So, starting a new job." 
11. "Just that it was really sad. I just remember feeling really, you know, not like depressed or anything like that over, but just like you feel like, oh man, you know those people and their families, and when the movie came out, I remember feeling kind of the same way where you just think about all what those people went through really. And what a horrible situation it was. And how much it could've been totally unavoided, I mean it could've been avoided. That didn't have to happen."

12. "I didn't really think much about it because I think everybody, I think everybody overwhelmingly had felt the same way. Like you didn't have anyone saying, oh well, it's no big deal or, you know what I mean. I think everybody was just, you know, was almost kind of unbelievable and then, and it wasn't like Ferguson - there wasn't a lot of tension in talking about it. So, you didn't feel, like you didn't feel uncomfortable talking about. Yeah, two totally different situations."

13. "Well, it doesn't seem like it's been that long, but it has. So, yeah, it just seems like it's been that long. And they still talk about it on the news and the affects it has on the environment. And the fact that BP is going to be paying for centuries for their mistake. The almighty dollar."

Subject 010

1. "I totally forgot it was an explosion. I remember a lot of oil spilling into the Gulf. Remember it affecting a lot of the sea life around the area. I remember seeing lots of people on the beach trying to help clean up the beaches and animals and such. I don't remember much else about that. I remember BP apologizing about it afterwards. They had some commercials. Then I remember South Park spoofing it. That silly commercial they did for BP."

2. "I didn't have any personal experiences other than just seeing it on the news."

3. "I totally didn't realize it was an explosion or an oil rig. I just thought it was like a pipe at the bottom of the ocean, I guess, or something like that. I was totally off with my memory."

4. "The explosion. I didn't remember anybody dying. While I was watching it, I remembered the Mark Wahlberg movie was about that. When I saw that film, I didn't put it together at that time."

5. "I didn't know people died. I'd forgotten it was an oil rig as opposed to just a pipe. (Interviewer: "Anything other than that?") "No."

6. "Just what I saw on the news. But like I don't have any specific."

7. "Just general. Nothing specific that I can remember."

8. "No."

9. "I remember seeing the previous film, (the) Mark Wahlberg movie. I remember being worried about how it was going to take for them to clean up the beaches and how many animals were going to die."

10. "Just that South Park episode."

11. "Probably a 2 again."

12. "I don't remember anything about what was first said about it."

13. "Very little. Actually, probably 1 out of $10 . "$ 


\section{Subject 011}

1. "It happened I think in April or May. It was the spring. I remember that. I remember at some point I must have been, my brother lives in Omaha, and I remember visiting him in Omaha and we had taken a trip to Kansas City. I had gotten tickets to a Royals game and we just made a day of it. We went to Kansas City. We did like the art museum and the Jack Stacks BBQ, and because I remember because I drove with them from Omaha to Kansas City, so I was in the car with them and I remember it was on NPR and we had a conversation like it was such a shame like... it was a catastrophe environmentally...so."

2. "I remember that trip very vividly. Yeah, but it's funny that it connects with that news story."

(Interviewer: Well yeah but you mention going to the Royals game. You happen to remember if they won or lost?)

"I don't remember if they won, it was, I had gotten 4 tickets and my niece she was just, let's see, a little over a year old. And so, I was going to babysit my niece and my parents and my brother and sister-in-law were going to go to the game, and I had gotten the four tickets for Christmas for them. But then we ended up getting a fifth ticket and just all went to the game. Because I think I had won the ticket in like a raffle or something."

(Interviewer: "So, you brought the niece in with you?")

"So, we brought the niece."

(Interviewer: "And she got in free, I guess?")

"I think so or I don't think we had to (purchase a ticket). She was like a month and she just sat on someone's lap. So yeah, so, I remember like I really have no idea. I don't really care too much about that."

(Interviewer: "So, she was just then born not too much before the Deepwater Horizon?")

"She was, because this was in '10, 2010, right? And she was born in '09, so she was like 13 or 14 months. So, she was like a little over a year old. Yeah, a little over a year, did I say a little over a month? Yeah, because I remember we went to NelsonAtkins (museum) and I remember my sister-in-law got a picture of us, like she's got Charlie, my niece, strapped to in one of those things - you put them in on your stomach to carry them."

(Interviewer: "And I think you said Jack's BBQ?”)

"Yeah, (and) the art museum, we did that. That's the only time we've ever done that, so that's why I remember it at all. Usually, if I see my brother, it's in Omaha and we stay in Omaha and like that's the only time we've ever done that."

3. "I think it concurred pretty well. I don't think I remembered exactly how many people had died. But I remember that, but just generally all the thousand gallons of oil and all the cleaning up."

4. "Yeah, I think I didn't remember there were so many who were or at least who were still missing, the exact number who had died. I don't think I had forgotten that part. Just because they kept going to clean up and the continuing thing. And I think the baseball game must have been a week or two after, because it was still on a news story that just kept (on), it just was in the news." 
5. "So, I think it was pretty factual. What I remembered."

6. "Probably similar, (but) I don't think I'd seen that particular one. I'm sure I've (seen) the similarity."

7. "Yeah, I remember that conversation in that trip from Omaha to Kansas City. I remember discussing that, you know, with my brother and his wife. It's just tragic, horrible environmental that it was."

(Interviewer: "Remember anything of their take on it?")

"Well, I mean they thought it was awful. I mean I think we all agreed like we didn't think we should be drilling out in the ocean."

8. "I think my memory is more in the aftermath. I don't remember specifically where I was. Just because it was a continuing story that just kept going."

9. "I think we touched on that a lot. Just remembering that whole Kansas City trip. (Interviewer: "Yeah it does sound like you agreed to it was something very special because it wasn't normal.")

"Yeah, it wasn't the norm."

10. "Probably just that. I can't think of anything. Just spending time with my niece. We might of, it was like we went and saw some fireworks in Omaha. It wasn't the Fourth of July. It was a special festival thing. I think that this festival, the Eagles were playing, I think. I remember something to that. Or some or the lead singer had died. I don't remember, but I don't remember when he died. I don't remember if we saw the original or if..."

(Interviewer: "Glen Frey?")

"Yeah, I don't remember when he died like if we actually saw him. Yeah, because I remember they played Eye of the Tiger and my dad, he like loved that song. He like loved Rocky and I remember them playing that song. Yeah, anyway. Well did the Eagles do that song?"

(Interviewer: "If memory serves I think that was by a band called Survivor?") "Survivor! That's who it was. It was not, no it was not the Eagles, I think it was Survivor actually we saw. I remember them playing that song. Yeah that's the song. It was Survivor and not the Eagles. Or maybe they were both there because there might have been a couple of bands there maybe. Because it was like a festival. But I do remember that song being played because like as soon as I said that, I was like sad."

11. "I guess it reminded me of just feeling like, you know, this is going to have widespread consequences for that region. And things are just a feeling of being helpless to do anything about stuff like that. And also sort of family stuff, being happy and having memories from that time."

12. "I think a little bit, yeah."

(Interviewer: "Anything specific that you can...?")

"That I said or did in relation to the news event?"

(Interviewer: "To that time.")

"To that time? I mean just that trip and excursion thing."

13. I can like see myself being kind of in those moments and that time period. You know, my brother's old house. They've moved since. Going back to that hotel room in Kansas City, it was a horrible little hotel room. Cheap one near the ballpark. Going to the museum and I remember seeing the Verdant statue that's in Nelson-Atkins." 
Subject 012

1. "Not nearly as much. I do, so my husband's from around the Gulf Coast area, so that there was a big concern about the environmental damage. What it was going to do to the beaches. I remember seeing it on fire. We were watching a news video and seeing it on fire. And I never watched the movie. So, I don't have that as a backdrop to set it on. Know it took them a long time to stop the leaking, like an insanely long time. And I do remember a lot of discussion in the newspaper and in the news media about why this was allowed to happen in the first place. Because basically the presumption was that all pipelines were going to leak eventually. So why are we letting them destroy our environment in the means of getting oil. And so I don't remember the specifics about what happened or what caused the pipeline to rupture. I just know it took an incredibly long time and I do remember the video of the leaking pipeline. That was one in the underwater where the oil was just like rupturing, coming out of the rupture. So, I do remember that piece of it, but I don't remember why it ruptured or what really happened after that except that it took an incredibly long time to stop it."

2. "I don't. I don't remember anything because it's been a long time ago."

3. "So, of what I remembered, what little I remembered, it did at least reinforce at least the small amount I remembered was actually accurate."

4. "Yeah, I had forgot that the platform had collapsed. But once I saw it, I was like, oh yeah, that's right. And then, I don't know why but I did not remember that there were 11 crew members missing. And I don't even think, I had an awareness of that until they actually brought it back. Like I don't think that I remembered that there were 11 crew members that were missing off of it that they didn't find."

5. "I think, I mean, it may have been a vague thing, but it was definitely surprising when I was like, oh. Then like the fact that the BP called off, kind of like pulled back the scale of the search because they just assumed that they were dead. I didn't remember, I didn't remember that at all."

6. "Yeah, I had watched when the originally explosion had happened. I know I had watched some videos because I remember seeing how I knew about the burning. I remember watching the rig being on fire. Also, the environmental impact. The oil did end up washing up on part of the gulf coast. It was weird."

7. "I mean, I can't think for sure. It would have been likely I would have talked to my husband about it because it would have impacted the area he's from. But I can't say with 100 percent certainty that we had a conversation about it or what that conversation actually was."

8. 'No, because I don't even remember what the time period was. It didn't indicate in the video, so I don't even remember what would have been going on at that time. I mean, I know I was married. So at least I have a good range of like where it probably was timewise but not the actual what I was doing personally."

9. "I think so, I did remember so, like after looking at the oil spread, I do remember, like that clicked with me, that later on there were actually a lot of cleanup on the beaches because the oil, they didn't completely contain it. It actually did start washing up on the shore. I remember Pensacola had an issue and the reason why I do remember that is because we were actually planning on going to Pensacola several months after it had occurred. And so, we were like, great. Now the beach is going to be completely 
destroyed because there's like the oil everywhere. And they were like still actually when we went down there, there were remnants like little oil like bubbles or pods that had got stuck in the sand that still existed on the beach. So, I sort of remember that piece of it. But outside of that not really much. And mostly because it impacted me going down there. And so that I think is why I probably remember that the most."

10. "I don't really have a clear idea of what the month or the year was."

11. "It definitely brought back the devastation to the environment because even though I remember seeing the pipe rupture and watching that video. Just seeing that spill like going over the Gulf and the bay area. It just brought up a reminder of how devastating that environment impact was from that spill."

12. "I still have vague memories of when that actually was, so I don't really remember what I was doing at that time."

13. "Yeah, it's sort of like that previous situation where it's a lot of watching and comparing to what I remember about it and seeing if my ideas were correct. Whether there were new things I was learning and, but it did kind of bring flashes back until like well as I mentioned before, the Gulf Coast. The beaches, the beaches what happened with that. The cleanup efforts. So, it kind of jetted me forward to what I knew happened successively after the event, but it was definitely down the road. It wasn't within the next day or two, after the event happened."

Subject 013

1. "Not a ton, at all. Any other comment I would make would just be speculation, but what comes to mind is the welfare of animal life and thinking about the equipment."

2. "None."

3. "Definitely the concern of the wildlife and the ocean. But I had forgotten about the human aspect of it that (people) were involved and missing."

4. "I hadn't mentioned there is an economic issue, the loss of gas and derivatives of such an explosion."

5. "No. Right."

6. "No."

7. "No not explicitly. Sure, I had a discussion with my father at the time. Oil prices and the impact."

8. "Nothing."

9. "No."

10. "No."

11. "Compassion for the people whose family members were missing. What a mess. They'll never clean up something like that."

12. "None."

13. "I think significant, but just really recalling the event because I indicated before I couldn't quite place it specifically. But certainly, when you see the smoke and the damage to the rig, it does take you back and you really remember. It seems to be it was a very catastrophic event." 


\section{Subject 014}

1. “It's been awhile, hasn't it? I remember, this was an explosion on a rig, south of Mississippi or Louisiana. I feel like some people were killed. I remember the responses to it being like, they had all these funny names for the ways they were going to plug the leak and everything, and I remember gallons and gallons and gallons of oil being released and they were putting surfactants into the ocean to try and break it up into little particles. I remember the animals we were trying to rescue with Dawn. They were still trying to actively market themselves like that. I remember at my work we had visitors who were saying this is the beginning of the end of our ecological systems. There was a sense that this oil spill was going to wipe out the ecology of the golf, and it would just, snowball from there. And I think Obama was highly criticized and he eventually tried to slow down the offshore (drilling)."

2. "I think I was kind of hopeful that this would be a wake-up moment. Like, whenever we talk about extinction events and like, this is close to home and is so clearly a negligent regulation system but also a negligent company, trying to make the most money even when there are alternatives. There needs to be a moment where we stand back and say, this needs to be a turning point. I think I might have been optimistic about that, and definitely pessimistic about our future. I'm not going to say I embraced the mass extinction event theory but I was very concerned about the ecological system in the Gulf."

3. "I think roughly it concurs. I don't remember how many people had died or that the entire platform had collapsed like they said. It helped me remember just how long it took them to plug the leak because this is very obviously kind of an optimistic, I mean like, 8,000 barrels a day, and it went on and on and on. I believe it came out later in the news that they were lying about how much it was leaking. At first it was like, yeah, it's 8,000 and then, no, it's 20,000. Way more than what they were telling us at first."

4. "Definitely the fatalities. I think when you first asked me I was unsure if people had died, and that was clearly not the most important part."

5. "The collapse of the rig and I think I knew that it exploded. That makes sense that that was probably part of the reason why it was so hard to plug. It had something to do with the way they had put the tubing in was why it was so hard to plug after the actual collapse."

6. "This particular one, no. I don't know of any specific ones. I'm not surprised that it exists. It got a lot of coverage at the time, and for many months because it took so long to plug up."

7. "Just that specific one about the guy coming down (inaudible) at the end. I think that stands out in my mind because I'd never seen it quite that tragically. I think I did say, whoa, yeah, I need to start revaluating just how serious it is. A friend of mine went to help clean up but that was a little after. I remember that and I know he wasn't allowed to talk about anything he saw because of the lawsuit." 
8. 'I don't recall anything specific...I'm trying to remember where I was living at the time because that helps sometimes. Like whom would I have been around at the time? No, I don't remember anything specific."

9. "No."

10. "The spring of 2010 I was working on extractive industries stuff, and oil and coal were both part of what I was doing, but I can't say that I recall anything specific. I'm sure my response was, 'Here's another example of how horrible the extractive process is for the communities around it and the broader ecological systems.' Yeah, I really do have a horrible memory. I was living in Columbia, and we had a group that comes from Appalachia with coal mining experience and their communities were being removed and we were visiting coal-mining communities in Columbia. So, I'm sure it was the trip I remember talking to this guy about how everything was bad. The mass extraction process."

11. "Just again that conversation with the guy about mass extraction. Also, kind of the sense of dread and fear and regret of how did we get ourselves here, how hard it is to make a ship change course."

12. "Nothing specific. I'm sure I talked to my family about it; my parents, over the phone. They usually have a response."

13. "Not too much. Unfortunately, we have too many of these tragedies and they all just start blurring together."

Subject 015

1. "OK, so they have the oil that they were drilling from the ocean floor in the Gulf, and there was that horrible leak and they couldn't get it under control for weeks and weeks and it was spilling. There was all kinds of negative impact on the environment and animals and it affected the tourism along the Gulf and yeah, just a lot of significant impact on the environment. They finally got it under control and stopped it but that cleanup process took a long time and might even still be going but I think for the most part it's done."

2. "So, I don't remember that as clearly as the first one, I think I was still living in Illinois. I don't remember as much, but I'm pretty sure that I was done with pharmacy school and I was married at that point, but I don't think I had kids, maybe my first daughter?"

3. "The one thing I didn't remember it all, was the loss of life, which I feel kind of bad about the fact that I remember the environmental impact but not the loss of life. So those figures were new but everything else concurred."

4. "The deaths, I didn't remember them at all. And now that I'm aware of the timeline, I'm much more clear on what I was doing in my life at that point."

5. "The loss of life. I mean that's a big detail I feel like I should remember whether or not I knew it. I guess it was one that I didn't remember."

6. "Not this specific video but it was all over the news."

7. "Yes, so I would have been living at home at the time, about to graduate pharmacy school, so I was living with my parents, so I'm sure we had conversations although I don't remember specific details. Just more of the amazement at how much oil was spilling out, and the rate and the pressure of the pipe and the size of the pipe and how 
huge all of that was, the technical details. I'm not sure I was even aware they were drilling in the ocean at that point, so just amazement of how big it was."

(Interviewer: "If I might follow up, are you certain about that, that you were not even aware that they were drilling in the Gulf prior to this new story?")

"No, I really didn't know about that. I was engrossed in pharmacy school at that point in my life."

8. "Not the specific day, but in April of 2010 I would have been on my very last rotation a pharmacy school, and studying for boards. So that was kind of my main focus. So I was probably on my rotation that day and I wouldn't have even thought of the news."

9. "Yes, so I was on my last rotation of pharmacy school, I was about ready to graduate, I was excited to be done, and I had been accepted to a residency program in

Kentucky. So, I was getting ready to move and to get my boards, so there was just a lot of excitement around graduation and starting my first job. I had gotten engaged a month prior, so that was so exciting. So, it was a lot going on."

10. "All those things I just said."

11. "It reminded me, the first one, probably because (inaudible). But it did bring up some reminders. I guess with this one and help recall more of what was going on in my life at the time versus the specific details of the new story itself."

12. "Just in general, I guess it's it brought up more of what was going on in my life outside of the new story, but I can't recall any specific conversations. I remember talking to my parents about it but that's it."

13. "Oh, definitely."

Subject 016

1. "I remember being disappointed of yet another oil spill. I always worry about the animals. I remember watching some of the footage with my daughter who was very little at that time and we saw them pull animals out of the muck. Also, just being disturbed and angry that someone didn't do something about it sooner and didn't take precautions beforehand."

2. "I had to explain to my daughter how this could happen and about how we would have to take care of the animals and trying to explain that we were going to have to clean all of this up and that this could still happen again, so, yeah."

3. "I had forgotten all about the individuals that had been on the boat. It's not that I had forgot that humans have been killed but for me it was more of a focus on the environment I think. I feel bad that I forgot about the humans, but, yeah."

4. "The human toll and the people waiting for family members so they could reunite. I remember that now. It was really hard for people to wait and see."

5. "I guess that not everyone on the rig was killed. And that they had actually tried to clean up the spill, I guess I forgot about that, that's not something that stood out to me as something I remembered, were their efforts on the cleanup."

6. "Not specifically, but again I feel like if I wanted to find it I could, but it wasn't necessarily a (problem)."

7. "Just what I remember about the environmental impact and my daughter, and my best friend, she lives on the Gulf, so I remember speaking to her about if the oil reached 
the shore and that impact, and that's really it. I probably talked about it to my parents or something."

8. "Nothing really."

9. "Talking with my best friend about the impact on the Gulf. And that the individuals were killed."

10. "Not really."

11. "Not really."

12. "A little bit. Just the call to my best friend."

13. "Mildly. It was unlike the first one in that I wasn't emotionally involved as much in this one."

Subject 017

1. "I remember that's when they were drilling and the whole thing exploded, but I thought that was more than 10 years ago. I don't remember specifics, but I remember thinking that something about the way they described it made me think that the people who are drilling it we're really stupid and they should have known better. It made me worried because I have BP stock and I was concerned about the effect that it would have on my stock. I thought I discussed that with someone, I might have, I'm unclear, I don't know who I discussed it with, but I do remember being concerned."

2. "I don't remember anything personally, I don't even remember what year it was."

3. "Not at all, because apparently I was confusing the explosion with the underwater drilling. That's what I was initially thinking, they broke a pipe when they were doing underwater drilling or something like that and oil started spilling out and because of the pressure of the water around it, they weren't able to fix it, they were having trouble sealing up the pipe. So, not at all because I just don't remember."

4. "Apparently all of them, I'm not sure that I actually saw that story."

5. "Most of it. I must not have been watching the news for a while when that story came out because I really don't recall it or like I said I just don't, I don't know there was a lot with BP and oil spills going on in some period of time, so I could have gotten them confused."

6. "No. I didn't do a lot of online searching, I didn't look at a lot of online videos."

7. "Apparently not, no, I was thinking of something else, so no, I don't remember."

8. "I remember you asking me questions (laughter)."

(Interviewer: "I'm going to follow up with you had talked about being concerned because you did have BP stock at the time. So, can you elaborate more on that?") "Yes, I was thinking, you mentioned the explosion and I was thinking of, I remember they were talking about expanding underwater drilling, and they were doing drilling, they were going to go to areas of oil where it's normally not easy to reach, and they were doing this underwater drilling where they install the pipe and it split, and it was deep underwater, and there was a lot of water pressure, holding the oil in and maybe there wasn't an explosion per se but that's what I was thinking of, because I remember thinking that was BP also, and that's what I was thinking of. But it was a completely different story."

9. "No." 
10. “2010. No I think my cat died and that's it. I was just plugging along, and I don't remember anything else. I had a lot more energy back then."

11. "Because I might have been slightly anxious about it, but I don't remember being more worried about my BP stock now that I was back then. I don't think that I thought this would have a significant impact on it. But I guess because I wasn't aware until after and it didn't really have an effect and I didn't know any of the people, so yeah."

12. "I didn't."

13. "It didn't give me any sense of going back because it wasn't a significant event in my life that was actually memorable to me at all. It wasn't, it had no influence on me whatsoever, so I don't remember going back. I mean I probably was vaguely aware of it happening but it just kind of, in one ear and out the other. It was on the periphery, it didn't affect me, and it wasn't enough to even stick in my memory."

Subject 018

1. "The only thing I can think when you say that is I remember there being an oil spill at one point in time and a lot of animals being affected and being concerned about animals, but I don't remember specifically if that's the incident I'm thinking of."

2. "No."

3. "The only facts I remembered it was the spill and the animals, so it did match that."

4. "I had forgotten about the people missing and the rig explosion, I forgot the entire premise of what caused the oil spill. The only part I really could remember was the oil itself just being in the water."

5. "I feel like it helped me recall the explosion, but I didn't know or had forgotten if I did know, the number of people impacted on the rig and those that were missing. Those statistics, if I did forget them then I still don't know."

6. "No."

7. "No."

8. "No."

9. "The video just helped me to recall, the occurrence of the oil spill, just that, nothing personally when reflecting on it."

10. "No."

11. "It did remind me of talking about the spill and sort of whether or not this was going to affect gas prices because that's always a concern; if they were going to get it contained and how the animals were going to be affected in the water. Whether it was going to spread and how serious of a disaster this was going to end up being on the economy, and on the ocean. I remember that just almost being a bigger deal then the people missing, which is kind of how I reflect on it."

12. "I remember just generally discussing it but I don't remember anything really specific about it."

13. "I did while I was watching it, feel like, had a sense of sitting there learning about it and the feelings I had watching it on the news whenever it happened." 


\section{Subject 019}

1. "I remember that it was, it was a big oil spill, and I remember people boycotting BP for quite some time, I still don't like to go to BP stations, like, like I still, like any time I drive past one I still think about, yeah, and I remember it went on for, it seemed like a very long time."

2. "I don't know. I remember not, like, going to the BP gas stations, but, we don't really have many here, it was pretty easy to avoid."

3. 'I didn't remember any of that, I mean, I didn't' remember that there were people missing, I didn't remember that it exploded, yeah, or sunk."

4. "I mean, I guess if I knew that stuff at the time, but like, I don't remember any of that."

5. "Yeah, I did, and I didn't know that like, I guess I did sense that there were people on it that were rescued, but like, I didn't think about that ever. Well, all I thought about was all the oil leaking into the Gulf."

6. "I had never seen that video before, but, yeah, I mean I knew that there were some."

7. "Not really, there wasn't really anything to talk about, you know, it just, it was what it was, you know, it wasn't, there weren't different sides to it, it was an event that happened, you know what I mean?"

8. "Nothing. Yeah, no."

9. "No."

10. "What was going on in my life then? No, nothing really, other than trying to not go to BP gas stations. Yeah. I don't know, I guess because that's like the only thing that I, like, you know, that's the only response that I could have, you know, it's not like I could have gone down and helped clean up the oil spill, you know."

11. "I did have a friend living in New Orleans at that time, and I do remember like, because she's an environmental engineer, so like I do remember reaching out to her. She was in a different part of Louisiana then, and she was living in New Orleans but she was working somewhere else."

12. "I guess a little?"

(Interviewer: "Again, you mentioned purposely avoiding BP, meaning BP gas stations.")

"Yeah, I don't know, I guess I definitely like vilified BP after that, although, like I have no idea if it was actually their fault, or like, if it was anyone's fault. It was just like, tragic accident, you know? I still have no idea. This is why I don't watch the news. I feel like it's manipulating me."

13. "A little, yeah. Definitely didn't have as much emotional impact as the first video."

Subject 20

1. "I remember that there was a big oil spill off the Gulf Coast. I forgot, or I just remembered that that the oil was spilling for a while and then it took a while for it to get stopped. I remember that a lot of animals were killed, and the beaches were at least temporarily kind of destroyed at least in terms of tourism. I also remember 
following it and BP putting an all-out push in terms of perception of the company to show that they were doing the right thing in terms of trying to correct it and clean up."

2. "I remember watching this with my husband and son because we watch the morning news together. I don't remember any conversations or interactions around the story, but I remember us being together watching the story."

(Interviewer: "As a follow-up question, watching the morning news with your husband and son, how frequently would you characterize that as something you did?")

"Every weekday."

(Interviewer: "For how long?")

"It was something my husband and I always did together and then when our boys were born they would just hang out with us while we watched, and it was something that went on for years. It's been a really good contact for us to talk about what's going on in the world with them, they've, it's given them context of everything that's going on and it's been a way for us to be able to communicate with them. So, it may only be 15 or 20 minutes that were all there in that spot but it's usually like 7 to $7: 15$ and we get the morning overviews."

3. "All of the facts that I remember did fit with the story. I don't think I had anything wrong."

4. "I actually forgot that there was an explosion and that people died and were missing. I remembered more that there was the spill in the aftermath but had actually forgotten the explosion."

5. "There wasn't anything that I didn't either remember or already knew, so no new information."

6. "No, I don't think so."

7. "Now I remember my husband and I talking about those days that follow the initial explosion when they were trying to figure out how much was leaking and how to stop it. And I remember both of us talking about how it felt like it was taking a long time and that we were surprised there wasn't a quicker or more obvious solution of how to stop the leak."

8. "I don't because I remember more of the days following, it's more of a group of days in my mind rather than a specific initial memory."

9. "The only memory is that I knew I had never visited the Gulf Coast and I remember talking about wanting to go and then I remember thinking, well, I guess we don't want to go right now, we'll hold off on that for a while."

(Interviewer: "Have you been since?")

"No, I've been to New Orleans for work but never to that part of the coast."

10. "I remember my son being a toddler or preschooler, nothing specific, I just remember watching the morning show with my husband and son before he went to preschool, but I don't remember that time in particular."

11. "It definitely did. One of the big reminders was about how tragic it was with the explosion of people dying and missing and the number of days they were missing. I remember the environmental impact and how tragic it was."

12. "Somewhat in that it did help me to remember the explosion part and remember feeling sad for the people involved and worried for their relatives." 
13. "Yes, I experienced that. For example, my son being a preschooler is a good example of sort of remembering where we were in our lives."

Subject 021

1. "It was really horrible, but I do not remember the story."

(Interviewer: Were you in the United States at the time the event occurred? Around 2010?")

"Yes."

(Interviewer: "But you don't remember the event?")

"No."

2. "I couldn't remember."

3. "I could not remember that event. When I watch the gave me some sort of idea and now I can go back and remember that incident."

4. "I knew about the oil spill but I forgot about it was in the Gulf of Mexico. I couldn't remember the place, I couldn't remember the details of what actually happened."

5. "Yes. I did not know about the death toll. This video gave me more information on the facts."

6. "No."

7. "No."

8. "I was surprised about how much it spilled over. I had curiosity about how would they manage the oil in the water. They say that BP has tried to stop but then how do they separate the oil from the water. I remember the technical part."

9. "When I first I knew about the title of the event, but I did not know where it happened or something like that. This video really helped me to go back to try and recall some of these things."

10. "No."

11. "Like 90 percent."

12. "I was thinking about the management of the spillover because it happened and there was no way to stop it. They were just trying to manage the leak and deploy a crew member to manage it to stop it from spreading. That's the main interesting part to me. I also didn't know about the extraction process (inaudible). I didn't know about the welding, how they would draw crude out. This video gave me the opportunity to learn."

13. "Yes. I really like to watch the news and I really want to learn how they manage something this big."

Subject 022

1. "Was that the one where there was the oil rig out in the Gulf and there was the oil spill?"

2. "I don't. It seems way longer than 5 to 10 years ago."

3. "I did not remember very much at all about that news so some of that was new."

4. "I don't remember there being 11 missing. I still don't recall that."

5. "I think the 11 people missing was probably new. I don't remember hearing a lot about that. I guess I didn't know that they had the containment vessels that were 
keeping the oil from going towards the land. I don't think I knew that the rig exploded. I was just kind of thinking that there was just some massive oil leak. I don't remember the fire."

6. "No, I just remember hearing about it. I don't remember watching any story about it."

7. "No."

8. "No recollection."

9. "No."

10. "No. I don't even remember when it happened."

11. "I remember that my mom has always been into recycling and not littering. Not a huge tree hugger like Save the Planet, but there was an oil spill. When I was I thinking fifth grade in the '90s sometime, I remember doing a science project about separating the oil from water in the classroom, and just remembering I think we were using straw or something to soak up the oil, and just remembering how massive however many barrels they said were in the ocean and how much of our resources it would take to remove that oil or contain it."

12. "I don't remember the time of the news event."

13. "Nope."

Subject 023

1. "I seem to remember that it was a faulty bracket over a clamp or something that had ruptured and it started leaking oil in the Gulf of Mexico, and it literally went on for weeks. It was leaking thousands of gallons a day into the Gulf of Mexico. It was so deep and so much pressure that they were having trouble getting it turned off. After the fact, the reports were that it was going to affect biological life in the gulf for generations and that they had actually started a whole new field of research on how to clean it up. They were making nets of human hair, I think, or flotation things that were made of hair that would soak up the oil and they could skim the surface of the water. And that it would affect the fishing industry as far as shrimp and other things because now that was not only being killed off, but even if it wasn't dead, if you harvested it, you couldn't feed it to humans, because it was contaminated."

2. "I would have been getting married maybe she would have been a baby, Or maybe we were expecting a baby. I remember I was pretty happy five or 10 years ago, my relationship, I don't know if we were married yet, we had just moved back here in 2008 and that's 10 years ago, I was just starting at the university, so, yeah."

3. "I wasn't even sure I was remembering the same news event. When you asked me before the video, I wasn't aware that the platform had collapsed, I wasn't aware that 11 people had died or been missing. as I watched it I was like is the event that I remember a separate event in the Gulf like just a rupture in a pipe, and then when they said it was British Petroleum, it was like, oh no, that's the same one. I just didn't realize the extent of what else it happened besides the oil spill. I remember them having problems with how they were going to get it clamped off because it was so deep. Like how are we going to put a cap on the pipe now that the rig has collapsed?"

4. "I would say the platform and the dead people, but is that even something you can forget if you didn't remember?" 
(Interviewer: "That seems like it relates to the next question, which is about facts you didn't know before watching the video.")

"Yeah, like I remember seeing the Mark Wahlberg commercials for the movie about it, but I never saw it, so I don't really know what facts I didn't know and what I'm just now remembering."

5. "Nothing comes to mind."

6. "Yes, I remember similar videos but I didn't know about this one. But I remember a video where they had cameras down on the ocean floor, and while there was oil on the surface they still had deposits of tar and crude oil that were settled on the ocean floor that they didn't know how they were going to clean up."

7. "A lot of people compared it to the Exxon Valdez spill. Like this was the next biggest thing that had happened. I can't remember anything else right now."

8. "From that I don't remember anything specific going on in my life." (Interviewer: "Nothing that stands out?")

"No."

9. "No."

10. "No."

11. "It was minimal. There wasn't a lot of anything triggered as far as a memory or emotion that came up."

12. "There wasn't anything that came up other than when you asked the question. There were conversations in reference to other oil spills that have happened."

13. "Not very much."

Subject 024

1. "I remember that there was an oil spill and that it was badly handled by BP. I remember that the $\mathrm{CEO}$ of $\mathrm{BP}$ gave what is probably one of the worst crisis responses ever, saying he wanted to have his own life back and he was seen as having no empathy for those who were severely hurt by this company's mess up. I remember at the time I don't know if I was in Denmark or the U.S., but I saw a video or heard that the politicians said that this could only happen because of the power of lobbyists in the U.S. They had lobbied to remove safety standards, so they didn't have to have something that would have stopped it. Sorry, I can't remember the technical terms. They could have saved a tiny bit of money by not having that extra security there, and they didn't, so now we have a disaster on so many levels. And then of course it had some severe consequences for the environment, And for the people in that area, fisherman, as well as tourism. It was in the Gulf of Mexico. The CEO of eventually retired or resigned his position, and there were efforts to clean it up, but they were not the most successful efforts."

2. "I don't remember any. I'm trying to pinpoint when it was, but I don't remember. I worked with this a little bit later when I was teaching classes, but I can't remember."

3. "I was surprised that I did not recall 11 people missing from the platform which is obviously horrifying. I can't believe that I forgot those. I remembered that there was an explosion, but I didn't remember that there was human tragedy involved. They didn't know if they were missing or if they were dead but when it was reported, it seems pretty likely that they were dead." 
4. "I had really forgotten the event in itself. I remembered the impact and the consequences and the reactions more so than the actual event."

5. "I don't know if I was completely unaware or had just forgotten that human lives were lost. And then also how long ago it was or how much has happened since then because the video looked super outdated like it's been several years but that's more of the visual side of it."

(Interviewer: "So you're saying the recording shows its age?")

"Yeah I was surprised; when I saw the Ferguson recording, and I know it's not as many years, it looks like something that could have been published today, and, wow, this was different. Logo wasn't pretty and something about the video quality stood out to me."

6. "I knew there were videos about the event but not this video."

7. "I don't recall conversations about this event when the news broke, I might have had them but I don't recall them. I've had conversations about this event later as I talked about crisis communication, but it hasn't really focused on the event itself on the reactions from BP and others."

(Interviewer: "And in your case in particular it became more of a communications teaching tool at some point?") "Yes."

8. "No, I have a hard time placing when this event happened. So if you told me the exact moment, I might remember things, but, no, I don't remember anything in relation to this event."

9. "No, because it feels like new information, I probably heard it before but I don't remember remembering it."

10. "No."

11. "It reminds me of the surprise and indignation that that could happen and the fact that it did happen. I was thinking back to these reports that it was because they saved money on security even though it was very avoidable, it was something that they could have helped, and a lot of frustration."

12. "Not much."

13. "A tiny bit but it was nowhere near as strong as the other video."

Subject 025

1. "The one off the shore of Texas that blew up if I remember right. That's all I really remember. I know that the environment was heavily impacted."

2. "None."

3. "It came back. I had the wrong state, but I remember the big rig exploding."

4. "I didn't realize there were that many missing people, and whether they ever found them."

5. "I didn't realize the rig actually fell into the ocean when it exploded, which makes sense."

6. "Similar to it, yes."

7. "We talk about the news every day, so yeah, we talked about it. You know, just thankful we didn't know anyone in that industry, and how hard that would be to not know where your loved one is." 
(Interviewer: "So sympathy for those affected?")

"Yes."

8. "I remember BP appearing to do the right thing to help clean up the mess, at least the spokesperson was out in the media saying they were making efforts."

9. "Nothing really. Maybe the oil spill in Alaska. The Exxon one? That impacted the environment. It made a connection to a similar incident."

10. "Nothing."

11. "That we still don't have environmental protocols in place to deal with these things. It's the 21 st century."

12. "I don't really have an answer."

13. "Somewhat."

\section{Subject 026}

1. "I remember hearing that it happened. I remember seeing pictures on the news of the water and the beaches and maps of where - I remember seeing the map, I wouldn't be able to pinpoint it on the map. But I remember part of the newscasts maps were involved. I don't remember - I remember there was talk of 'what is this going to do.' I think it felt like it wasn't going to immediately affect anyone. I think I remember the exact day, but I don't remember if this is the right thing. I didn't pay a whole lot of attention."

2. "Not much of any I think. When I thought it would affect me."

3. "I definitely —what I remembered was confirmed with the video. There was definitely some things in the video I forgot about."

4. "I mean obviously I think I had forgotten there was an explosion. The cost, I forgot about missing crew members. Like I said, the only things I remember were the oil spill itself and the environmental effects afterward."

5. "I don't think so. I think at the time I would have went about the explosion, but it's back in the back of head. Or it just got lost, or too much information. Like as far as totally new information, like you may have missed when the news came out. Maybe the number of people that were missing, I don't know if I knew the number was that high. And that's probably about it."

6. "No, I assume there would be news clips, but no." (Interviewer: "You got your news information at the time from television?") "Yeah."

7. "No, not really."

8. "No."

9. "No, I don't think so. Yeah like I said, at the time it just didn't seem like as big of a news deal."

(Interviewer: "Another way of saying you didn't — you remember thinking as the time it wasn't as disastrous.")

"Yeah, like I remember thinking at the time, it wouldn't have the lasting effects that it did and end up being these defining news moments in history. So, I think when I was a really small child I remember hearing about oil spills from time to time, so I wasn't super aware of the situation."

10. "No, I don't think so." 
11. "I think it reminded me a little bit of my concern for Gulf and ecosystem and environmental effects. I think that was my biggest concern. When I was younger, I think the environment was more an issue to me than anything else. I feel like that was more a thing for my parents."

12. "Not much."

13. "I mean a little bit. I just don't remember a whole lot of what I was doing during the time of the event. I mean even watching the video, I couldn't tell you where I was or what I was doing. And like the other one I can distinctly remember where I was that day because I happened to be flying into St. Louis. But for that one..." (Interviewer: "Do you think it was more mundane of a day?") "It was probably just classes and homework. Just a day."

\section{Subject 027}

1. "It was in the Gulf of Mexico. I don't remember exactly what happened but I believe - I don't remember exactly what happened - there was a well down towards the seafloor that started leaking. There was a lot of wildlife, it was owned by BP. Definitely a big call for climate change discussions and things like that and about oil especially and a lot of locations like that."

2. "It made gas prices go up so that personally affected me. Other than that, it was just on the outside kind of watching."

3. "Not that I recall. I don't think so."

4. "Mostly I forgot there was an explosion involved and there were crew members that were missing and died from it."

(Interviewer: "Anything else as far as something you forgot?") "No."

5. "No."

6. "I assumed there are videos about almost anything but I never looked at any regarding this subject."

7. "I don't remember any conversations."

8. "I don't remember."

9. "It reminded me that I was learning about that time how oil can get cleaned up once it's in the water. There's technology to get it cleaned up and stuff. And at that time, I was learning a lot about environmentalism and things associated with that."

10. "I was just starting my first or second year of college, so going through all that kind of stuff. Writing papers. I think I might have wrote a paper about oil, if not this particular incident. So, just going through that. I was forming most of my political beliefs so this was associated with that."

11. "Not very much. I think I had forgotten about the explosion, I'm not sure if I ever really realized the risk of fatalities. I think I had more new emotions associated with watching it than memories."

12. "I think there was a BP station and I went to a lot so I remember, not very in depth, if I should continue to go to that station or visit a different one."

13. "Yeah, I did. Another event I hadn't really thought of for a while. Because it was just a time I was going into college, like, yeah, I remember this happening." 


\section{Subject 028}

1. "With that one, I'm, was that a spill?"

(Interviewer: "Let ask what you remember.")

"I just remember there was an oil spill. And it was really bad. Like really bad. I think, yeah, like, I don't remember about that one."

2. "I don't really remember much from this one. I just don't remember much."

3. "Well, all I remember was, it matched. That was one I don't think I really saw it a lot of. Or I was not super aware of everything. I don't remember people missing and getting hurt. I just remember a spill. I feel like I was under a rock. I just had kids!"

4. "I think a lot that I just didn't know what to begin with. I'm sorry!"

(Interviewer: "So you're saying a lot in the video were things you were not aware of. And what were those?")

"People were missing, that people were injured. Yeah. I didn't know anything about that."

5. "No."

6. "No, I don't."

7. "I do remember that there was - like it was catastrophic. I do remember that if this oil gets to shore. I do remember that being a big deal. I remember this would be really, really bad. Like it was one of the worst oils, like one of the worst oil spills, yeah."

8. "I do kind of remember there was a fear, the oil, coming to sure and it being one of the worst oil spills. Like it would be really, really bad for the environment. I remember that part."

9. "I can't think of any really personal, just the thought of 'Oh, crap that's going to be bad.' The fear and worry, the environment."

10. "I can't think of any."

11. "Just concern I had about the oil."

12. "I didn't think a lot about what I did or said."

13. "Not a lot either. I guess it wasn't very strong memory I guess."

\section{Subject 029}

1. "I remember I remember more about what they did more in the months followings, again, where they were trying to stop the massive purge of oil into the ocean. I remember watching video of the capping process. I also remember watching the Mark Wahlberg movie. That was much later of course. It was just referenced I was watching something last night."

2. "Mostly in our food-related business, we had to make some pretty large changes to where our seafood was being sourced, specifically shrimp. Because we used a lot of Gulf shrimp in our operations and then all of sudden it was not going to be available. And from that time going on, it was just getting to be that much more frustrating from our end and thinking what else is this doing to the ocean if they even can't stop them."

3. "What's funny is that I can't remember if I remember from a news video or if I remember [inaudible]. I don't have strong memories of the operation or the rescue 
efforts. Just more about the months following, there was nothing necessarily that surprised me."

4. "Probably how many people were missing. And I'm still sitting here I don't know if any of them were ever recovered."

5. "Nothing that came to me, I don't think."

6. "Again, I assumed clips like that existed. I don't know if I saw that one, but I saw similar ones at the time that it was going on."

7. "I remember kind of talking about how long it seemed to take to get the fire out. They never it did. It eventually sank on its own. And then just how many conversations that I have about how long are they going to take to do the cap thing and stop the spill. Because I don't have a specific memory of how long it did take. But I remember it seemed unreasonable for the amount of time."

8. "Nothing super vivid."

9. "Just again, some of those conversations about the image of BP following all of that and they really were being shown as poorly ran, bad guy company."

10. "Like I mentioned before, the effect on the food flow on the U.S. Because it had a pretty lasting effect. We've had to change menus and things to remove some of that because the alternative that we were going to have to get was going to be far more expensive. So there were things that we had to change or couldn't offer at all. That I started hearing about from customers."

11. "Pretty well. Like again, the attitude towards BP at the time. I'm pretty (sure) I thought, not that there's a ton of BP stations around here, but I thought I better not go there anymore."

12. "There was nothing I remember saying or doing, other than just seeing their final solution to cap the well."

(Interviewer: "You're talking about when they finally got it stopped?") "Yeah."

13. "Not as much on that one because there was nothing that I ever really witnessed. It kind of gave me the same kind of feeling. The image in my mind is literally something I saw on TV of the well getting capped and some of the similar footage of the fire. Because I didn't personally witness any of it, it doesn't feel that way." (Interviewer: "Like a more distant witness?") "Yeah."

Subject 030

1. "That news event was more salient to me because I live in Texas near the Gulf. We have an oil saturation down there. Oil is essential to the San Antonio economy. Fracking at the time, it was the fracking boom. So, you had guys who were felons, who were getting 80-90 thousand (dollar) jobs, and buying things and revitalize. Basically, what is south of the west side is what we refer to as the ghetto. And they went through a massive economic rebirth. There was a concern this would somehow harm that. But at the same time, the Gulf of Texas, the Gulf, is where I live. It is affecting the beaches we go to in Texas. It was affecting people I know who live in Louisiana. You know, I knew how important the fishing industry was to the entire Gulf region. Not only that, people from Louisiana, they saw this as a threat to their 
entire culture. Because their entire culture is their whole culture, their diet is based in seafood. I mean eating crawfish is extremely important to them. I remember James Carvell was really mad at Obama because he's not taking acceptable action. He's destroying our entire Cajun culture. Which you know, kind of resonated with me. At the same time, BP, I was mad, I was angry. I was mad at their CEO, he was going sailing, like a big deal. So, it was conflicting. On the one hand, oil is important to us. This event is causing harm that could have potentially been bad."

2. "What year was it?" (Interviewer: "I believe it was 2010.”)

"I had just gotten out of the military, so I was, you know, I had a lot of injuries I was recovering from. So, I had a lot of things going on, frankly. So, this I mean, it was salient to me, but this wasn't the most important thing in life."

3. "Pretty thoroughly at the time, yeah."

4. "No."

5. "No, I mean. I know I learned the information later. But the information in this particular video was very blunt and direct with facts that I knew."

(Interviewer: "Nothing that surprised you?") "No."

6. "Well, I mean there were lots of videos online, reports online."

7. "At the time? I was taking, I was getting ready for a master's program. So, I had to take some undergraduate prereqs to get in. And we were talking about this. I don't remember much about them. At the time, a lot of people in Texas were mad Obama was lackadaisical about in his response to this. They were comparing him to Bush and Katrina. Some people were saying conspiracy theories he wanted to wipe out southern culture. There was some talk, this might harm the oil industry in the way it would hurt our state economy and our city's economy when it was starting a boom because of oil. I don't remember too much more than that."

8. "Honestly, I don't think it was the thing I was most concerned about. I mean it affected me. It was on my radar screen. I don't recall this affected me the way 9/11 did."

9. "No."

10. "I mean I had a going on at the time, personally health-wise. I had a lot of other stressful factors so in the grand scheme of things this was not that important." (Interviewer: "But from a time associations standpoint, you correlate it to when you were having some serious health issues. Just to be clear.")

"Yeah. Some serious health issues."

11. "Once again, I started recalling. In Iraq, the pipelines would get attacked all the time. Terrorists, Al-Qaeda mostly. So, you know oil fires were very common, it was a nonstop thing. So, it triggered more memories about Iraq than it did anything else."

12. "You know, it was just casual conversations. It was just casual conversations with friends, it just happened to be the news of the day. they just wanted to talk about it."

13. "It wasn't that personally important to me at the time. So, it's not like it brought me back to that particular event. It was just non-stop series of tragedies. And in the grand scheme of things it could have been a lot worse." 
Subject 031

1. I hope I'm remembering the right event. I believe this is the one that happened off the Gulf of Mexico. I could be wrong, but if this is the one that happened in the Gulf of Mexico. The oil came on shore by Alabama, the whole coastline, panhandle coastline. It affected nature and tourism. I hope I'm talking about the right now. I believe this is what you're referring to."

2. "Well assuming I'm thinking of the right thing, I just remember watching the pictures on TV and realizing how many miles of the coast this was affecting. And just feeling sorry for you know the pictures of the birds and the natural wildlife in general and scenery just kind of not even that it was coated. That was water's toxic. And thinking what a mess and how can they possibly clean this? Like will it ever be cool again to go down to the Gulf on vacation? It was just an, oh no, not again scenario. It doesn't happen all the time, but when it does it seems like a big, insurmountable mess. Like do you possibly clean this up? Because I'm thinking of the Exxon in Alaska. So, it was kind of going back to that kind of reminded me. I don't know, would you want to drink the water, when can you drink the water, when can you go in the water. I've never been down to that area personally. But I've thought about it. In fact, we were thinking of going last year and I knew it's been a while, and supposedly its safe, but it still makes me think about it. I probably would still go. But it definitely makes you think."

3. "About half. Somehow, I wonder how I forgot about the explosion which makes me feel terrible because people died. So anyway, I just remembered the big oil spill, it wasn't really a spill, it was an explosion that caused leaks. But I was thinking more about the environmental factor than the loss of lives."

4. "I felt terrible I forgot about the explosion, how it happened in the first place. I just remember the giant spill and all the news that came afterward, that months and months of clean up and having to clothes all the turn sites down."

5. "No, there was stuff I had forgotten, but once I saw it, I remembered about the people on board."

(Interviewer: "So the loss of life was something you forgot rather than something you didn't know?")

"Yeah, my mind was focused more on the environmental aspects and the economic aspects which I don't know what that says about me as a person, but I totally forgot about the explosion it caused in the first place. I guess I was relating it to the Exxon oil rig where it was little a hole in the ship and thinking of it like that."

6. "Yes, maybe not this specific one, but I had seen news clips of when it happened. I know it was heavily covered in news media. And I think they made a movie about it." (Interviewer: "I believe you're right.")

"I didn't see it, but I know they made a move. A lot of poetic licenses."

7. "Just I think mostly with my husband. Just about the again the ecological impact and just I remember afterward BP was doing a lot advertising about their efforts to clean up, I don't know. I just remember we were watching that. I mean accidents happen. This could have happened to any company. But I remember the ads as just kind of like, yes, we're glad you're cleaning up, but of course, you're doing that. And I 
remember that the ads were a little self-serving. I don't know. Almost like borderline offensive because they were really just doing what they should have done."

8. "I really don't remember much of when it immediately occurred. I think for me, I think, I don't know what this says for me as a person because there was an explosion, I remember after the fact. I remember being impacted on how long it was taking resolve itself. And when it became clear in what environmental and economic disaster this was."

9. "I didn't remember the explosion somehow. Or the lost lives. But when I see it, it reminds me when I did see it how terrible like this, I just remember thinking of course there's not going to be any survivors. Look at that fire. You just don't know how there's going to be any survivors."

10. "Just you know me and my husband always wanted to go down to the Gulf Coast and just realizing, definitely not doing it right now. Definitely putting that off for obvious reasons. You know it kind of brought around some automatic discussion again about the Exxon Valdez. And all of that, like the here we go again. And just seeing the beautiful scenes on the shore. And just feeling bad for the people that live there and depend on their shore for their livelihood. Like and the fishing. Like where are they getting their fish? Are the fish safe? Just all of that."

11. "It reminded me the biggest impact of the video is I can't believe, how do you forget the explosion. Like how did I forget that? I just felt really bad because human life is human life. So, I guess it's kind of striking that I'm thinking of the 11 lives lost and all of that, not to mention the people injured. So, it's kind of interesting in my mind that I forgot about all of that wildlife lost. And people who were put out of jobs and all of that."

12. "I was just thinking about conversations with my husband. I know some coworkers who like to vacation down there. We've never been down there so we don't have any personal ties. But we have friends who like to vacation down there. I remember we have one set of friends who said they were going down there just as soon as they opened the hotels again. They weren't worried, and I remember us, aren't you afraid to get it the water and swim. They had no concerns whatsoever. Thinking they're braver than we are. I hope everything's OK."

13. "I did have a little bit. Not as much as the Ferguson issue. And maybe because the Ferguson issue was closer to home and I feel somewhat removed from the coast and all of that just never having been there. However, I grew up in a military family and I used to be, and when you're around, diversity is your life. It's not even an issue. And I remember when I went away to college. And I went to Westminster College in Fulton. And it's odd because even though I'm a white female, I almost felt like a minority there. Which I know is hard to understand. But even though I'm not AfricanAmerican, I was struck - and now it's more diverse - but when I was in school there, somehow I didn't realize until I actually there, but I didn't realize until I was actually enrolled and actually went there, I was like, everyone is white. You know, and everyone, you know not everyone, but the majority of students at the time were of a certain economic class, which I was not. And it was just really odd. And I think prior to that I was so used to everyone being around everyone else. Race wasn't really a topic until like I kind of got out that scenario. And I was like there are really places where there's a lot of segregation going on. And quite frankly I haven't been to Fulton 
recently, but quite frankly just in the town of Fulton, there's a lot of segregation going. And it's like stepping back in the decades. And I think from that point on is when I became really conscious of that. And so, I think the Ferguson event affected me more than the BP event just because it's more close to my heart." 


\section{Bibliography}

About. Retrieved from www.texasarchive.org/library/index.php?title=About

About the Internet Archive. (2001). Retrieved from https://archive.org/about/

Allen, R. B., \& Johnson, K. A. (2008). Preserving digital local news. The Electronic Library(3), 387. doi:10.1108/02640470810879527

Arthurs, J., Drakopoulou, S., \& Gandini, A. (2018). Researching YouTube. Convergence: The Journal of Research into New Media Technologies, 24(1), 3.

Atkinson, R. C., \& Shiffrin, R. M. (1968). Human memory: a proposed system and its control processes. In K. W. Spence (Ed.), The psychology of learning and motivation: Advances in research and theory (Vol. 2, pp. 89-195). New York: Academic Press.

Baddeley, A. (2002). The concept of episodic memory. In A. D. Baddeley, J. P. Aggleton, \& M. A. Conway (Eds.), Episodic memory: New directions in research. Oxford; New York: Oxford University Press: Royal Society, 2002.

Baddeley, A., \& Hitch, G. J. (1974). Working memory. In G. A. Bowers (Ed.), Recent advances in learning and motivation (Vol. 8, pp. 47-89). New York: Academic Press.

Baddeley, A., \& Warrington, E. K. (1970). Amnesia and the distinction between longand short-term memory. Journal of Verbal Learning \& Verbal Behavior, 9(2), 176-189. doi:10.1016/S0022-5371(70)80048-2

Baddeley, A. D., Aggleton, J. P., \& Conway, M. A. (2002). Episodic memory: new directions in research : originating from a Discussion Meeting of the Royal Society: Oxford ; New York : Oxford University Press : Royal Society, 2002.

Barker, T. (2018). Television in and out of time. In A. Hoskins (Ed.), Digital memory studies: Media pasts in transition (pp. 173-189). New York, NY: Routledge.

Bottomore, S. (2002). "The sparkling surface of the sea of history" - Notes on the origins of film preservation. In C. A. Surowiec, R. B. N. Smither, \& A. International 
Federation of Film (Eds.), This film is dangerous: A celebration of nitrate film (pp. 86-97).

A Brief History of YouTube. (2010). Retrieved from https://sites.google.com/a/pressatgoogle.com/youtube5year/home/short-story-ofyoutube

Britt, T. (2014). Bringing back the past: New media and archived media content providers. Paper presented at the Association for Education in Journalism and Mass Communication, Montreal, Quebec, Canada.

Britt, T. (2015a). Another time, another place: Archival media content as temporal consciousness and collective memory. (M.A.), University of Texas at Austin, Austin, Texas.

Britt, T. (2015b). Back and forth in time: Online news archvies and presence as transportation. \#ISOJ Journal, 5(1), 113-125.

Britt, T. (2017a). The News of Your Youth: Memory and Subjective Experience of Time During Major News Events. \#ISOJ, 6(1).

Britt, T. (2017b). Saving the future past: Digital news content archiving. RJI Online. Retrieved from www.rjionline.org

Broadbent, D. E. (1958). - Perception and communication.

Brown, J. (1958). Some tests of the decay theory of immediate memory. Quarterly Journal of Experimental Psychology (0033-555X), 10(1), 12.

Bury, R., \& Li, J. (2015). Is it live or is it timeshifted, streamed or downloaded? Watching television in the era of multiple screens. New Media and Society, 17(4), 592-610. doi:10.1177/1461444813508368

Campbell, J., -. (2002). Reference and consciousness. Oxford : New York :: Clarendon Press; Oxford University Press. 
Cariani, K. (2011). AMIA's local television project. The Moving Image: The Journal of the Association of Moving Image Archivists, 11(1), 139-145. doi:10.5749/movingimage.11.1.0139

Cariani, K. (2017). Making news archives discoverable online. Paper presented at the Dodging the Memory Hole, San Francisco, Calif.

Chalfen, R. (1987). Snapshot versions of life. Bowling Green, Ohio: Bowling Green State University Popular Press.

Clossen, A. S. (2018). Trope or Trap? Roleplaying Narratives and Length in Instructional Video. Information Technology \& Libraries, 37(1), 27-38. doi:10.6017/ital.v37i1.10046

Court, J. (2017). Picturing History, Remembering Soldiers: World War I Photography between the Public and the Private. History \& Memory, 29(1), 72-103.

Cowan, N. (1988). Evolving Conceptions of Memory Storage, Selective Attention, and Their Mutual Constraints Within the Human Information-Processing System. Psychological Bulletin, 104(2), 163-191. doi:10.1037/0033-2909.104.2.163

Cowan, N. (1995). Attention and memory: An integrated framework: New York : Oxford University Press ; Oxford : Clarendon Press, 1995.

Cowan, N., Winkler, I., Teder, W., \& Näätänen, R. (1993). Memory Prerequisites of Mismatch Negativity in the Auditory Event-Related Potential (ERP). Journal of Experimental Psychology: Learning, Memory, and Cognition, 19(4), 909-921. doi:10.1037/0278-7393.19.4.909

Crombag, H. F. M., Wagenaar, W. A., \& van Koppen, P. R. (2011). From the archive: 'Crashing memories and the problem of 'source monitoring" by H. F. M. Crombag, W. A. Wagenaar, \& P. J. van Koppen (1996). Applied Cognitive Psychology, 10, 95-104 with commentary. Applied Cognitive Psychology, 25, S91-S101. doi:10.1002/acp.1779

Dainton, B. (2010). Temporal consciousness. In E. N. Zalta (Ed.), The Stanford Encyclopedia of Philosophy (Spring 2014 ed.). 
De Zengotita, T. (2005). Mediated: how the media shapes your world and the way you live in it: New York : Bloomsbury, 2005. 1st U.S. ed.

DeRidder, J. (2016). Digital preservation: How much is it going to cost, and who can I work with? Journalism Digital News Archive. Retrieved from

Detenber, B. H., \& Reeves, B. (1996). A bio-informational theory of emotion: Motion and image size effects on viewers. Journal of Communication, 46(3), 66-84. doi:10.1111/j.1460-2466.1996.tb01489.x

Dynel, M. (2014). Participation framework underlying YouTube interaction. Journal of Pragmatics, 73, 37-52. doi:10.1016/j.pragma.2014.04.001

Edmondson, A. J., Brennan, C., \& House, A. O. (2018). Using photo-elicitation to understand reasons for repeated self-harm: a qualitative study. BMC Psychiatry, Vol 18, Iss 1, Pp 1-11 (2018)(1), 1. doi:10.1186/s12888-018-1681-3

Edwards, E. (2004). Ephemeral to Enduring: The Internet Archive and Its Role in Preserving Digital Media. Information Technology \& Libraries, 23(1), 3-8.

Eich, E. (1984). Memory for unattended events: Remembering with and without awareness. Memory \& Cognition, 12(2), 105-111. doi:10.3758/BF03198423

Fiddy, D. (2001). Missing, believed wiped: Searching for the lost treasures of British television. England, UK: British Film Institute.

Foote, K. E. (1990). To remember and forget: archives, memory, and culture. The American Archivist, 53(3), 378-392. doi:10.2307/40293469

Frey, L. R., Kreps, G. L., \& Botan, C. H. (2000). Investigating communication : an introduction to research methods. Lawrence R. Frey, Carl H. Botan, Gary L. Kreps: Boston : Allyn and Bacon, (C2000. 2nd ed.

Garau, M., Friedman, D., Widenfeld, H. R., Antley, A., Brogni, A., \& Slater, M. (2008). Temporal and Spatial Variations in Presence: Qualitative Analysis of Interviews from an Experiment on Breaks in Presence. Presence: Teleoperators \& Virtual Environments, 17(3), 293. 
Gardiner, J. M. (2002). Episodic memory and autonoetic consciousness: A first-person approach. In A. D. Baddeley, J. P. Aggleton, \& M. A. Conway (Eds.), Episodic memory: New directions in research. Oxford; New York: Oxford University Press: Royal Society, 2002.

Gehl, R. (2009). YouTube as archive: Who will curate this digital Wunderkammer? International Journal of Cultural Studies, 12(1), 43-60. doi: $10.1177 / 1367877908098854$

Ghosh, P. (2015). Google's Vint Cerf warns of 'digital Dark Age'. Retrieved from http://www.bbc.com/news/science-environment-31450389

Giles, D. (2003). Media psychology: Mahwah, N.J. : Lawrence Erlbaum Publishers, 2003.

Gitelman, L. (2006). Always already new : media, history and the data of culture (Vol. Media as historical subjects -- I: The case of phonographs -- New media publics -New media users -- II: The question of the Web -- New media bodies -- New media -- Doing media history.). Cambridge, Mass. :: MIT Press.

Glaser, B. G. (1965/2008). The Constant Comparative Method of Qualitative Analysis. Grounded Theory Review: An International Journal, Vol 7, Iss 3 (2008)(3).

Greenberg, J. M. (2010). From Betamax to Blockbuster: Video Stores and the Invention of Movies on Video: MIT Press.

Griffin, N. R., Fleck, C. R., Uitvlugt, M. G., Ravizza, S. M., \& Fenn, K. M. (2017). The tweeter matters: Factors that affect false memory from Twitter. Computers in Human Behavior, 77, 63-68. doi:10.1016/j.chb.2017.08.032

Gulf oil spill voted top news story of 2010 in AP editors' poll. (2010). NOLA.com. Retrieved from NOLA.com website: https://www.nola.com/news/index.ssf/2010/12/gulf_oil_spill_voted_top_news.ht $\underline{\mathrm{ml}}$

Han, J., \& Federico, C. M. (2018). The Polarizing Effect of News Framing: Comparing the Mediating Roles of Motivated Reasoning, Self-stereotyping, and Intergroup Animus. In (Vol. 68, pp. 685-711). 
Hansen, K. A., \& Paul, N. (2017). Losing the news. Online Searcher, 41(5), 36-40.

Harper, D. (2002). Talking about pictures: a case for photo elicitation. Visual Studies, 17(1), 13-26. doi:10.1080/14725860220137345

Hebb, D. O. (1949). The organization of behavior : a neuropsychological theory (Vol. The problem and the line of attack -- Summation and learning in perception -Field theory and equipotentiality -- The first stage of perception: growth of the assembly -- Perception of a complex: the phase sequence -- Development of the learning capacity -- Higher and lower processes related to learning -- Problems of motivation: pain and hunger -- The problem of motivational drift -- Emotional disturbances -- The growth and decline of intelligence.). New York :: Wiley.

Hilderbrand, L. (2007). Youtube: Where cultural memory and copyright converge. Film Quarterly, 61(1), 48-57. doi:10.1525/fq.2007.61.1.48

Hughes, J. (2016). New life for old bones: moving image collections at the National Archives of Australia. Studies in Documentary Film, 10(3), 252-272. doi:10.1080/17503280.2016.1249046

James, W. (1909/1996). A pluralistic universe: Hibbert Lectures at Manchester College on the present situation in philosophy. Lincoln, Neb.: [S.1.]: University of Nebraska Press, 1996.

Jørndrup, H. (2016). News Framing in a Time of Terror. NORDICOM Review, 37, 85-99. doi:10.1515/nor-2016-0025

Katarzyna, J., Sofie, S., \& Dominique, V. (2017). Building tourism-resilient communities by incorporating residents' perceptions? A photo-elicitation study of tourism development in Bruges. Journal of Tourism Futures, Vol 3, Iss 2, Pp 127-143 (2017)(2), 127. doi:10.1108/JTF-04-2017-0011

Kelly, M. (2017). Final report -- Dodging the memory hole. Paper presented at the Dodging the Memory Hole 2016, Los Angeles, California. https://www.rjionline.org/stories/mat-kelly-final-reportdodging-the-memory-hole

Kim, J. (2012). The institutionalization of YouTube: From user-generated content to professionally generated content. Media, Culture \& Society, 34(1), 53-67. doi: $10.1177 / 0163443711427199$ 
Kim, J., \& Song, H. (2016). Celebrity's self-disclosure on Twitter and parasocial relationships: A mediating role of social presence. Computers in Human Behavior, 62, 570-577. doi:10.1016/j.chb.2016.03.083

Krippendorff, K. (2013). Content analysis: An introduction to its methodology (3rd ed.). Los Angeles; London: SAGE.

Kwan Min, L. (2004). Why Presence Occurs: Evolutionary Psychology, Media Equation, and Presence. Presence: Teleoperators \& Virtual Environments, 13(4), 494.

Lasswell, H. (1948). The structure and function of communication in society. In L. Bryson (Ed.), The communication of ideas. New York: Institution for Religious and Social Studies.

Laws, R., Hunt, G., \& Antin, T. M. J. (2018). Social media platforms as a photoelicitation tool in research on alcohol intoxication and gender. NAD Nordic Studies on Alcohol and Drugs, 35(4), 288-303. doi:10.1177/1455072518781998

Levinson, P. (1999). Digital McLuhan : A Guide to the Information Millennium. New York: Routledge.

Lizardi, R. (2015). Mediated nostalgia: Individual memory and contemporary mass media. Lanham; Boulder; New York; London: Lexington Books.

Lombard, M., \& Ditton, T. (1997). At the heart of it all: The concept of presence. Journal of Computer-Mediated Communication, 3(2), 0-0. doi:10.1111/j.10836101.1997.tb00072.x

Mania, K., \& Chalmers, A. (2001). The Effects of Levels of Immersion on Memory and Presence in Virtual Environments: A Reality Centered Approach. CyberPsychology \& Behavior, 4(2), 247-264. doi:10.1089/109493101300117938

Marsh, T. (2003). Presence as Experience: Film Informing Ways of Staying There. Presence: Teleoperators \& Virtual Environments, 12(5), 538.

Martin, P. (1999). Popular collecting and the everyday self. Leicester, England, UK: Leicester University Press. 
Mateer, J. (2017). Directing for Cinematic Virtual Reality: how the traditional film director's craft applies to immersive environments and notions of presence. Journal of Media Practice, 18(1), 14-25. doi:10.1080/14682753.2017.1305838

May, A. L. (2010). Who Tube? How YouTube's News and Politics Space Is Going Mainstream. International Journal of Press/Politics, 15(4), 499-511. doi:10.1177/1940161210382861

McCain, E. (2015). Plans to save born-digital news content examined. Newspaper Research Journal, 36(3), 337-347. doi:doi:10.1177/0739532915600747

McKay, R. (2018). Rescuing Texas history: Your Library Can Play a Part. Texas Library Journal, 94(2), 51-52.

McKee, A. (2011). YouTube versus the National Film and Sound Archive: Which Is the More Useful Resource for Historians of Australian Television? Television \& New Media, 12(2), 154-173. doi:10.1177/1527476410365707

McLuhan, M. (1964/2001). Understanding Media (2 ed.). Hoboken: Taylor \& Francis.

Minsky, M. (1980). Telepresence. Omni, 44-52.

Moss, M. (2018). Memory institutions, the archive and digital disruption? In A. Hoskins (Ed.), Digital memory studies: Media pasts in transition (pp. 173-189). New York, NY: Routledge.

MSNBC. (2008). 2008 Presidential Election Results. Retrieved from https://www.youtube.com/watch?v=x-V2zLEzxKk

Nass, C., \& Moon, Y. (2000). Machines and mindfulness: social responses to computers. Journal of Social Issues, 56(1), 81-103. doi:10.1111/0022-4537.00153

Newell, J. (2012). Old objects, new media: Historical collections, digitization and affect. Journal of Material Culture, 17(3), 287-306. doi:10.1177/1359183512453534

Nicks, D. (2014). Shootings by police voted top story of 2014 in AP poll. Time. Retrieved from Time.com website: http://time.com/3643962/police-killings-top-story-appoll/ 
Patten, L. B. (2007). From safe harbor to choppy waters: YouTube, the Digital Millennium Copyright Act, and a much needed change of course. Vanderbilt Journal of Entertainment and Technology Law, 10(1), 179-214.

Paul, S. (2017a). Changing media landscape adds yet another challenge to archivists of born-digital news content. Retrieved from https://www.rjionline.org/stories/changing-media-landscape-adds-yet-anotherchallenge-to-archivists-of-born-d

Paul, S. (2017b). Changing media landscape adds yet another challenge to archivists of born-digital news content. Retrieved from https://www.rjionline.org/stories/changing-media-landscape-adds-yet-anotherchallenge-to-archivists-of-born-d

Pavlik, J. V. (2008). Media in the digital age. New York: Columbia University Press.

Peer, L., \& Ksiazek, T. B. (2011). YouTube and the challenge to journalism. Journalism Studies, 12(1), 45-63. doi:10.1080/1461670X.2010.511951

Peterson, L., \& Peterson, M. J. (1959). Short-term retention of individual verbal items. Journal of Experimental Psychology, 58(3), 193-198. doi:10.1037/h0049234

Pierce, D. (1997). The Legion of the Condemned - Why American Silent Films Perished. Film History, 9(1), 5-22. doi:10.2307/3815289

Pietrobruno, S. (2013). YouTube and the social archiving of intangible heritage. New Media \& Society, 15(8), 1259.

Porter, S., Taylor, K., \& ten Brinke, L. (2008). Memory for media: Investigation of false memories for negatively and positively charged public events. Memory, 16(6), 658-666. doi:10.1080/09658210802154626

Potter, R. F., \& Bolls, P. D. (2012). Psychophysiological measurement and meaning : cognitive and emotional processing of media. New York :: Routledge/Taylor and Francis Group.

Reeves, B., Lang, A., Kim, E. Y., \& Tatar, D. (1999). The effects of screen size and message content on attention and arousal. Media Psychology, 1(1), 49-67. doi:10.1207/s1532785xmep0101_4 
Reeves, B., \& Nass, C. I. (1996). The media equation : how people treat computers, television, and new media like real people and places: Stanford, Calif. : Center for the Study of Language and Information ; Cambridge [England] ; New York : Cambridge University Press, (C1996.

Rosen, R. J. (2012). A man who saw Lincoln get shot in 1865 was on a TV show in 1956. The Atlantic. Retrieved from https://www.theatlantic.com/technology/archive/2012/10/man-who-saw-lincolnget-shot/263800/

Rubin, D. C., Wetzler, S. E., \& Nebes, R. D. (1986). Autobiographical memory across the adult lifespan. In D. C. Rubin (Ed.), Autobiographical memory (pp. 202-221). Cambridge; New York: Cambridge University Press, 1986.

Sas, C., \& O'Hare, G. M. P. (2003). Presence Equation: An Investigation into Cognitive Factors Underlying Presence. Presence: Teleoperators \& Virtual Environments, 12(5), 523.

Schacter, D. L. (2001). The seven sins of memory : how the mind forgets and remembers: Boston : Houghton Mifflin, 2001.

Sedikides, C., Wildschut, T., Cheung, W.-Y., Routledge, C., Hepper, E. G., Arndt, J., . . . Vingerhoets, A. J. J. M. (2016). Nostalgia fosters self-continuity: Uncovering the mechanism (social connectedness) and consequence (eudaimonic well-being). Emotion, 16(4), 524-539. doi:10.1037/emo0000136

Shein, E. (2016). Preserving the Internet. Communications of the ACM, 59(1), 26-28. doi:10.1145/2843553

Sherman, S. M., Follows, H., Mushore, A. B. R., Hampson-Jones, K., \& Wright-Bevans, K. (2015). Television advertisements create false memories for competitor brands. Journal of Applied Research in Memory and Cognition, 4, 1-7. doi:10.1016/j.jarmac.2014.06.001

Shoemaker, P. J., \& Reese, S. (2014). Mediating the message in the 21st century: A media sociology perspective. New York: Routledge.

Shohet, L. (2010). YouTube, Use, and the Idea of the Archive. Shakespeare Studies, 38, 68-76. 
Silverman, D. (2005). Doing qualitative research: A practical handbook: London ; Thousand Oaks, Calif. : Sage Publications, 2005. 2nd ed.

Smit, R., Heinrich, A., \& Broersma, M. (2017). Witnessing in the new memory ecology: Memory construction of the Syrian conflict on YouTube. New Media and Society, 19(2), 289-307. doi:10.1177/1461444815604618

Spagnolli, A., Lombard, M., \& Gamberini, L. (2009). Mediated presence: virtual reality, mixed environments and social networks. Virtual Reality, 13(3), 137-139. doi:10.1007/s10055-009-0128-z

Strange, D., Garry, M., Bernstein, D. M., \& Lindsay, D. S. (2011). Photographs cause false memories for the news. Acta Psychologica, 136(1), 90-94. doi:10.1016/j.actpsy.2010.10.006

Tapscott, D. (2009). Grown up digital: How the net generation is changing your world. New York: McGraw-Hill.

Tennessee Archive of Moving Image and Sound. Retrieved from www.knoxlib.org/localfamily-history/tennessee-archive-moving-image-and-sound

Tulving, E. (1972). Episodic and semantic memory. In Organization of memory. Oxford, England: Academic Press.

Tulving, E. (1985). Memory and consciousness. Canadian Psychology/Psychologie canadienne, 26(1), 1-12. doi:10.1037/h0080017

Tulving, E. (2002). Episodic memory and common sense: How far apart? In A. D. Baddeley, J. P. Aggleton, \& M. A. Conway (Eds.), Episodic memory: New directions in research. Oxford; New York: Oxford University Press: Royal Society, 2002.

Wang, Q., Leen, S., \& Hannes, K. (2018). How Do South American International Students Experience Student Life in Flanders? A Photo Elicitation Project. Journal of International Students, 8(2), 742-768.

Waterworth, J. A., Waterworth, E. L., Riva, G., \& Mantovani, F. (2015). Presence: Form, content and consciousness. In M. Lombard, F. Biocca, J. Freeman, W. Usselsteijn, 
\& R. J. Schaevitz (Eds.), Immersed in media: Telepresence theory, measurement and technology (pp. 35-58). Switzerland: Springer International.

Wissmath, B., Weibel, D., \& Groner, R. (2009). Dubbing or subtitling?: Effects on spatial presence, transportation, flow, and enjoyment. Journal of Media Psychology: Theories, Methods, and Applications, 21(3), 114-125. doi:10.1027/18641105.21.3.114

Zeleny, K. (2016). Amateur Archives: The Uses of Public and Private Archives in a Digital World. International Journal of the Image, 7(3), 33-44.

Zelizer, B. (2014). Memory as Foreground, Journalism as Background. In K. TenenboimWeinblatt \& B. Zelizer (Eds.), Journalism and memory (pp. 32-49): Houndmills, Basingstoke, Hampshire : Palgrave Macmillan, 2014. 


\section{VITA}

Terry L. Britt is a native of Sweetwater, Tennessee, and subsequently spent most of his adult life as a journalist in Texas. He became a Missouri School of Journalism Teaching Fellow in the school's doctoral program in 2015. Prior to that, he earned a master's degree in journalism at the University of Texas at Austin. His research area incorporates media sociology, new media studies, and psychology in examining cognitive, emotive, and sociological processes of engagement with archival media content, including news, advertising, and entertainment media. This research focuses upon the role of new media and digitization of news archives in providing unprecedented levels and avenues of access to individual (episodic) and collective memory, mediated concepts of time and space, and the challenges of preserving the mediated past for future generations. Theories and concepts utilized in this research include collective memory, episodic and autobiographical memory, telepresence, social identity theory, selfperception, gatekeeping, and uses and gratifications.

Prior to his graduate school work, Britt spent nearly 30 years in print and digital journalism, mainly working with weekly and small daily news organizations in Texas, Tennessee, Arkansas, and Mississippi. 